\title{
Compatibility as guiding principle for ergonomics work design and preventive occupational health and safety
}

\author{
Helmut Strasser ${ }^{1}$ \\ Accepted: 19 February 2021 / Published online: 4 June 2021 \\ (c) The Author(s) 2021
}

\begin{abstract}
Mutual adaptation and inter-changeability of system elements are very important prerequisites for machines, technical devices and products. Similar to that technical compatibility which can be achieved by standards and regulations, optimum design of human-oriented workplaces or a man-machine system cannot be attained without, e.g., a compatible arrangement of connected displays and controls. Over and above those stimulus/response relations, all technical elements and interfaces have to be designed in such a way that they do not exceed human capacity in order to optimize human well-being and overall system performance. Compatibility between the properties of the human organism on the one hand, and the adaptable technical components of a work system on the other hand, offers a great potential of preventive measures. Examples of ergonomically designed working tools show that compatibility is capable of reducing the prevalence of occupational diseases and repetitive strain injuries as well as leading to lower physiological cost in such a way that the same output results from a lower demand of human resources or even a higher performance will be attained. Compatibility also supports the quick perception and transmission of information in a man-machine system, and as a result of lower requirements for decoding during information processing, spare mental capacity may enhance occupational safety. In the field of software, compatibility also helps to avoid psychological frustration. All in all, the center core competency, which reflects the major significant function of the ergonomist in work design, consists in determining the compatibility of human capacity and planned or existing demands of work. In order to provide efficient working tools and working conditions as well as to be successful in occupational health and safety, ergonomics and industrial engineering in the future are expected to pay more attention to the rules of compatibility. Applied in an appropriate way, these rules may convince people that ergonomics can be a powerful means for reducing prevalence of occupational diseases and complaints, and has a positive effect on overall system performance. Besides presenting examples of work design according to the principle of compatibility, also methods will be shown which enable the assessment of the ergonomic quality of hand-held tools and computer input devices.
\end{abstract}

Keywords Compatibility $\cdot$ Ergonomic work design $\cdot$ Preventive occupational health $\cdot$ Physiological cost

Univ.-Prof. (rt.) Dr.-Ing. habil. Helmut Strasser

h.strasser@aws.mb.uni-siegen.de

1 Ergonomics Division, Siegen University, Paul-Bonatz-Str. 9-11, 57068 Siegen, Germany 


\section{Kompatibilität, Leitlinie für ergonomische Arbeitsgestaltung und präventiven Arbeitsschutz}

\section{Zusammenfassung}

Das Einhalten von Normen und Regeln garantiert in der Technik die gegenseitige Anpassbarkeit und Austauschbarkeit von Konstruktionselementen sowie die Qualität von technischen Produkten. Ebenso sollen soziotechnische Regelungen und Standards zu möglichst weitgehend genormten Schnittstellen zwischen den „Human Factors“ und den technischen Komponenten des Systems „Mensch - Arbeit“ bzw. eines Mensch-Maschine-Systems führen. Damit soll zum einen die erwünschte Arbeitsleistung (der Output) sichergestellt werden. Andererseits sollen unerwünschte Rückwirkungen der Arbeit auf den Menschen vermieden werden. Die als oberstes Ziel der ergonomischen Gestaltung von Arbeitsplätzen und Arbeitsmitteln anzustrebende Kompatibilität zwischen den Eigengesetzlichkeiten bzw. Funktionsprinzipien des menschlichen Organismus einerseits und den gestaltbaren technischen Komponenten eines Arbeitssystems andererseits birgt ein hohes Potential an Präventionsmöglichkeiten auf dem Gebiet des Arbeitsschutzes. Am Beispiel ergonomisch gestalteter Arbeitsmittel im Vergleich zu konventionellen Werkzeugen wird gezeigt, dass Kompatibilität in der Regel eine Reduzierung der Prävalenz von Berufskrankheiten und arbeitsbedingten Erkrankungen erwarten lässt. Zumindest ergeben sich aber daraus geringere „physiologischen Kosten“, die vom Menschen für die Arbeit zu „bezahlen“ sind. Nicht selten resultiert aber auch aus einem Weniger an Aufwand der gleiche Output, u. U. sogar ein Mehr an Leistung, d. h. es ist sogar eine Harmonisierung von Humanaspekten mit Wirtschaftlichkeitsaspekten möglich. Kompatibilität ist auch der raschen Informationsaufnahme und -abgabe in einem Mensch-Maschine-System förderlich, und infolge des weniger hohen Umkodier-Aufwandes in der Informationsverarbeitung werden zugunsten einer Erhöhung der Arbeitssicherheit mentale Kapazitäten frei. Kompatibilität im Software-Bereich hilft schließlich auch mit, Frustrationen psychischer Art zu vermeiden. Um in der Praxis des Arbeitsschutzes erfolgreich zu sein, haben sich aber Arbeitswissenschaft und Ergonomie sowie die Akteure des dualen staatlichen und halbstaatlichen Arbeitsschutzsystems in Zukunft mehr um anschauliche Beispiele zur Umsetzung des vorhandenen Wissens als lediglich um abstrakte schematische Regelungen und Normen zu bemühen, wobei sie sich des bereits reichhaltigen Erkenntnisstandes auf diesem Sektor erinnern sollten.

Schlüsselwörter Kompatibilität · Ergonomische Arbeitsgestaltung · Präventiver Arbeitsschutz $\cdot$ Physiologische Kosten

\section{Table of contents}

1 Standards, rules, and regulations

2 Compatibility in technology and in man-machine systems

3 Compatibility relations between human factors and adaptable technical system elements

4 Stimulus/stimulus-, response/response-, and stimulus/ response-compatibility

5 Ergonomic layout approaches as contributions to occupational safety and increased performance via response/ response-compatibility

5.1 Hand-held vibrating tools

5.2 Keyboards according to standard proportions and ergonomic versions

5.3 Excerpt of a study investigating the ergonomic quality of keyboards via electromyographic and subjective methods

5.4 Men's hairdresser scissors compatible to the anatomic specialities of the hand-arm system

5.5 Screwdriver handles compatible with the hand curvature for reduction of physiological cost of work

5.6 Handles of trowels tailored to the mason's hand

5.7 Ergonomically designed file handles
5.8 Electromyographic methods for optimization of movement-based work design in harmony with physiological laws

6 Complex applied ergonomics design example: scanner checkouts with goods throughput from left to right

7 Compatibility between anatomical and functional joints in products as a prerequisite for comfort

8 Compatibility of body dimensions and provided space in confined areas

9 Harmonizing interior and exterior dimensions of work places (for $95^{\text {th }}$ and $5^{\text {th }}$ percentile users) via $50^{\text {th }}$ percentile of eye and shoulder reference point and appropriate seat height adjustment

10 Stimulus/stimulus-compatibility in the sensory interface of a man-machine system or man-computer-interactions for minimization of physiological expenditure

11 Stimulus/response-compatibility in the arrangement of controls and displays for enhancing information transmission and safety

12 Compatibility in the field of software as a means for avoidance of frustration and for reducing psychological stress

13 Conclusions and prospect 


\section{Standards, rules, and regulations}

The development of standards took place at the beginning of the last century almost simultaneously with the industrialization and diversification of technology. Waldemar Hellmich, the first chairman of the Committee for Standards of the German Industry - the predecessor of the German Institute for Standardization—once said

"Standardization is a tricky task. People involved in this process oftentimes do not argue impartially but pursue economic goals" and "Standardization is of no use where order kills liberty, but it is necessary where liberty wants to escape order".

With regard to an united Europe and world-wide globalization tendencies, this often practiced "walk on a knife's edge" of standardization between order and liberty causes a great deal of trouble with respect to factual and economic issues. But unarguably, the real breakthrough of technical standards came at the same time as the beginning of mass production, which was the basis for prosperity and growth of all industrialized countries. As visualized in Fig. 1, this situation is based on

- standardized screws and nuts, bolts, rivets and slots,

- plugs and bulbs which fit into standardized sockets and lamp holders,

- standardized sizes for papers and folders,

Fig. 1 Aspects of compatibility in technical devices

Abb. 1 Kompatibilität in technischen Systemen for audio- and video cassettes, as well as for disks and CDs,

- the creation of standards for telephone, radio, and television or for data transmission via electronic mail,

- standardized interfaces for printers and monitors or

- compatible PCs.

\section{Compatibility in technology and in man- machine systems}

Technical standards guarantee the quality and interchangeability as well as the compatibility of structural elements, and they permit an evaluation of technology, whereby the immense flood of standards, guidelines, and technical rules, especially in Europe, occasionally comprises a high degree of solidity and reliability. But what about the field of sociotechnical and ergonomic rules and standards, which should lead to inter-alia high level of usability of products and consumer safety, high overall system performance and a high standard of occupational health and safety?

Well, passivity is the last thing, the "Expert Committee on Standards" and the various committees of the "Association of German Engineers" (VDI) can be accused of, and the legislative body and, especially, various trade associations and unions in many countries do their very best for establishing laws, standards and guidelines, as well as for developing accident-prevention regulations. But nevertheless-or even because sometimes quantity was or still is
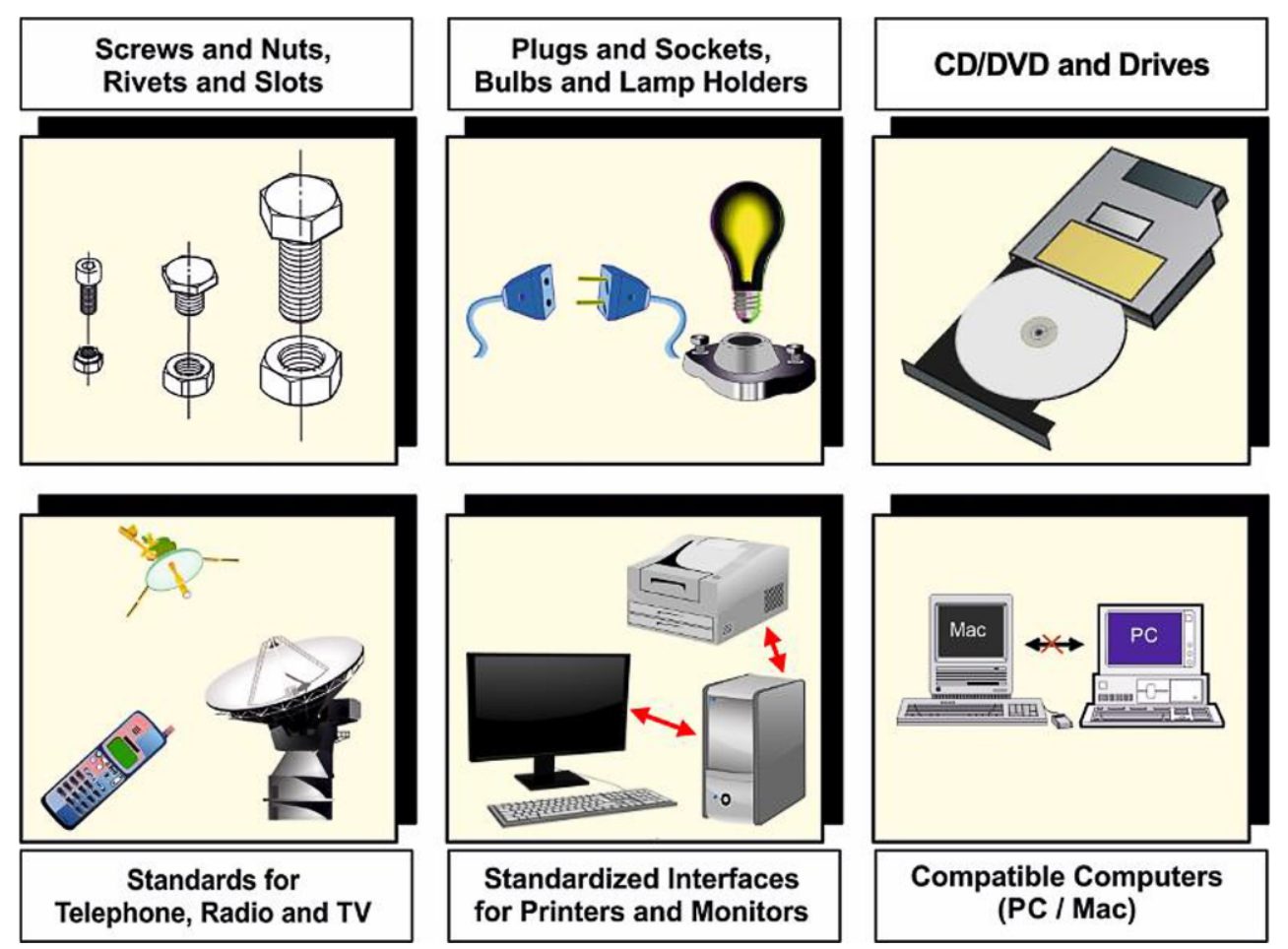

Standardized Interfaces for Printers and Monitors

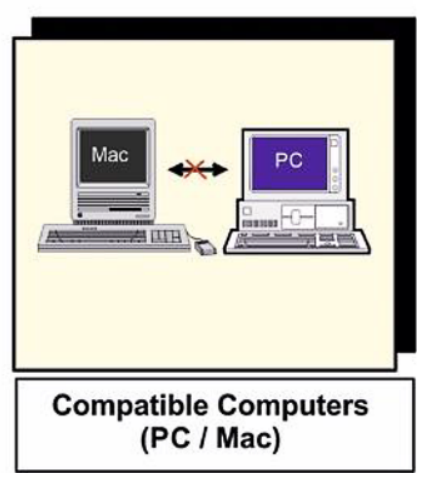


of more importance-occupational safety cannot compete with technical development, with regard to quality and precision.

The strict application of mostly simplified ergonomic rules, standards, guidelines, and user manuals, whose use mainly is limited to selective design principles, can never attain the same degree of accuracy as technical standards can do. Simple recipes, as very often demanded, can scarcely be adapted to complex problems, problems which always arise when different physiological, psychological, and social human interests must be taken into account in a work system, when tasks, jobs, products, organizations, environments and systems have to be planned, designed and evaluated in order to make them compatible with the needs, abilities and limitations of people. It goes without saying that ergonomics practitioners must possess "Core Competencies in Ergonomics" (see e.g. N. N. 1998a or IEA 2006) which have to be taught by solid practically oriented lecture courses (amongst others see N. N. 1998b; Strasser 1998; Strasser 2000; Strasser and Zink 2007). A set of units of competency reflect the major significant functions of the ergonomist who always has to start with investigating and analyzing the demands for ergonomic design to ensure the optimal interaction between work, product or environment on the one hand and human capacities and limitations on the other hand. Most important hereby is determining the compatibility of human capacity and planned or existing demands.

\section{Compatibility relations between human factors and adaptable technical system elements}

Compatible techno-organizational conditions are in many aspects expected to meet general human properties. Yet, that in reality this demand is rarely fulfilled can be proven by occupational diseases and repetitive strain injuries, as well as by a great deal of trouble and irritation during work with, e.g., unhandy tools. This is also indicated by a high rate of absenteeism as a consequence of low motivation and frustration of the employees at work. For the preventive protection of the workers during work via an anthropo-technical design of a man-machine system-and here it must be briefly commented on Fig. 2-the highest possible degree of compatibility must be attained between the various elements of the system.

It must be ensured that the design of technical components of a work system according to human capacity - shown in the yellow block of Fig. 2-is viewed as the most important duty. Since work success (output) is generally regarded as the actual value in a closed loop with the human controller, and since work efficiency and precision of the controller "man", in this process depend on the design of his workplace with the connected sensory and motoric interfaces, the overall system performance of such a man-machine system is determined by the quality of the total ergonomic layout. It should be ensured that work task and job content within the operational and organizational boundary conditions (the occupational prerequisites) as nominal value, as input to the control loop are adapted to man's capabilities and expectations. These demands again represent the broad range of activities of ergonomic efforts,
Fig. 2 Depiction of the main tasks of Micro-Ergonomics by fitting the adaptable technical system elements to the properties of man acting as a controller in a man-machine system Abb. 2 Visualisierung der Hauptaufgaben der Arbeitswissenschaft in der Anpassung der gestaltbaren technischen System-Elemente in der Arbeitswelt an die „Human Factors“ des Menschen als Regler in einem Mensch-Maschine-System

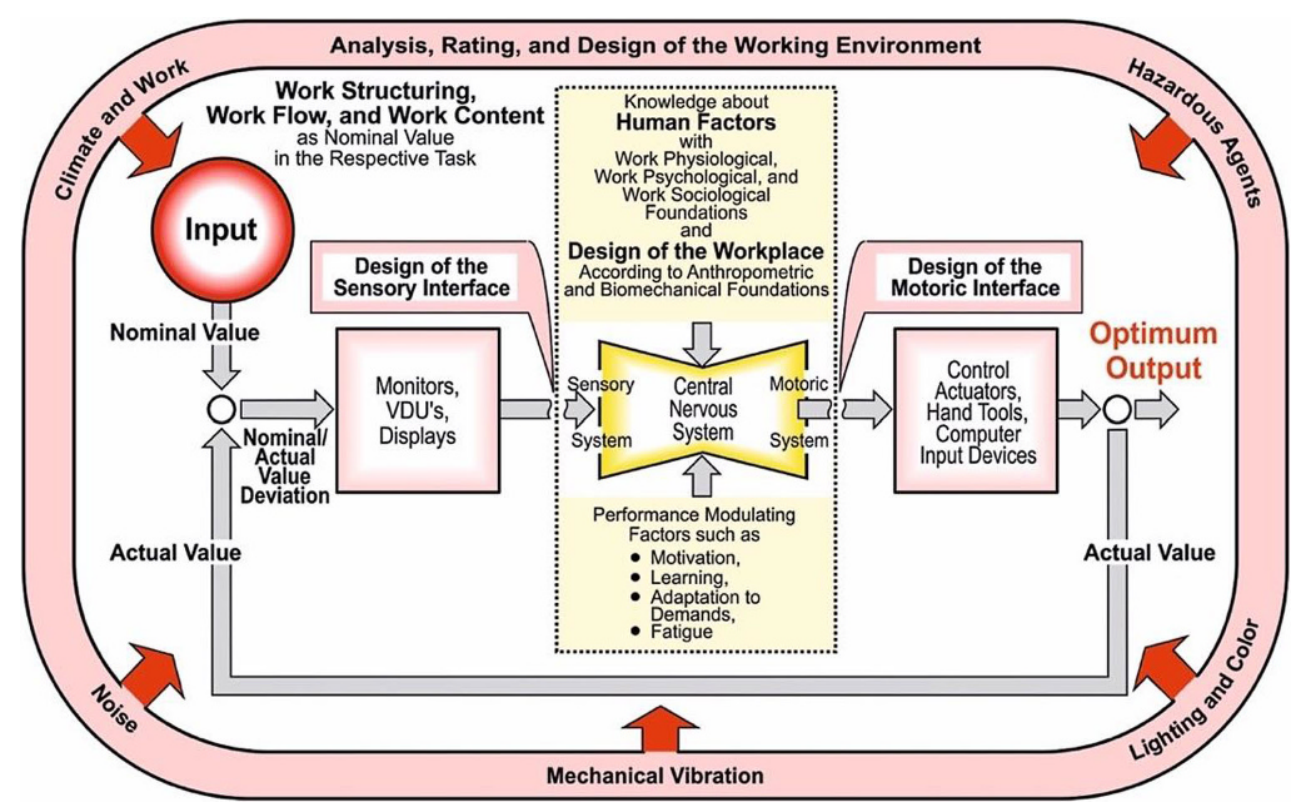


Fig. 3 Macro-Ergonomics objectives in the socialtechnological design of the system "Man (People)-Technology-Organization" Abb. 3 Makro-Ergonomische Ziele in der sozio-technischen Gestaltung des Systems „Mensch - Technik - Organisation“

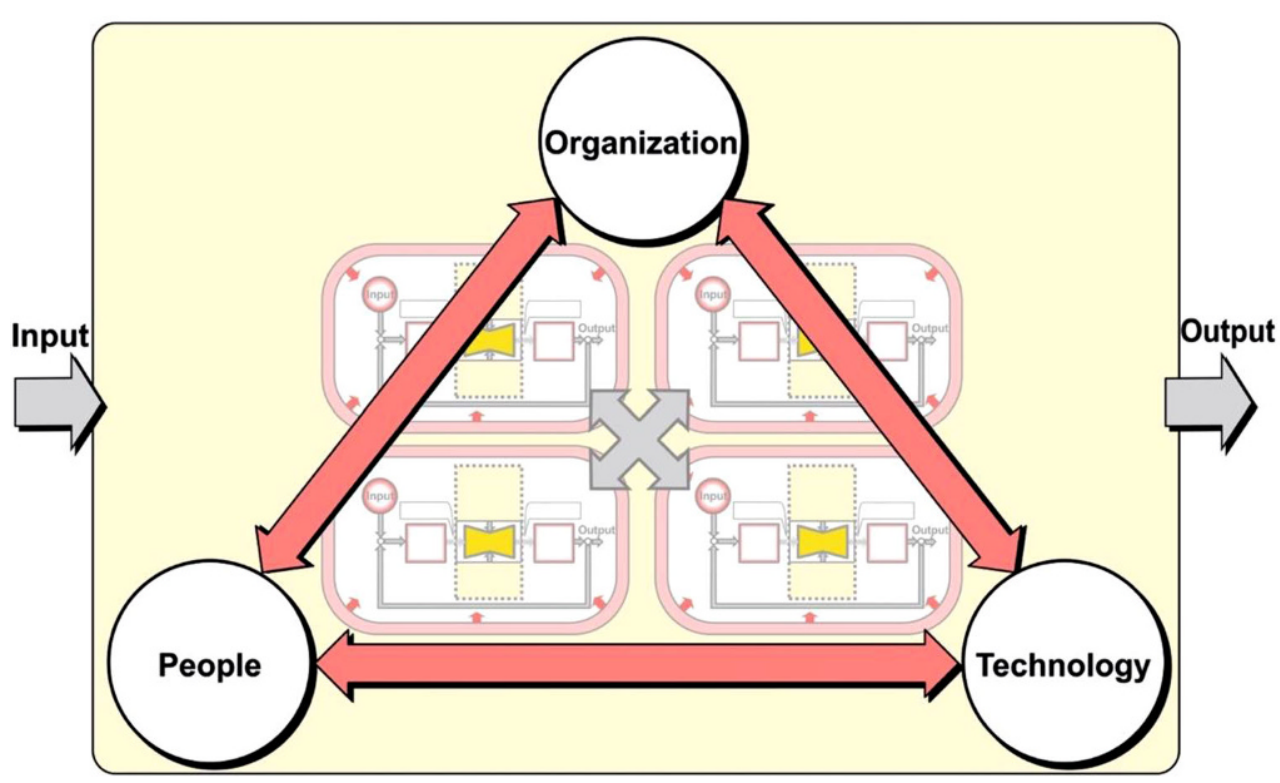

during which it must be taken into account that man is not a time-invariant servo-element within its controlling function. Of course, disturbance variables from the physical environment such as, e.g., noise, mechanical vibrations, inappropriate illumination etc. have to be limited. As a consequence, compatibility between technological possibilities and necessities on the one hand, and human characteristics as well as needs and expectations of the workers on the other hand must be aimed at (must be striven for).

Fig. 3 visualizes the objectives of Macro-Ergonomics focusing on optimizing the relations between people, organization and technology. Within this topic also the aims of Participatory Ergonomics (see e.g. Imada 1991) have to be addressed. An overwhelming and the most comprehensive presentation of the various objectives, methods and techniques of ergonomics and human factors have been documented by Karwowski (2006).

\section{Stimulus/stimulus-, response/response-, and stimulus/response-compatibility}

Micro-ergonomic endeavors can roughly be visualized by means of Fig. 4. Stimulus/stimulus-compatibility in the sensory interface can be achieved when natural appearance and the artificial display suit one another most favorably, when reality and its technical image correspond as much as possible.

In the same way as a low decoding effort is necessary in a compatibly designed sensory interface, this objective must be attained in the motoric sector of a man-machine system with the help of response/response-compatibility. This is achieved by an appropriate adaptation of a technical device to the motoric and physiological properties of the hand-arm system. For stimulus/response-compatibility, it is necessary to achieve a useful arrangement of information-which is presented on displays - and the motoric responses which are demanded for operating the control means. This relationship is normally the basis for targetoriented actions and reaction possibilities of man for the purpose of safe and quick operation. In the following, it will be demonstrated that obeying the rules of compatibility can provide efficient support for preventive occupational safety, low physiological cost that has to be invested, and high performance.

The main emphasis is put on the design of the motoric interface of a man-machine system in which the equation "right for the man = right for the hand" must be strictly followed. Yet, fulfilling this demand for response/response-

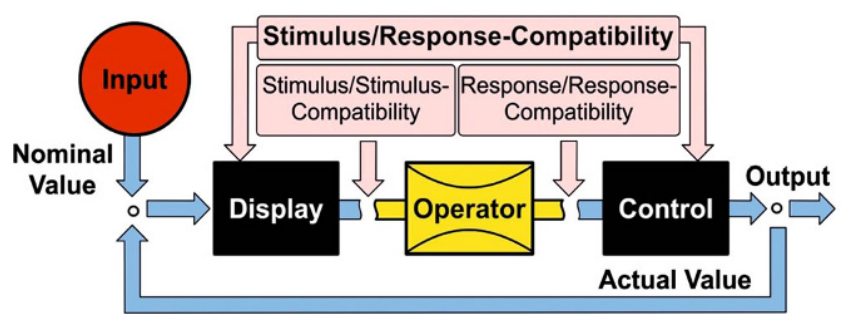

Fig. 4 Compatibility via adaptation of technical equipment to human properties in the sensory and motoric link of a man-machine system (Stimulus/Stimulus-Compatibility and Response/Response-Compatibility) as well as via corresponding relations between causes and effects, i.e. displays and controls (Stimulus/Response-Compatibility) Abb. 4 Kompatibilität durch Anpassung von technischem Gerät an die menschlichen Eigenschaften in der sensorischen und motorischen Nahtstelle eines Mensch-Maschine-Systems (Reiz-Reiz-Kompatibilität und Reaktions-Reaktions-Kompatibilität) sowie sinnfällige Zuordnung von Ursache und Wirkung bzw. von Anzeige und Stellteileffekt (Reiz-Reaktions-Kompatibilität) 
compatibility requires, at least, some basic knowledge of anatomy and physiology of the hand-arm system.

\section{Ergonomic layout approaches as contributions to occupational safety and increased performance via response/ response-compatibility}

Some examples for ergonomic layout approaches may visualize these contributions to preventive occupational safety measures. For details see Strasser (1994a, 1994b, 1995a, 1995b, 2007).

\subsection{Hand-held vibrating tools}

Long-time exposure to mechanical vibrations on the handarm system caused by shaking, agitating, and vibrating tools and machines can - as is well-known-lead to early fatigue and a decline in performance as well as to tremendous health risks. Above all, excitation frequencies between 10 and $30 \mathrm{~Hz}$ caused by manually handled pneumatically driven tools, such as rammers and hammers, when occurring within the resonance frequencies of the hand-arm system, can-as a last consequence-cause degeneration and damage in bones and in the joint system (BK 21032005 and BK 2104 1979). This situation can be observed especially when conventional (horizontally aligned) handles, as presented in the left part of Fig. 5, demand an ulnar abduction (deviation) - a displacement of the wrist to the elbow-which, because of physio-anatomic reasons, is limited to an angle of approximately $30^{\circ}$.
When pressure is applied to the device using both hands, then the contact pressure on the work side is the result of force vectors exerted via the forearms at an obtuse angle (very often up to $90^{\circ}$ ) on the hand side (cp. upper left part of Fig. 5). Inside the wrist the ulnar deviation causes-as can be seen in the left-hand figure-the direction of the total force lines from the forearm through the hand across the lunate (one of the eight mid-carpal bones). In the long term, this could result in the lunate being virtually ground down by a high vibration immission when, additionally, a high contact pressure is required, and it is true to say that the lunate is not "created" for such an unnatural hand posture and load.

The abrasion of the lunate with the associated danger of a stiffening of the wrist (accepted as an occupational disease in almost all countries, e.g. BK 21032005 in Germany) can be extremely reduced if the hammer handle enables handling in a "normal" hand posture (without ulnar abduction, see right part of Fig. 5). This simply requires the sloping of the handles downwards and towards the worker. In this hand posture the force pressure directed from the hand towards the forearm bones is spread over a noticeably larger coupling surface, which is created by the lunate and the bigger scaphoid.

Therefore, the resulting pressure is substantially reduced for the same contact pressure and the same vibration intensity. When, additionally, handles are selected according to the shoulder width, the angle between the force vectors is also reduced, and this reduction for equal arm forces causes a higher resultant on the work side.

In other words, the forces exerted by the worker can be lower for an equal resistance to be overcome. This not only leads to a general facilitation of work, but also reduces the
Fig. 5 Ulnar deviation of the wrist and normal hand posture with different handles of pneumatic working tools as well as effects on the resulting force pressure on the tool's side as well as on the force transmission in the carpal bones

Abb. 5 Ulnare Abduktion im Handgelenk und normale Handhaltung bei unterschiedlichen Pressluft-Hammergriffen sowie Auswirkungen auf die aus den beiden Armkräften resultierende Anpresskraft auf der Arbeitsseite des Werkzeugs sowie den Kraftfluss in den Handwurzelknochen
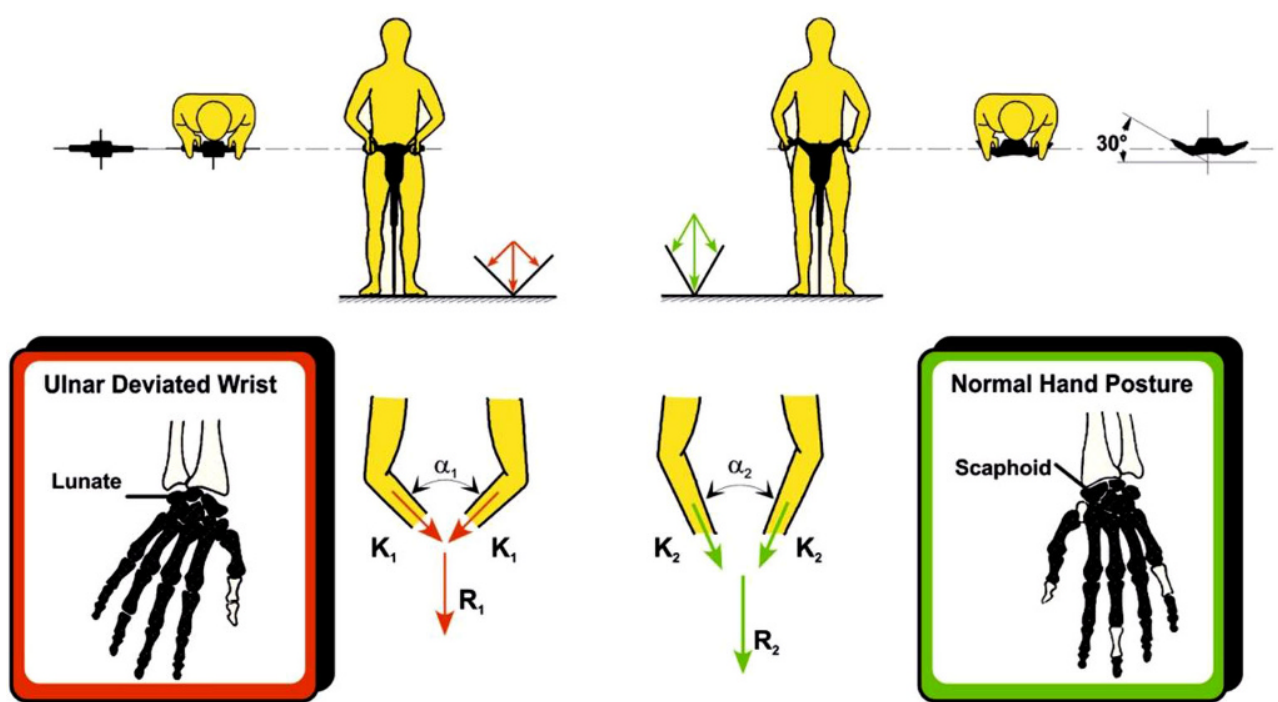

Contact pressure
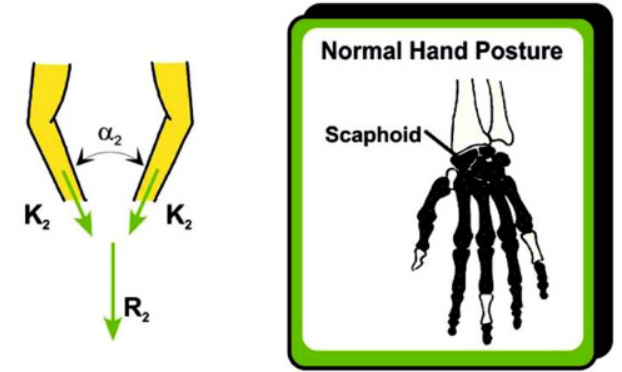

$\mathrm{R}_{1}<\mathrm{R}_{2}$ if $\quad \alpha_{1}>\alpha_{2}$

for $\alpha=90^{\circ} \mathrm{R}=\sqrt{2} \mathrm{~K}$ for $\alpha=0^{\circ} \mathrm{R}=2 \mathrm{~K}$ 
danger of abrasion in the mid-carpal joints. Finally, this device can be handled more safely when access compatible to the normal hand posture is provided. It also reduces the risk of injuries and positively influences occupational safety, even if vibration cannot be reduced much by primary protective measures, since that would be too costly with regard to technical and economic aspects.

Apart from "arthrosis deformans" and the vasospastic syndrome (described in BK 21032005 and BK 2104 1979) caused by hand-arm-vibrations during static finger work when handling tools, different occupation-related medical problems can also be provoked during dynamic finger work when operating fixed control tools.

\subsection{Keyboards according to standard proportions and ergonomic versions}

Examples of these problems associated with traditional keyboards, designed according national and international standards (e.g. DIN EN 2137-2 1999 or ISO 9241-4 1998), can be found in static tenseness and complaints affecting the total hand-arm-shoulder system as well as tenosynovitis mainly occurring in the wrist region. This example of daily used equipment shows that the tremendous progress in the development of technology and experience unfortunately has brought no substantial change to the layout of a keyboard design based on a one-hundred-year-old standard.

It therefore follows that the arrangement of a standardized QWERTY - or QWERTZ-keyboard (cp. Fig. 6) according to specifications of standardization committees, with its spatial layout of keys in four horizontal lines (and with a higher asymmetric demand on the left hand), is incompatible to the hand-arm system with its limited axial and translatoric motion capacities, as it will be shown in the following.

It is true that compared to the Sixties of the past century, tenosynovitis has lost its importance as an occupational disease (BK 2101 1963) in the field of office work, whereby this is mainly due to the introduction of electric typewriters and PCs. So the necessary finger's contact force on the keys could be reduced to one tenth of that which was required by mechanical typewriters in the past. But there are still several problems arising from the traditional key-layout ending up in complaints and muscle tenseness, i.e., myogelosis in
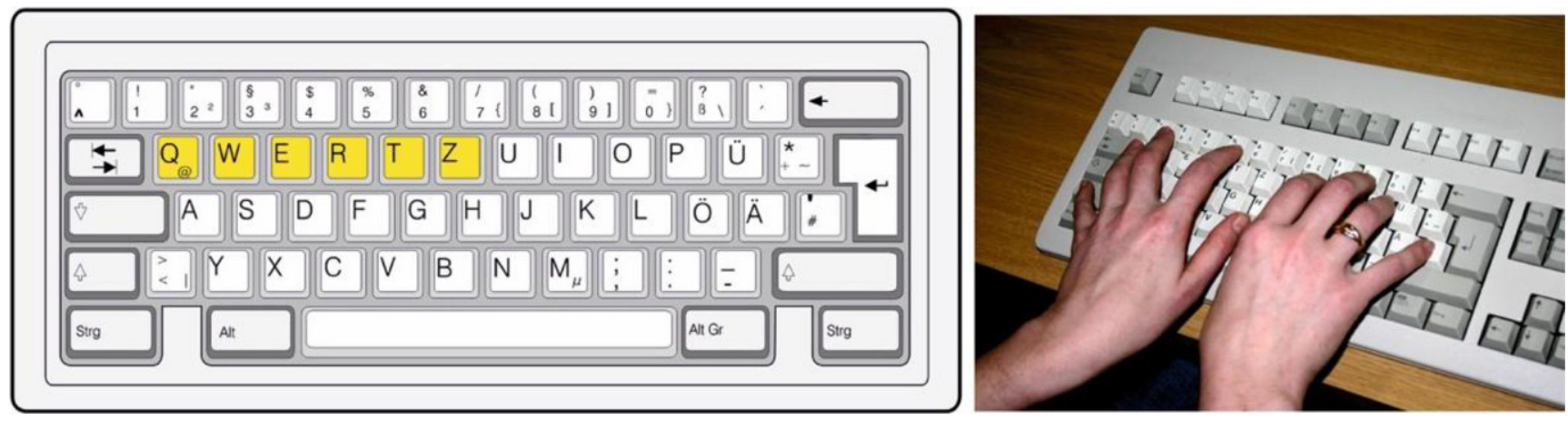

Fig. 6 Conventional QUERTZ-Keyboard (DIN EN 2137-2 1999) demanding inward rotation (pronation) of the forehand and ulnar deviation of the hand-an unnatural posture due to the parallel arranged rows of a keyboard

Abb. 6 Konventionelle QUERTZ-Tastatur (nach DIN EN 2137-2 1999), die eine Einwärts-Rotation (eine Pronation) des Unterarms und eine ulnare Auslenkung der Hand erfordert - eine unnatürliche Haltung des Hand-Arm-Systems als Folge der parallel angeordneten Tastenreihen

Fig. 7 Axial and translatoric displacement capacities of the hand

Abb. 7 Bereiche der axialen Verdrehbarkeit der Arme und der translatorischen Auslenkmöglichkeiten der Hand
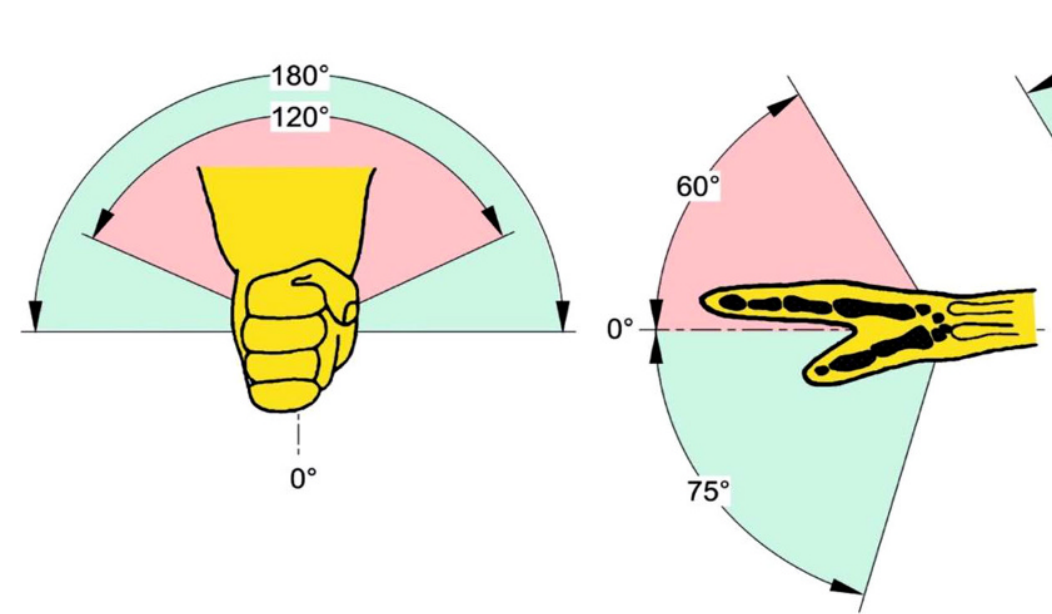
several body parts. With the help of Fig. 7, some properties of the hand are shown in simplified form in order to explain the above mentioned case in point.

The (translatoric motion) displacement range of the hand towards the back of the hand, i.e., the dorsal extension—namely $60^{\circ}$-and towards its palm with even $75^{\circ}$ is relatively high (cp. middle part of Fig. 7). But with regard to the ulnar direction, as can be seen in the right part of Fig. 7 just a movement capacity of about $30^{\circ}$ exists and an area of only $15^{\circ}$ is available for the radial direction. Furthermore, the stretched arm can rotate $180^{\circ}$ with regard to its longitudinal axis resulting in a range of $90^{\circ}$ for each direction, i.e. pronation (rotation inwards) and supination (rotation outwards). This high axial torsion capacity, that is made possible by the ball-and-socket joint which connects the upper arm to the shoulder, is reduced to two thirds, i.e., $120^{\circ}$ (see left part of Fig. 7), if the rotation must be executed by the forearm in an angled posture. And this fact has consequences for utilizing keyboards.

The normal hand posture is given when the arms are hanging down and the palms (the insides of the hands) point towards the hips. If an angle of $90^{\circ}$ between upper arm and forearm has to be built, as is necessary for typing, then a typewriter or a keyboard can only be operated by unnatural adjustments to the hand-arm system.

Due to the limited rotation capacity of the forearm operating the keyboard demands an additional abduction of the upper arm, a spreading of the elbows away from the body in order to accomplish the necessary inward rotation of $90^{\circ}$. Yet, this causes a substantial angle between both forearmhand lines so that adequate operating can only be achieved by an additional outward bend (an ulnar deviation) of the hand. Of course, it is possible to work in this posture, but over longer periods of time it is not convenient when hand and arm have to be held in a static way.

As a consequence of using the human support system as a tripod for hand and eye, increasing tenseness not restricted just for the hand but also for the whole upper extremity must result. Similar increased physiological costs are associated with dynamic finger movements when operating the keys, and can also be revealed in the friction within the tendons, especially in the area of the bent wrist.

The tendons and the tendon's sheaths represent the mechanical link between forearm muscles-acting as servo motors-and the fingers-functioning as final control elements. This link can be compared to a bowden wire (Fig. 8). What now can be done to, at least, reduce these problems?

Work-physiological (electromyographic) analyses carried out already in the early Eighties in Europe revealed muscular strain of the arm associated with the corresponding angles, whereby-as can be seen in Fig. 9-the strain level (indicated by the electromyographic activity) rises over-proportionally with an increasing angle between the natural position of the hand and the posture associated with operating the keys.

Drawing the conclusion, the first step would then be (as shown in the upper left part of Fig. 10) splitting the traditional keyboard with an angle between the two keyboard halves.

Furthermore, a slight pantile-like inclination of both halves (see upper right part of Fig. 10) would be favorable to pronation of the arm. Angles of just $25^{\circ}$, to reduce the hand's ulnar deviation and sideward inclination angles of only $10^{\circ}$ with a corresponding lowering of the arm's inward rotation (pronation) lead to a proven substantial relief of those muscle groups, which are involved statically in the
Fig. 8 Tendons moving in tendon sheaths (tubes which have an extremely well lubricated inner lining) and cross-section of the carpal tunnel

Abb. 8 Sehnen in den Sehnenscheiden (,Röhren“, die eine ausgezeichnete innere Gleitfähigkeit für die Sehnen bieten) und Querschnitt durch den Karpal-Tunnel

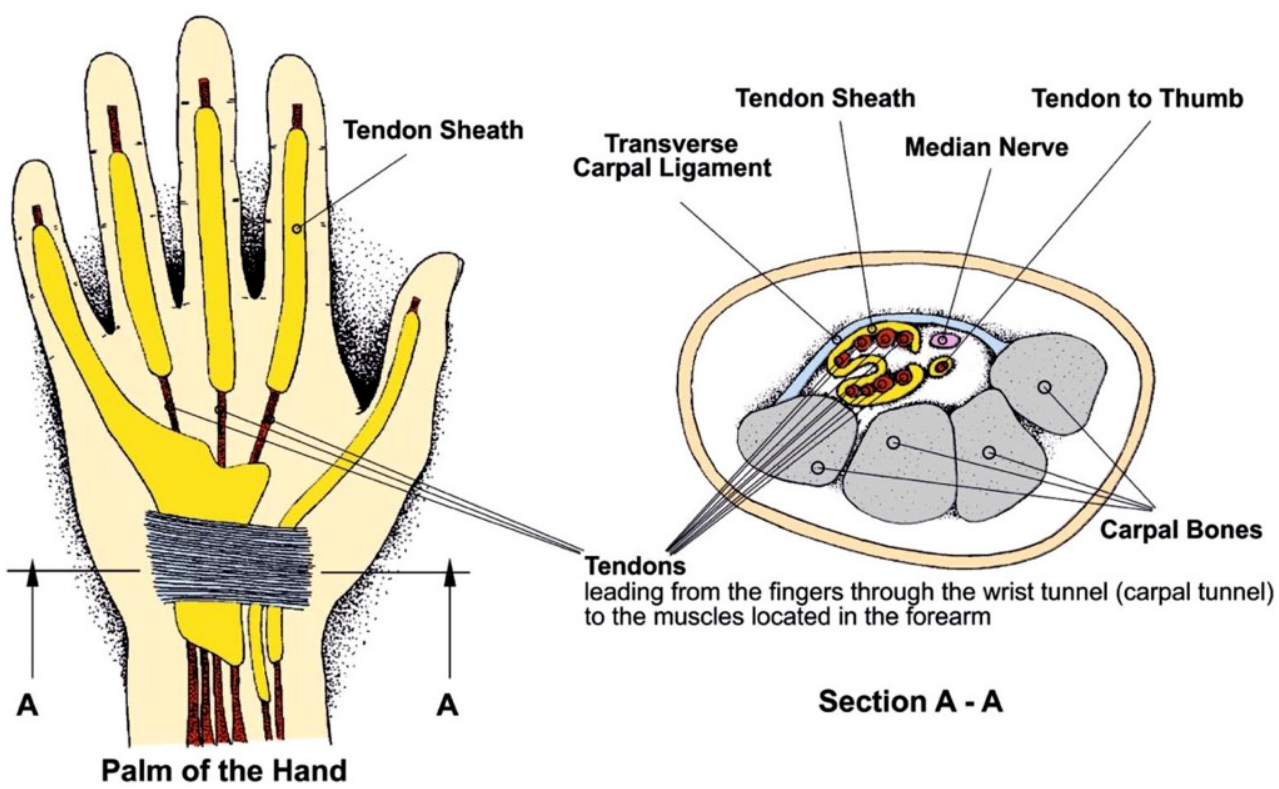


Fig. 9 Electromyographic Activity (EA) of the extensor carpi ulnaris and the flexor ulnaris dependent on the ulnar deviation of the hand (left part) and Electromyographic Activity (EA) of the pronator teres, the flexor carpi radialis, and the pronator quadratus dependent on the inward rotation (pronation) of the hand (right part). EA in arbitrary units (Source: Zipp et al. 1983) Abb. 9 Elektromyographische Aktivität (EA) des Extensor carpi ulnaris und des Flexor ulnaris in Abhängigkeit von der ulnaren Abduktion der Hand (linker Teil) und Elektromyographische Aktivität (EA) des Pronator teres, des Flexor carpi ulnaris und des Pronator quadratus der Hand (rechter Teil). EA in willkürlichen Einheiten (Quelle: Zipp et al. 1983)
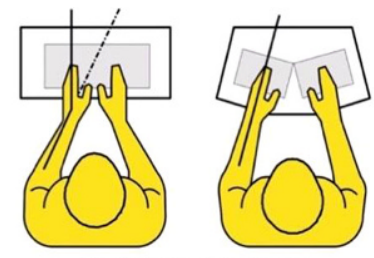

Split-Field Keyboard with Rotation of the Two Fields to Reduce the Degree of Ulnar Abduction

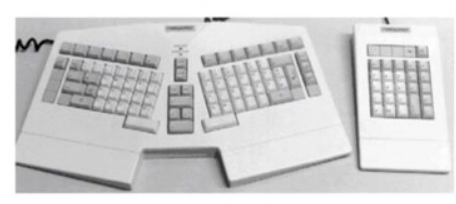

Ergonomic Keyboard (ILG, 1987)

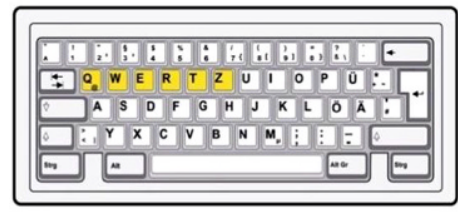

Conventional Keyboard (DIN 2137)
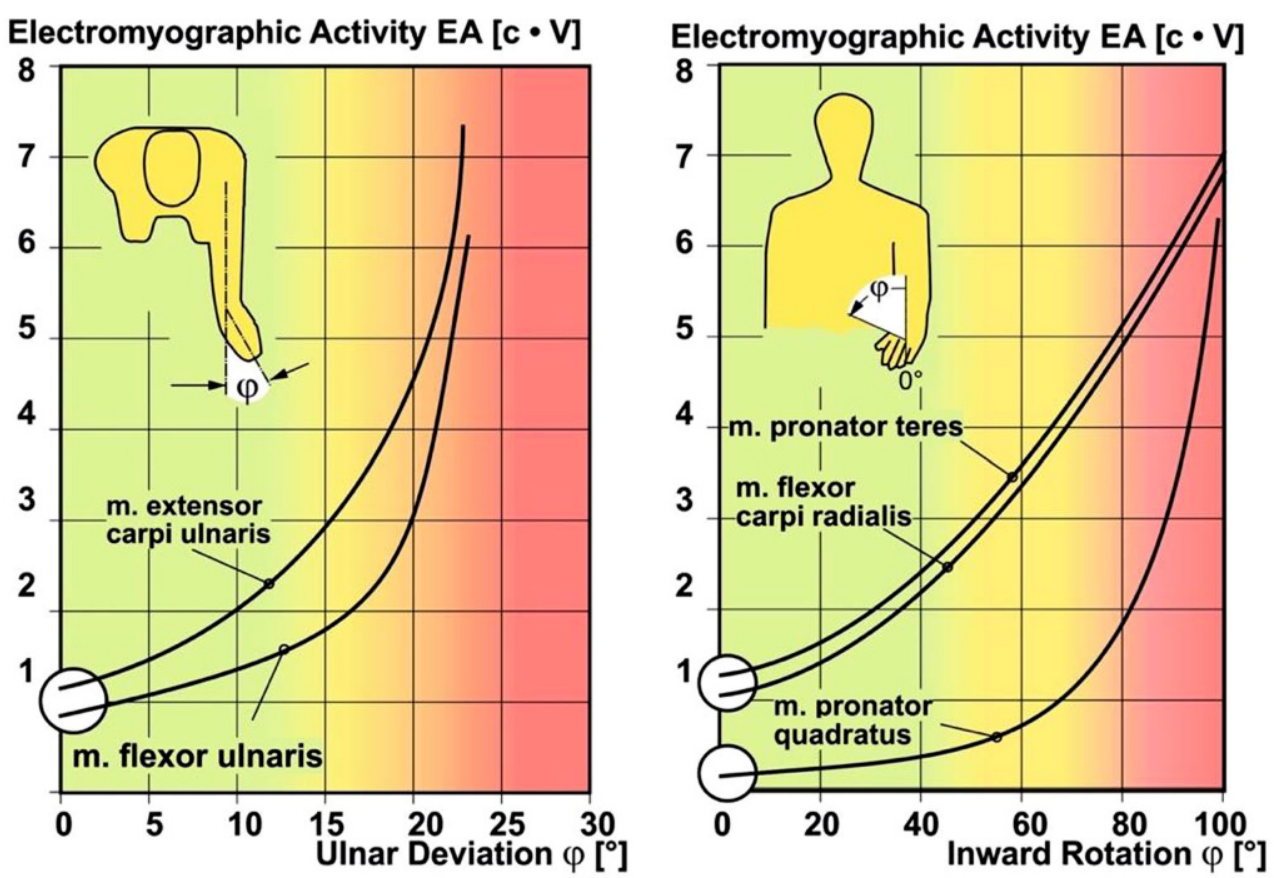

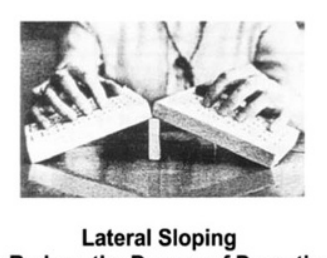

to Reduce the Degree of Pronation

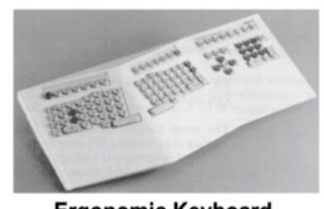

Ergonomic Keyboard (GRANDJEAN et al., 1981)

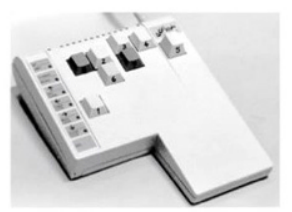

Ergonomic Chord Keyboard

Fig. 10 Conventional Keyboard (lower left part) according to DIN Standards (QUERTZ-Keyboard) and models with an ergonomic layout (from Keller et al. 1991)

Abb. 10 Konventionelle Tastatur (linker unterer Teil) gemäß DINNormen (QUERTZ-Keyboard und Modelle mit ergonomischem Layout (aus Keller et al. 1991)

bent hand posture and the forearm inward rotation. This will be shown in the following Chap. 5.3.

Such designed keyboards, which are shown in the middle part of Fig. 10, can represent a possibility of more conveniently working since they represent an equipment compatible to the anatomic properties of the hand-arm system. The keyboard shown in the lower right part of Fig. 10 (an Ergonomic Chord Keyboard) in an experimental study (Keller et. al 1991) has proven to be optimized for one-handed persons.

\subsection{Excerpt of a study investigating the ergonomic quality of keyboards via electromyographic and subjective methods}

The following Fig. 11 through to 19, an excerpt of a comprehensive investigation into the ergonomics quality of keyboards, carried out by Keller et. al (2004) and Strasser et. al (2004) will illustrate the efficiency of work physiological and subjective methods of ergonomics research approaches. A group of test subjects had to work at an ergonomically designed VDU workstation (Fig. 11) with a divided heightadjustable table for the individual adaptation to manual and visual working height enabling an orthogonal top view (right angle between the relaxed visual axis, the preferred line of sight and the monitor surface). 


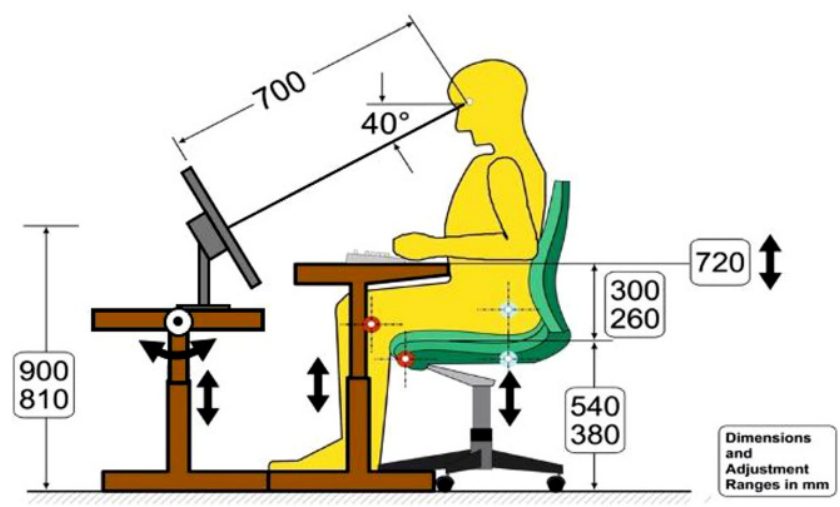

Fig. 11 Ergonomic designed VDU workstation with separate height adjustment facilities for screen, table and seat

Abb. 11 Ergonomisch gestalteter Bildschirm-Arbeitsplatz mit individuellen Einstellmöglichkeiten für den Bildschirm, die Arbeitsplatte und den Sitz

The chair, of course, allowed dynamic sitting. Alternatively they had to use a conventional (standard) and an ergonomic (test) keyboard (Fig. 12) while entering text that ensured equal stress on the left and right hand. Fig. 13 illustrates the necessary ulnar abduction of the hand when using the standard keyboard. Fig. 14 outlines the procedures start- ing with simultaneously picking up myoelectric activity of 8 selected muscles, data transmission to a PC, analysis of the series of measurements, recording and plotting the results. Finally, the static and dynamic parts of muscular strain associated with 10-min test phases of alternatively working with both keyboards were of interest.

Fig. 15 shows the time series of the standardized electromyographic activity, sEA (\%), of the 4 muscles acting on the forearm and the hand (lower block) and of the 4 muscles acting on the upper arm and shoulder (upper block) while alternatingly entering text with the standard keyboard, $(S 1$, $S 2, S 3)$ and the test keyboard (T1, T2, T3), during altogether six 10-min blocks. The black and white parts of the columns associated with static and dynamic muscle strain represent 1-min values from 10 Subjects (Ss).

At first it has to be stressed that muscle strain varied considerably from muscle to muscle. This is true for the total electromyographic activity and, especially, for the static part (black columns in Fig. 15). The height of the bar graphs for some muscles also may be associated with utilizing the two types of keyboards. But apparently these effects were not very strong. Working was associated with total sEA values of about $25 \%$ for the descendent part of the trapezius (upper row of upper block) and very low values of about $5 \%$ for the
Fig. 12 VDU workplace with Standard Keyboard (according to DIN 2137-13 1995) and Test Keyboard (N. N. 1994) as well as chosen character combination (Test Task) for text input that ensured equal stress on the left and right hand

Abb. 12 Bildschirmarbeitsplatz mit Standard Tastatur (gemäß DIN 2137-13 1995) und TestTastatur (N. N. 1994) für die Eingabe von Text, der eine gleiche Belastung für die linke und rechte Hand erforderte

Fig. 13 Chosen character combination for text input that ensured equal stress on the left and right hand: ICH SCHOB EINEN KINDERWAGEN ASDF JKLÖ

Abb. 13 Gewählte Text-Kombination, die eine gleiche Belastung der linken und der rechten Hand vorsah: ICH SCHOB EINEN KINDERWAGEN ASDF JKLÖ
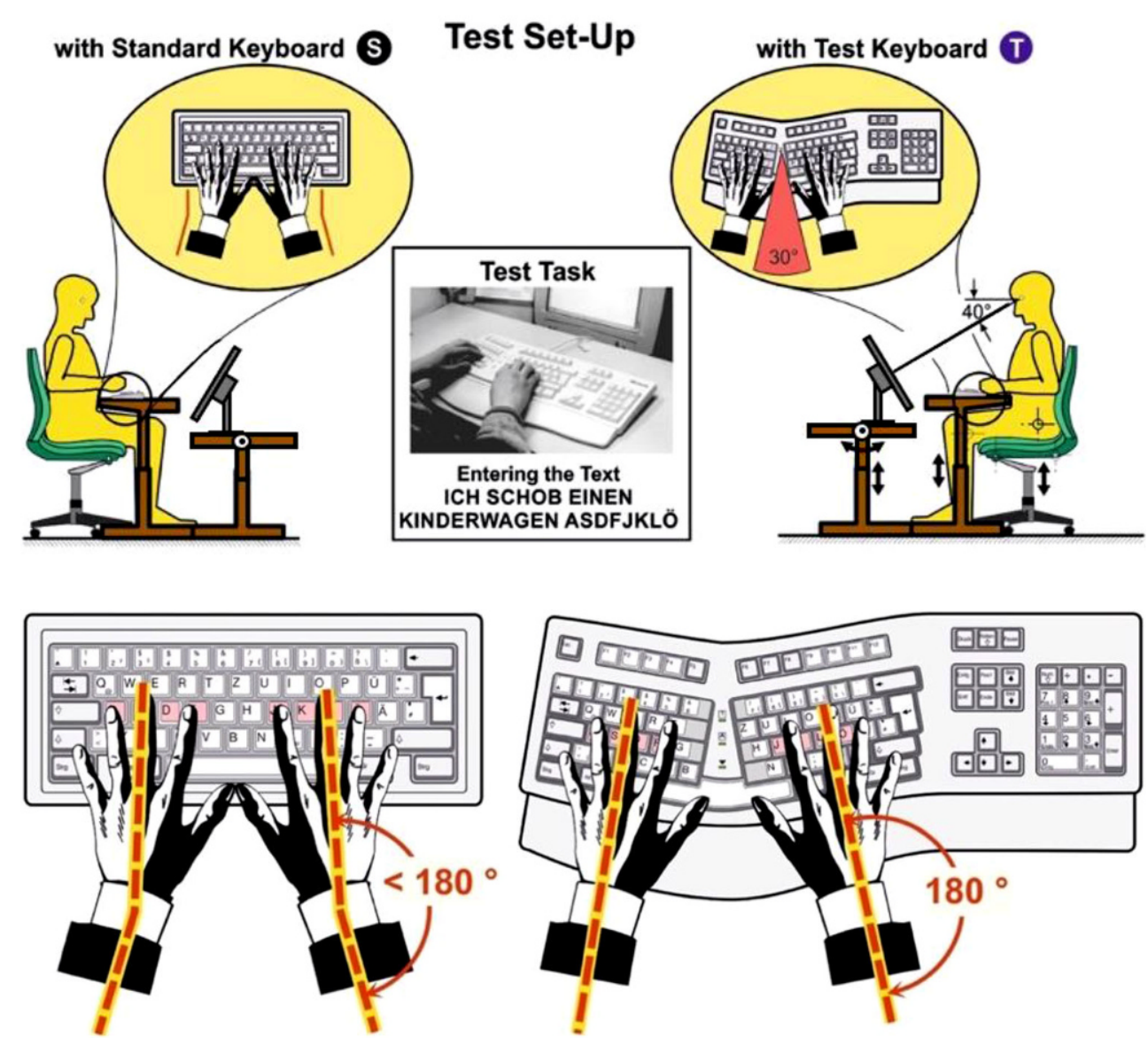


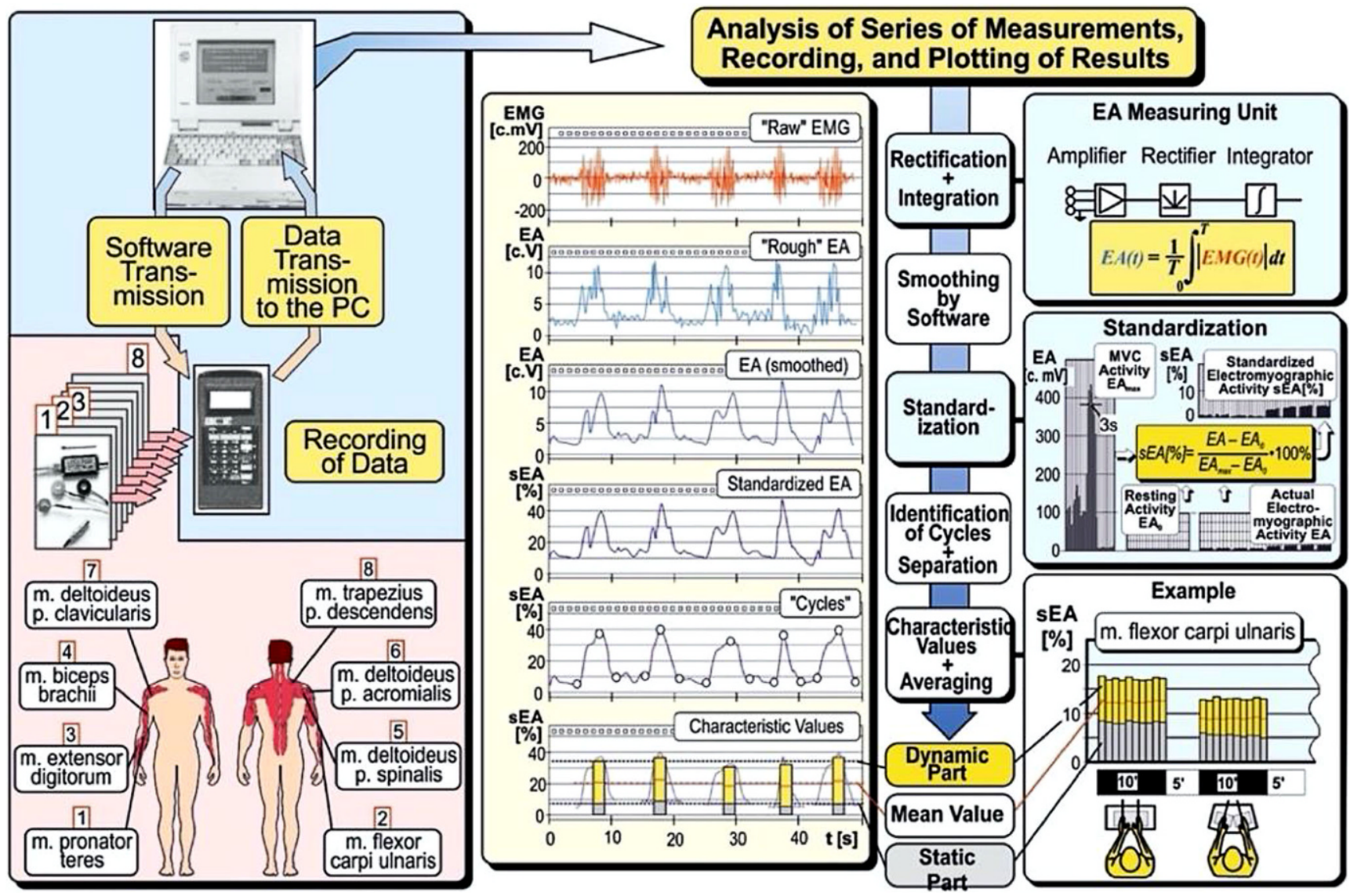

Fig. 14 Outline of electromyographic procedures, starting with picking-up myoelectric signals from muscles involved in work, recording time series of Electromyographic Activity EA ( $t$ ) by a portable data recorder and standardization of the A/D-converted Electromyographic Activity as well as splitting up EA into static and dynamic components

Abb. 14 Darstellung der elektromyographichen Verfahren, beginnend mit der Ableitung elektromyographischer Signale von, in die Arbeit involvierten Muskeln, Aufzeichnung aller Zeitserien der Elektromyographischen Aktivität EA(t) durch einen tragbaren Datenrekorder und Standardisierung der A/D-gewandelten (gleichgerichteten) und geglätteten Elektromyographischen Aktivität, sowie schließlich Aufsplittung der EA in ergonomisch bedeutsame statische und dynamische Komponenten

spinal part of the deltoid (lower row of upper block). The generally high static part of the $\mathrm{m}$. trapezius pars descendens, which almost regulariely exceeds the $15 \%$ threshold of the endurance level with both keyboards, seems noteworthy. Therefore, it is not surprising that muscle fatigue is already detectable in increasing sEA values within the relatively short working phases of $10 \mathrm{~min}$. Once again it can be shown very clearly that the descendent part of the trapezius muscle must generally be considered a bottleneck muscle during sitting work as has been shown in several prior experimental studies (Strasser and Keller 1997; Strasser and Müller 1999).
Physiological responses to utilizing the different keyboards can scarcely be detected in this presentation of the results of Fig. 15. In order to quantify potentially immanent effects, i.e. on the one hand the possible muscle relief brought about by the ergonomic test keyboard and on the other hand the additional physiological cost associated with the standard keyboard, all sEA-values from working with the two keyboards have been related to the overall mean values stemming from working with the test keyboard. For all single 1-min average values of the 10-min blocks of work, the quotient $\left.\left(\operatorname{sEA}(\mathrm{t})-\mathrm{sEA}_{\mathrm{T} 1+\mathrm{T} 2+\mathrm{T} 3}\right) / \mathrm{SEA}_{\mathrm{T} 1+\mathrm{T} 2+\mathrm{T} 3}\right)$ was calculated. This way of forming a value as a percent- 
Fig. 15 Time series of static and dynamic $\square$ parts of the Electromyographic Activity sEA (\%) of 4 muscles acting on the forearm and the hand (lower block) and of 4 muscles acting on the upper arm and shoulder (upper block) over 6, 10-min working phases while alternatingly entering text with the standard keyboard $(S 1, S 2$, S3) and with the test keyboard (T1, T2, T3). (1-min mean values of $10 \mathrm{Ss})$. Source: Strasser et. al (2007a)

Abb. 15 Zeitserien der statischen $\square$ und dynamischen $\square$ Teile der standardisierten Elektromyographischen Aktivität sEA (\%) von 4 Muskeln, die auf den Unterarm und die Hand einwirken (unterer Teil) und von 4 Muskeln, die auf den Oberarm und die Schulter einwirken (oberer Teil). Dargestellt sind die Werte über 6, jeweils $10 \mathrm{~min}$ lange Arbeitsphasen, in denen alternierend Text mit der Standard Tastatur (S1, S2, S3) und mit dem Test Keyboard (T1, T2, T3) eingegeben wurde. (1min-Mittelwerte von 10 Testpersonen). Quelle: Strasser et al. (2007a)
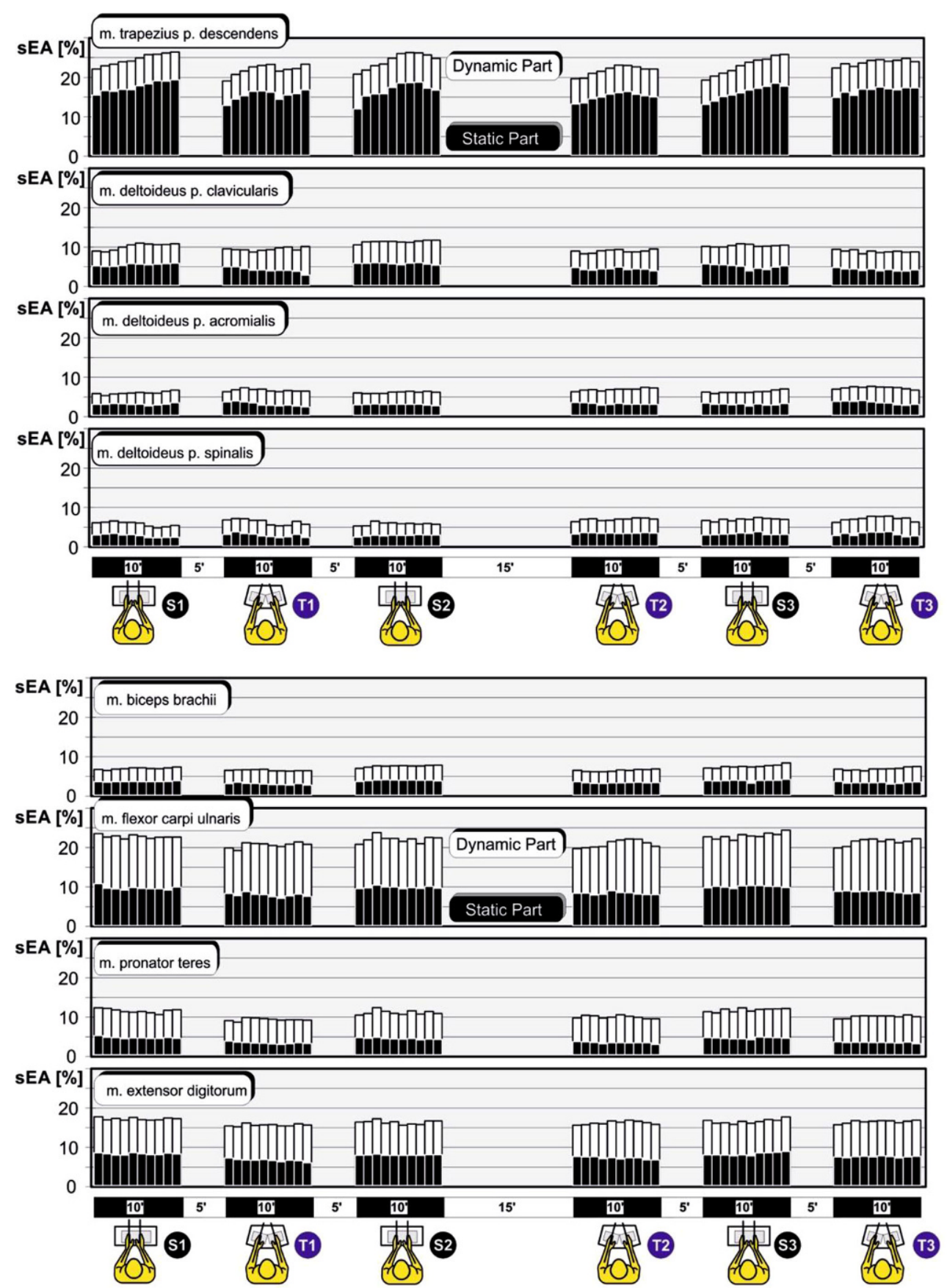

age, promises to reveal much better increases or reductions of muscle strain due to the type of keyboard. Hypothetically, for the columns associated with the test keyboard in the sections $T 1, T 2$, and $T 3$, this form of relating the sEAvalues, which have been visualized in Fig. 16, should result in only small deviations from zero. On the other hand, an increase in muscle strain-represented in the columns above the zero-line-should be the result of typing on the standard keyboard during the sections $S 1, S 2$, and $S 3$.
As can be seen in Fig. 16, this expected pattern indeed occurs, but it is not consistent and always true for the muscles acting on the shoulder and upper arm (upper block). The descendent part of the trapezius, at least sometimes, reveals higher physiological cost for the sections $S 1, S 2$, and $S 3$ and almost a zero level during the sections $T 1, T 2$, and T3. Yet for the two parts of the deltoid ( $p$. acromialis and p. spinalis), which are involved in abduction and retroversion of the upper arm, no systematic effects were 
Fig. 16 Increase or reduction of physiological cost of the 8 muscle groups acting on the forearm and the hand (lower block) and on the upper arm and shoulder (upper block) in \% related to the mean value of EA during text input using the test keyboard

$\left(\mathrm{sEA}(\mathrm{t})-\mathrm{sEA}_{\mathrm{T} 1+\mathrm{T} 2+\mathrm{T} 3} /\right.$

$\left.\mathrm{sEA}_{1}+\mathrm{T} 2+\mathrm{T} 3\right)$.

Significance level of increase or decrease of physiological cost is indicated by the symbols *, ** and *** (One-sided T-test). Source: Strasser et. al (2007)

Abb. 16 Zunahme oder Abnahme der Physiologischen Kosten der 8 Muskeln, die auf den Unterarm und die Hand (unterer Block) sowie auf den Oberarm und die Schulter (oberer Block) einwirken. Dargestellt sind die Werte in Prozent, die sich ergeben, wenn die Werte aus den jeweiligen (insgesamt) 6 Testabschnitten auf den Mittelwert aus allen Arbeitsphasen mit der Test-Tastatur bezogen werden, wobei die folgende Formel benutzt wurde:

$(\mathrm{sEA}(\mathrm{t})-\mathrm{sEA} 1+\mathrm{T} 2+\mathrm{T} 3 /$

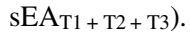

Die statistische Signifikanz der $\mathrm{Zu}$ - oder Abnahme der physiologischen Kosten nach dem einseitigen T-Test ist durch die Symbole *, ** und *** gekennzeichnet (Quelle: Strasser et al. (2007)
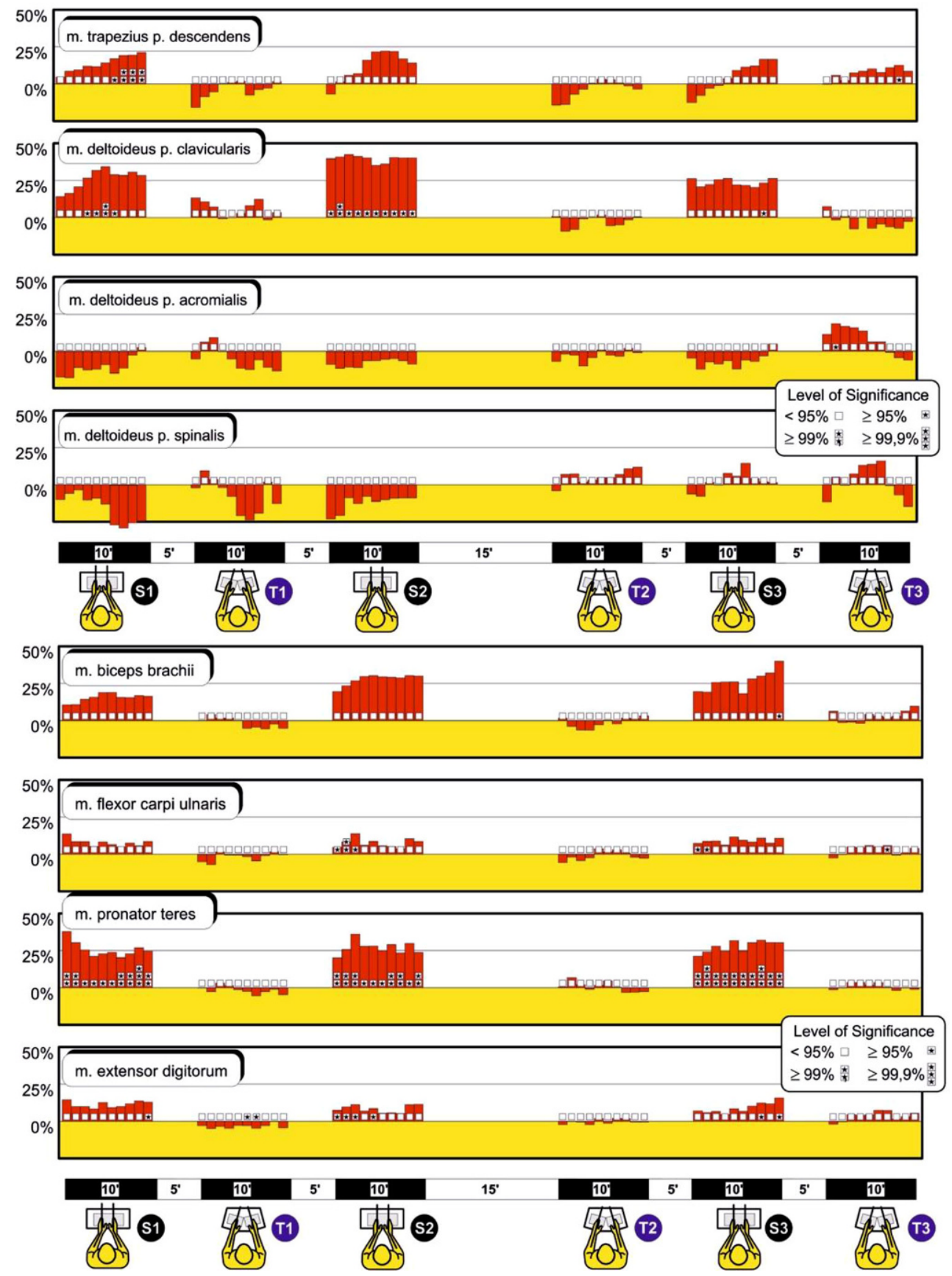

found which could be attributed to the keyboards. The pattern of changes in the percentage values due to the type of keyboard is more pronounced and consistent for the frontal (clavicular) part of the deltoid, which usually is involved in stabilizing the upper arm in a somewhat forward-moved position. About 25\% extra-physiological cost or even more during $S 2$ has to be paid when typing at the standard keyboard, or can be saved when utilizing the test keyboard.

The lower block of Fig. 16 exhibits clearer physiological responses of all muscles acting on the forearm and the hand, which can well be associated with the type of the keyboard. During all the phases when the 10 Ss worked with the test keyboard $T 1, T 2$, and $T 3$, only marginal increases or decreases in the relative values, i.e. variations around the 0 -line, occur.

On the other hand, the systematic increase of strain associated with the standard keyboard during the sections $S 1$, $S 2$, and $S 3$-represented in columns above " 0 "-indicate that, e.g. about $25 \%$ of the physiological cost of the biceps which has to be paid by this muscle when working with 
the conventional keyboard can be saved while typing at the ergonomic split keyboard. The effects can-as shown for $S 2$ and $T 1$-be verified in a second and third measurement.

Since the total sEA-values from the biceps as flexor and supinator (outward rotator) of the forearm are rather low (visualized in Fig. 16), from a work-physiological point of view, the very clear and (in two retests) reproducible effects due to the type of keyboard are less important than those of the other 3 muscles acting on the forearm and the hand.

Regarding the flexor carpi ulnaris, which brings about ulnar deviation of the hand, and the extensor digitorum, involved both in dorsal extension of the hand and in typing operations (as antagonist of the flexor digitorum), the physiological cost is increased by about $10 \%$ while typing at the conventional (standard) device.

Using the split keyboard with a pantile-like inclination, which is more compatible with the normal position of the hand and arm while typing, saves about $25 \%$ of the physiological cost which has to be paid by the pronator teres as inward rotator of the forearm when operating the conventional (standard) keyboard.

Despite the fact that this study delivered consistent electromyographic results in favor of the ergonomic keyboard, it may not be neglected that a computer keyboard today should not be evaluated in isolation. In this context, it was pointed out that, ironically, new "ergonomic" keyboards that have been designed with angled keys to reduce ulnar deviation by splitting or widening the orientation of keys, may encourage pointing device placement to a position that abducts the arm. This type of "wider" keyboard, while reducing the risk of wrist and hand injury, may unintentionally lead to a significant increase in trapezius muscle tension during mouse use. It should be mentioned that this can be compensated by an armrest (Keller and Strasser 1996) or a wrist rest (Keller and Strasser 1998).

Subjective questioning (the results are visualized in the Fig. 17 through to 19) revealed that the test subjects did not at all favor the conventional (standard) keyboard layout. They preferred the new and innovative ergonomic layout very clearly. The posture of the hand, the forearm and the upper arm and shoulder (upper part of Fig. 17) during text input with the standard keyboard was not evaluated positively, while the working posture when using the ergonomically designed keyboard was rated significantly higher. As can be seen in the lower part of Fig. 17, both keyboards were rated equally well during the test phases, whereas the ratings after the test clearly differed. Working with the standard keyboard was evaluated as worse than expected, and use of the test keyboard was evaluated better than expected. The global assessment of the test keyboard (Overall Impression) was much better than that of the standard keyboard
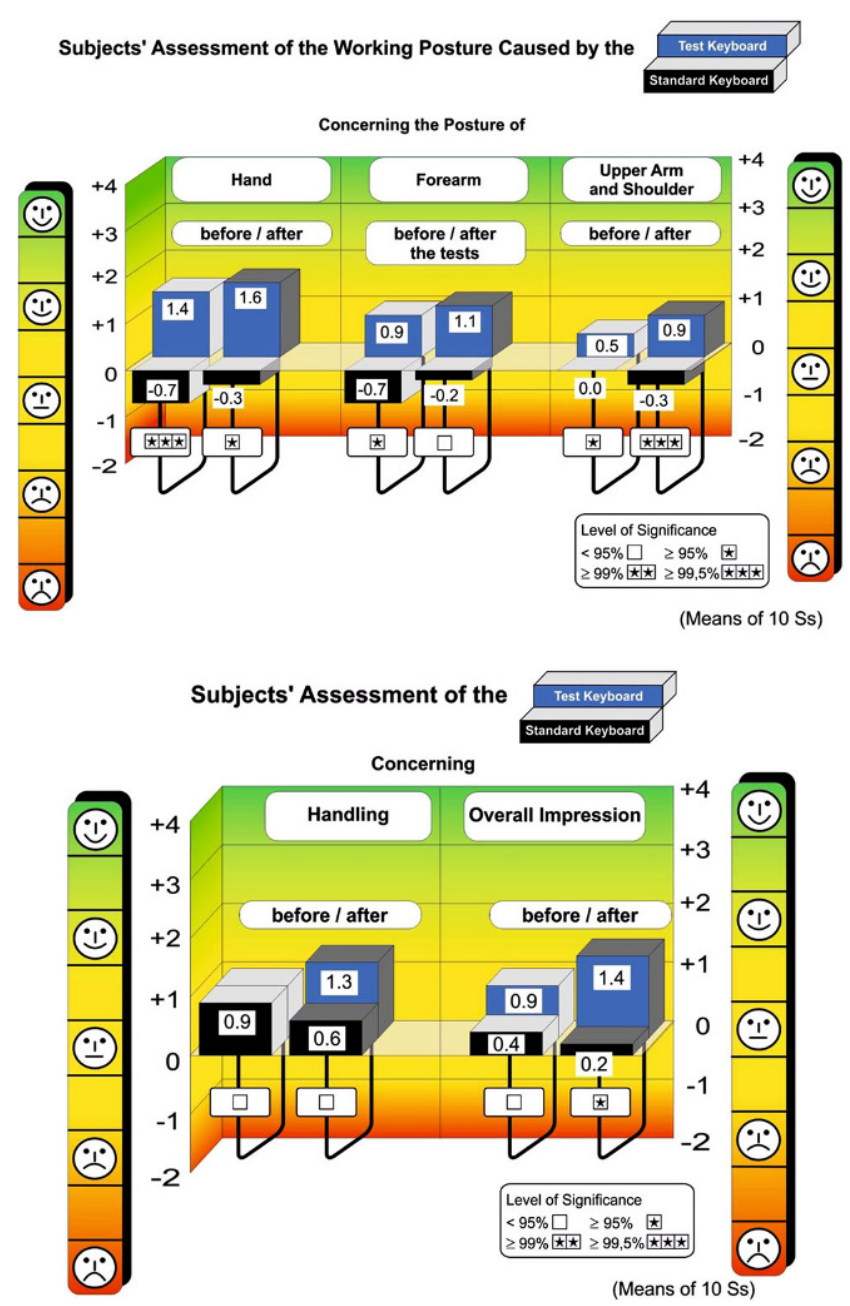

Fig. 17 Subjective assessment of the working posture caused by the Test Keyboard and the Standard Keyboard (upper part), and assessment of the handling and overall impression of the keyboards (lower part). Assessments were made both before (without) and after the tests (with experience of the subjects)

Abb. 17 Subjektive Beurteilung der Arbeitshaltung, verursacht durch die Test Tastatur und die Standard Tastatur (oberer Teil) sowie Beurteilung des „Handlings“ und des generellen Eindrucks der Tastaturen (unterer Teil). Die Beurteilungen wurden von den Probanden sowohl vor als auch nach den Tests vorgenommen, d.h. sie beruhen auf Einschätzungen ohne bzw. mit eigenen Arbeitserfahrungen

both before and after the test series. The Ss suspected already in advance that the text input with the new keyboard would be more comfortable and less strenuous (Fig. 18).

According to Fig. 19, typical design features of the ergonomic keyboard and their actual realization by the producer were positively evaluated at a bipolar 4-step scale. The ratings mostly ranged from "1" (somewhat favorable) to "2" (fairly favorable). The Ss, e.g., were satisfied with the arrangement of the keys, and it is noticeable that the space bar (which is not in accordance with standards) was 


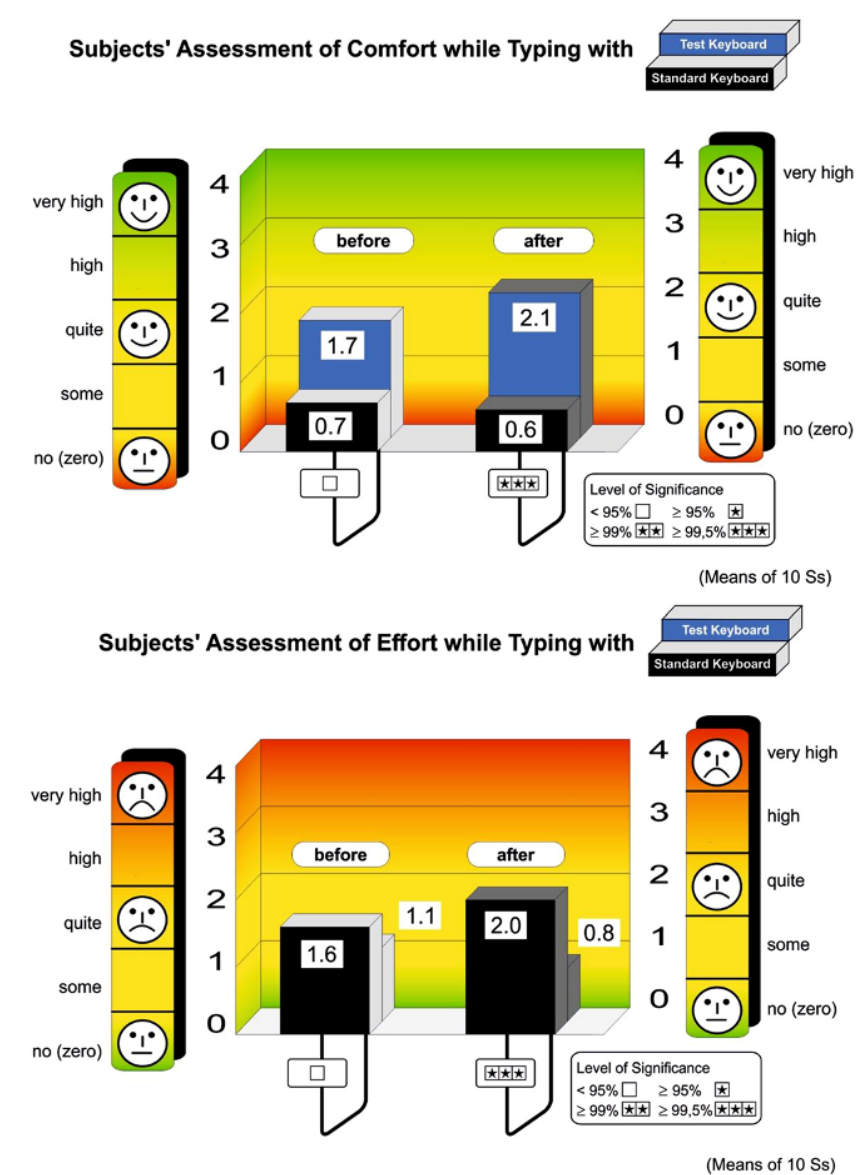

Fig. 18 Subjects' assessment of comfort (upper part) and effort (lower part) while typing with the Test Keyboard and the Standard Keyboard (before/after the tests)

Abb. 18 Subjektive Beurteilung des Komforts (oberer Teil) und des Aufwands (unterer Teil) während des Arbeitens mit dem Test Keyboard und der Standard Tastatur (bevor und nach den Tests)

especially well-liked. The overall appearance, with a mean value of 2.2 (see very right part of Fig. 19) turned out rather well.

All in all, the ergonomic design of the tested keyboard led to objectively verifiable and plausible reductions of muscle strain, especially in the muscles acting on the forearm and the hand. But the effects were not as strong as was to be expected from simultaneously recorded subjective assessments. For avoiding overestimation or underestimation of experimental results, i.e. for an adequate and correct evaluation of the ergonomic quality of working tools it is always advisable to utilize both objective and subjective methods as it was recommended by Strasser et. al (2007).

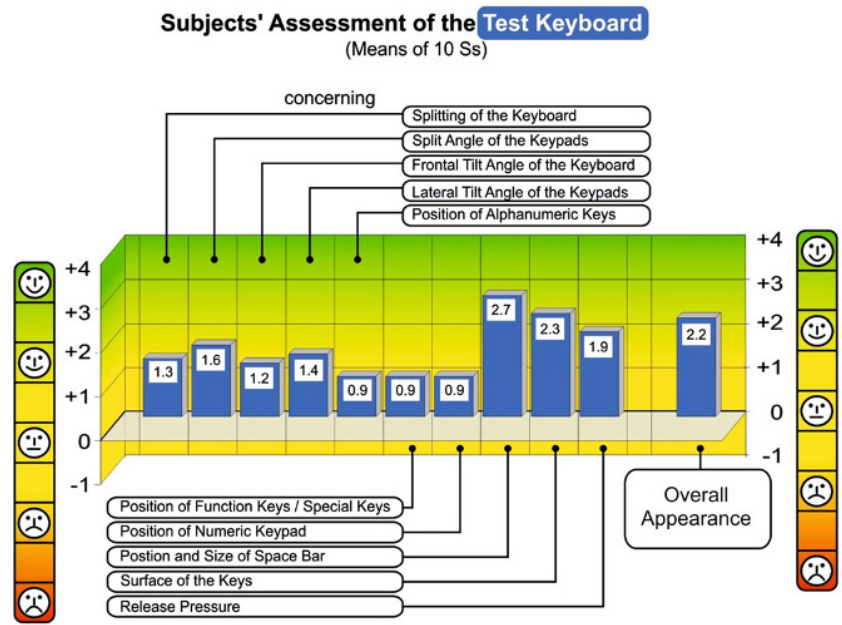

Fig. 19 Subjects' assessment of the Test Keyboard (means of $10 \mathrm{Ss}$ ) Abb. 19 Subjektive Beurteilung des Test Keyboards (Mittelwerte aus 10 Probanden)

\subsection{Men's hairdresser scissors compatible to the anatomic specialities of the hand-arm system}

With the help of an additional case study, it can be demonstrated that an ergonomically designed tool, that is highly compatible with the anatomic characteristics of the handarm system, not only provides immediate positive effects on the hand-arm system itself but, surprisingly, also has positive indirect effects on other body regions, that are far away from the active upper extremity. For details see Strasser and Bullinger (2007).

A study that had been commissioned some time ago by the Federal Institute for Occupational Safety and Health (the German NIOSH) had shown that men's hairdressers (barbers) are over-proportionally affected by occupational diseases in the form of varicose veins with associated consequences in the calf area. As is well-known, the profession of men's hairdresser (barber) belongs to the group of "standing-up" occupations and, therefore, is exposed to higher static stress. Yet, at first glance, it seems astonishing that work with comb and scissors can cause varicose veins and that this can be linked to the tools of the trade. In a comprehensive work study, Bullinger and Solf (1978) identified the hand's limited displacement capacity of about $60^{\circ}$ in the dorsal direction as the main cause of problems, which may be surprising at first glance. But when considering that a barber has to cut hair not just in the head area but also in the nape it becomes evident. 
To avoid stepped cuts in the nape region, a hairdresser normally works in a bent-backwards posture in order to get the cutting blades into a vertical position. In that position, nearly the total weight is transferred onto one leg, whereby the blood flow in the calf region is lowered-caused by the increased static load to the muscles of the lower leg. The generally increased static pressure in that region also has a negative influence on the venous back flow as well as on the vein's shape, so that the consequential genesis of varicose veins seems plausible as a long-term effect.

It can be seen now in Fig. 20 how anatomical features were the main influences on and showed the way to a new design for compatible scissors. Firstly, the crossed saddle joint of the thumb in relation to the finger joints had to be considered. Secondly, the natural movement of the thumb (as shown in the left part of Fig. 20), which is neither directed towards the index finger nor towards the little finger but nearly exactly towards the middle finger, had to be obeyed. If the men's hairdresser adopts a two-finger-pinch grip using thumb and ring finger-with the palm facing the work object - and if he mostly uses his thumb dynamically, then the scissor shaft manipulated by this finger must be shortened by one's finger width to provide the natural movement towards the middle finger. Nowadays, it should be self-evident that the shape and size of the eyes for thumb and ring finger are to be matched to their dimensions and that the main axis of an elliptically shaped thumb eye is to be designed with a sloped angle to achieve the highest possible compatibility between technical and anatomical joints.

The effect to be expected from these detailed improvements is a more comfortable use and a positive long- term protection against finger deformation for men's hairdressers. But the decisive improvement to this tool (as shown in the lower right part of Fig. 20) is a pre-adjustment of the cutting blades in such a way that an angle of about $30^{\circ}$ between blades and handle axis can reduce the formerly unnatural bent-backwards posture without any disadvantages for the hairdresser, even when he has to use the cutting blades in a horizontal plane.

\subsection{Screwdriver handles compatible with the hand curvature for reduction of physiological cost of work}

Another case study shall be presented in order to explain the slogan "adapted to man=adapted to the hand" and to demonstrate the issues of working.

Screwdrivers are the most widely used tool. They can be found in every tool box and every handyman most likely has screwdrivers in several different sizes. But screwdriver handles in the past (until the 90's of the last century) seldom had the shape and dimensions which would be suited to the anatomy of the hand, so that after finishing work, many users complained about muscle pain and blisters. The everyday-handles of the past, as well as handles still used today, which are designed according to a standard (DIN 5268 1973), have a straight longitudinal contour and a round cross-section-like the ones shown in the right-hand part of Fig. 21-often with a grooved and rough surface. They can be used neither in a comfortable manner for a power grip during driving in a screw or for producing a torque for unscrewing, nor for a pinch coupling which is mostly
Fig. 20 Anatomical features of the fingers and the hand, and functional consequences for a compatible design of men's hairdresser scissors

Abb. 20 Anatomische Besonderheiten der Finger und der Hand sowie funktionale Konsequenzen für eine kompatible Gestaltung von Friseurscheren
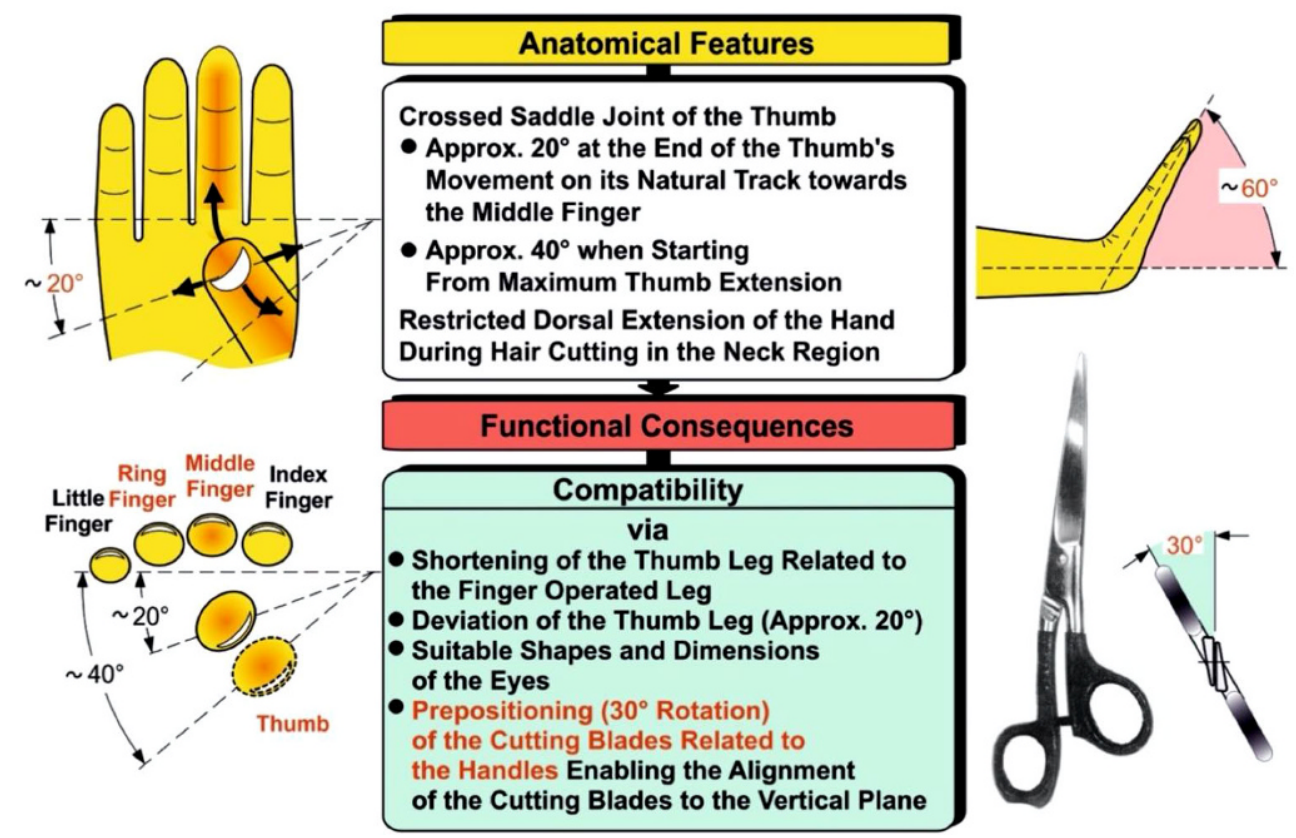
Fig. 21 Screwdriver handle contours, compatible (left) and incompatible (right) with the hand curvature

Abb. 21 Kontouren von Schraubendreher-Griffen, kompatibel (links) und in-kompatibel mit der Form der menschlichen Hand (rechts)
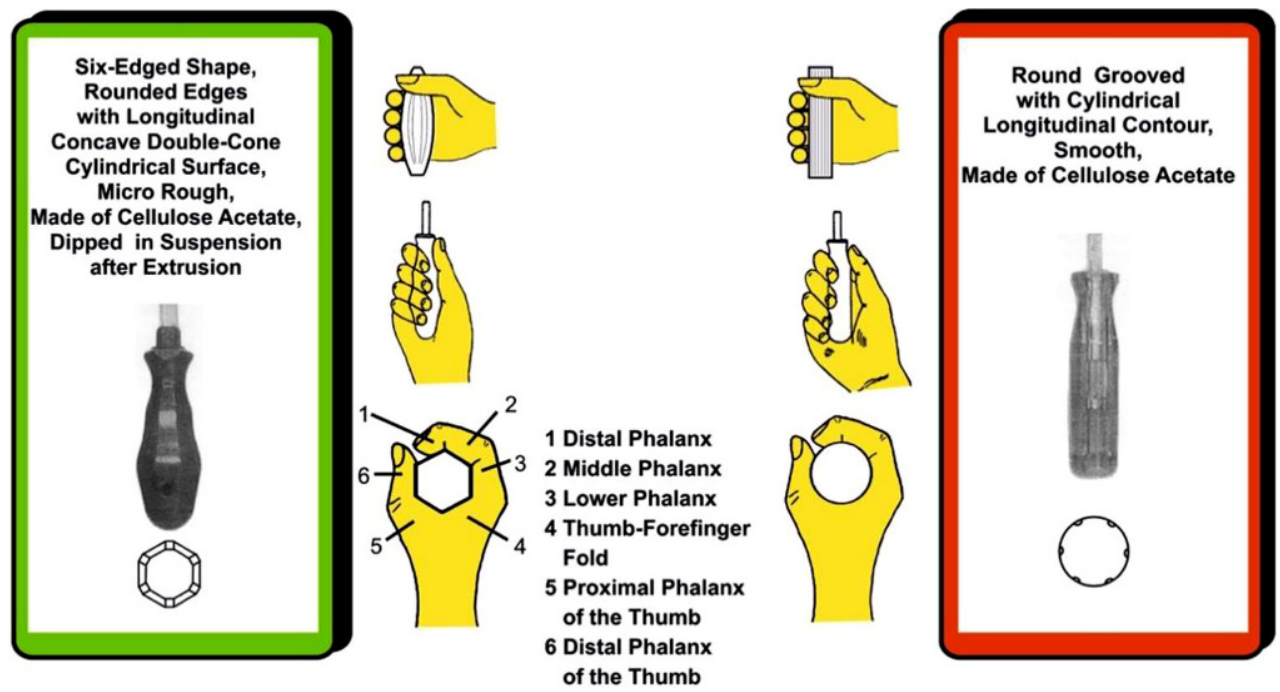

appropriate for quick driving in and unscrewing a loose screw. These handles are not compatible with the natural hand characteristics.

Handles fitting the hand (left part of Fig. 21) must have a longitudinal contour which is compatible with the hand, i.e., a so-called convex double-cone cylindrical surface. This surface also must guarantee the necessary friction resistance for creating an adequate torque, as the contact surface-with regard to the cross-section - is much bigger.

As distal and middle phalanges together with lower phalanges of the fingers, distal and proximal phalanges of the thumb, and the crease between thumb and index finger create a polygon-like shape, a hexagon, a similar cross-section of the handle leads to the most favorable coupling if the equipment is used for rotational movements.

Additionally, the bio-mechanical transmission of force for the creation of torques during screwing depends also on the surface and material of the handle, whereby a smooth surface with a slight concave groove and a corresponding friction material enables the best coupling for convexshaped phalanges. Such tools compatible with the hand's anatomy enable exertion of higher forces and torques, and reversely lead to lower physiological cost if the same output is required. That shall be presented roughly in the following Fig. 22 through to 24. Fig. 22 illustrates some technical aspects of the measuring devices for quantifying the operational output (maximum torque that can be exerted) and the physiological responses to working with various screwdrivers.

In standardized working tests, in the course of which 7 different common models of screwdrivers (shown in the lower part of Fig. 23) were evaluated, the standard handle $\mathrm{H} 6$ and a new designer handle $\mathrm{H} 4$ proved to be the least adequate models. The maximum torques which could be exerted-shown in the blue columns of Fig. 23-were at approximately just $50 \%$ of those executed by $\mathrm{H} 5$ as well as by $\mathrm{H} 2$, which is considered to have an ideal ergonomically designed handle.

It is remarkable that these findings result from the same physiological input, measured by the electromyographic activity EA 1 of the flexor digitorum as muscle involved in closing the fist and EA 2 of the biceps as outward rotating muscle, as supinator of the arm.

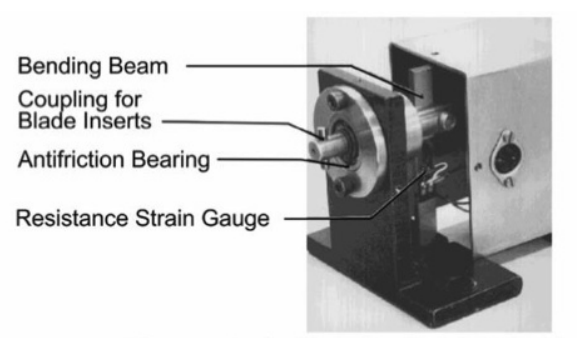

Torquemeter for Measuring the Maximum Torque and for Determining Submaximum Static-Isometrical Demands for Torque

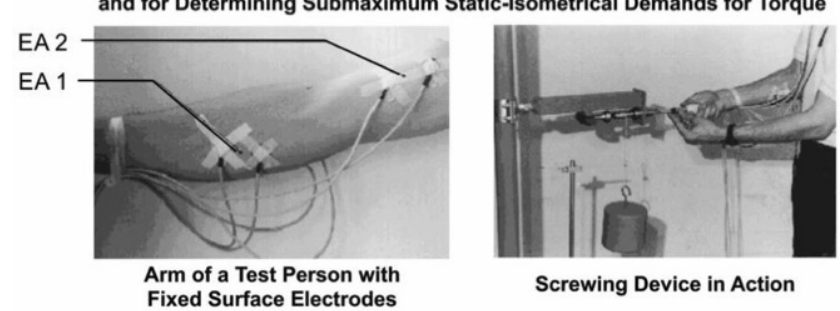

Fig. 22 Device for the measurement of the maximum torque which can be exerted (top), positions for the electrodes attached on the arm of a worker for recording the Electromyographic Activity of the musculature closing the hand (EA 1) and the biceps brachii (supinator, EA 2) as the most important muscles for screwing work (bottom left), as well as the screwing device in action (bottom right)

Abb. 22 Vorrichtung zur Messung des maximal aufbringbaren Drehmomentes (oben), Position der Elektroden am Arm eines Probanden zur Messung der Elektromographischen Aktivität der Handschließmuskulatur (EA 1) und des Bizeps (als Hand- bzw. Unterarm-Außenwender EA 2) als den wichtigsten, in die Schraubarbeit involvierten Muskeln (unten links), sowie Schraubvorrichtung in Aktion (unten rechts) 


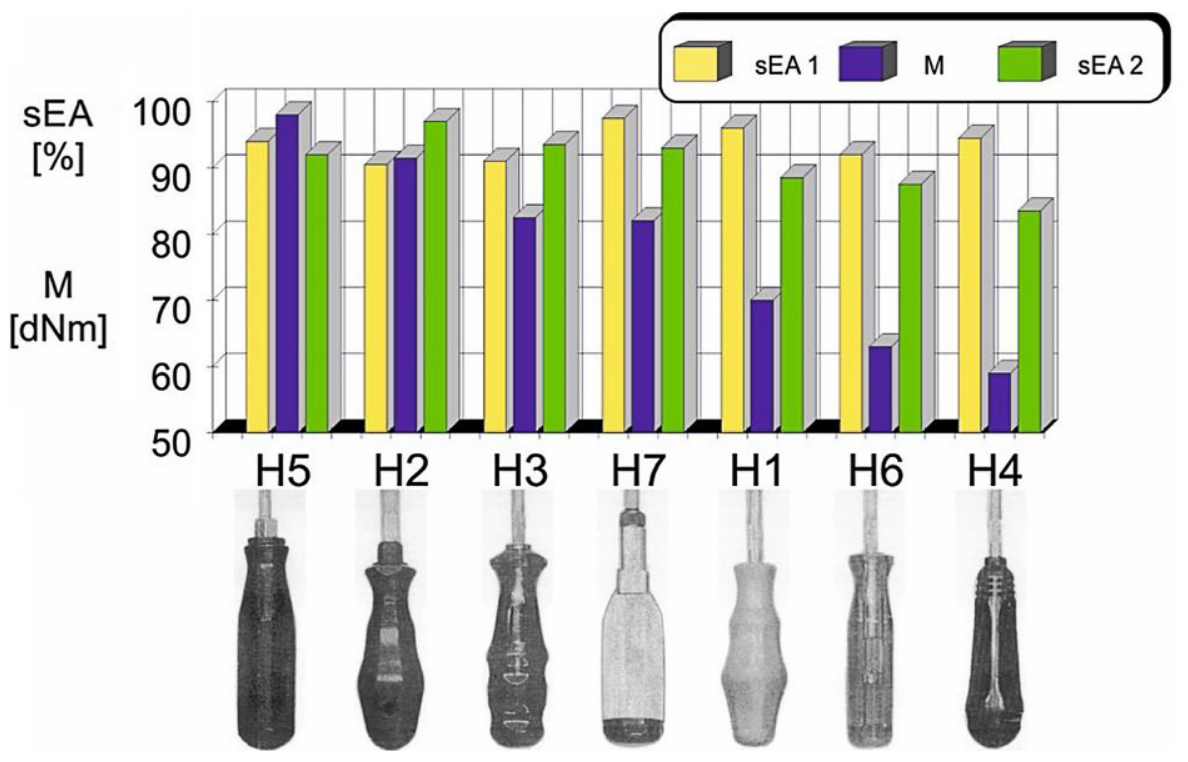

Fig. 23 Maximum torque $M$ to be exerted (in deci-Newton-meter) with standardized Electromyographic Activity of the musculature closing the hand (sEA 1) and outward rotating of the forearm (sEA 2) (in \% of individual electromyographic maximum values). Mean values of all screwdriver handles $(\mathrm{H} 1-\mathrm{H} 7)$ from 5 subjects

Abb. 23 Maximal aufbringbares Drehmoment $M$ (in Deci-Newton-Meter) mit standardisierter Elektromyographischer Aktivität der Handschließmuskulatur (sEA 1) und des Bizeps (sEA 2) als Supinator bzw. Unterarm-Außenwender (in \% der maximalen individuellen elektromyographischen Aktivitätswerte). Mittelwerte für alle Schraubendreher-Griffe (H1-H7) von 5 Probanden

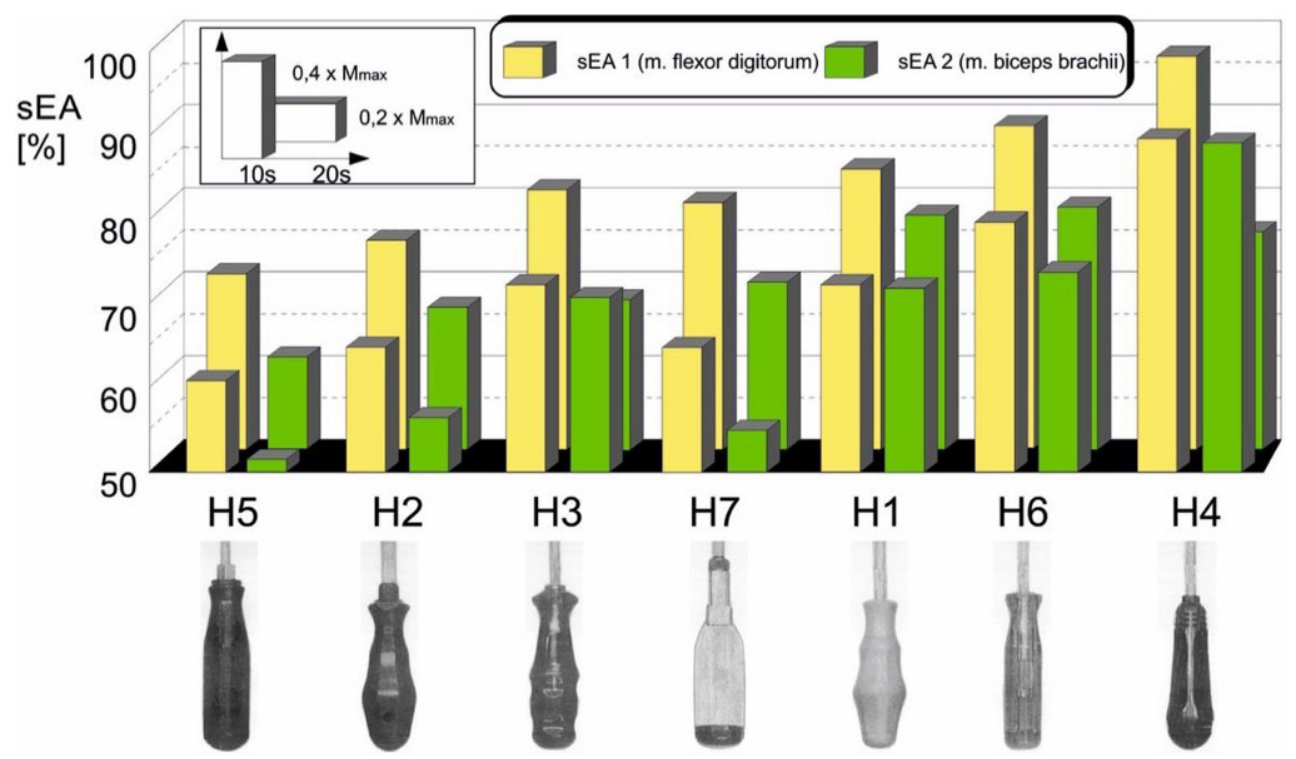

Fig. 24 Relative height of the static strain regarding the musculature for closing the hand (sEA 1) and outward rotating of the forearm (sEA 2) (standardized Electromyographic Activity in \% of individual electromyographic maximum values) during equal sub-maximum (static) screwing performance (mean values from 5 subjects)

Abb. 24 Relative Höhe der statischen Muskelbeanspruchung der Handschließmuskulatur (sEA 1) und des Unterarm-Außenwenders (sEA 2). Standardisierte Elektromyographische Aktivität in \% der individuellen elektromyographischen Maximalwete bei gleicher (statischer) submaximaler Schraubleistung. (Mittelwerte von 5 Probanden) 
During tests with equal sub-maximum workload-20\% of the individual maximum torque over $20 \mathrm{~s}$ and $40 \%$ over $10 \mathrm{~s}$ - the electromyographic data shown in Fig. 24 make clear that working with un-ergonomic tools demands higher physiological cost —as a consequence of higher muscular forces-since the tool is not adapted to man and his anthropometric characteristics. Regarding these results, the necessity of ergonomic design solutions to reduce human efforts, as well as to avoid marks and blisters, and to enhance operational performance should become evident. Conclusions can be drawn that the bulbous shape of a handle is, in principle, compatible to the natural hand form. Yet, the crosssection almost never should be circular, but rather should have a rounded hexagonal form, especially for screwdrivers.

After this first investigation (details see Strasser 1991), lots of experimental studies have been carried out in which the ergonomic quality of an already substantially improved set of a new generation of professional-grade screwdrivers had been comprehensively evaluated (Kluth et al. 2004). Besides this book, published in German, details of these and additional studies are described in English in various chapters of a book edited by Strasser (2007).

Depending on the task which is to be performed, also an edged or squared cross-section is appropriate for the tool. This can be shown by mason's trowels and file handles.

\subsection{Handles of trowels tailored to the mason's hand}

If trowels are, indeed, shaped to the mason's hand (see lower right part of Fig. 25) and, therefore, have grips compatible with the hand-arm system, then they should have a crowned instead of a straightened longitudinal outline to facilitate the contact of all fingers during a power grip.

A straight longitudinal contour of the handle and a circular cross-section according to a German Standard (DIN 6440 1988) does not facilitate a power grip. The fingers can fit the handle without any unnatural deformation of the palm solely when a crowned longitudinal outline of the handle is provided. Since, furthermore, a mason uses a trowel not just for translatory motions in a socalled form coupling, but also in a friction coupling for swinging movements-for instance in plastering a vertical wall-a somewhat rounded and squared rather than a circular cross-section can be helpful to avoid the trowel slipping inside the fist-formed hand.

A smoothed trapeziform cross-section-as shown on the lower left side of Fig. 25-enables an essential reduction of the muscle forces for the same output, i.e., the same performance, and a flat (somewhat concave) surface for the straightened thumb ensures a less restricted flexibility of the wrist than a thumb that is enclosed in forming the fist, as the thumb is the hand's strongest finger. For details, especially the systematic development, and the evaluation of the ergonomic quality of Mason's trowels via electromyo-
Fig. 25 Mason's trowels with a handle compatible to the palm with a crowned instead of a straightened longitudinal outline and a rounded trapeziform instead of a rotationally symmetrically cross-section Abb. 25 Maurerkellen mit zur Innenhand bzw. zum Handgewölbe kompatiblen Griffen mit einer balligen anstatt einer geraden Längskontur und einem verrundeten trapezförmigen anstatt einem rotationssymmetrischen Querschnitt

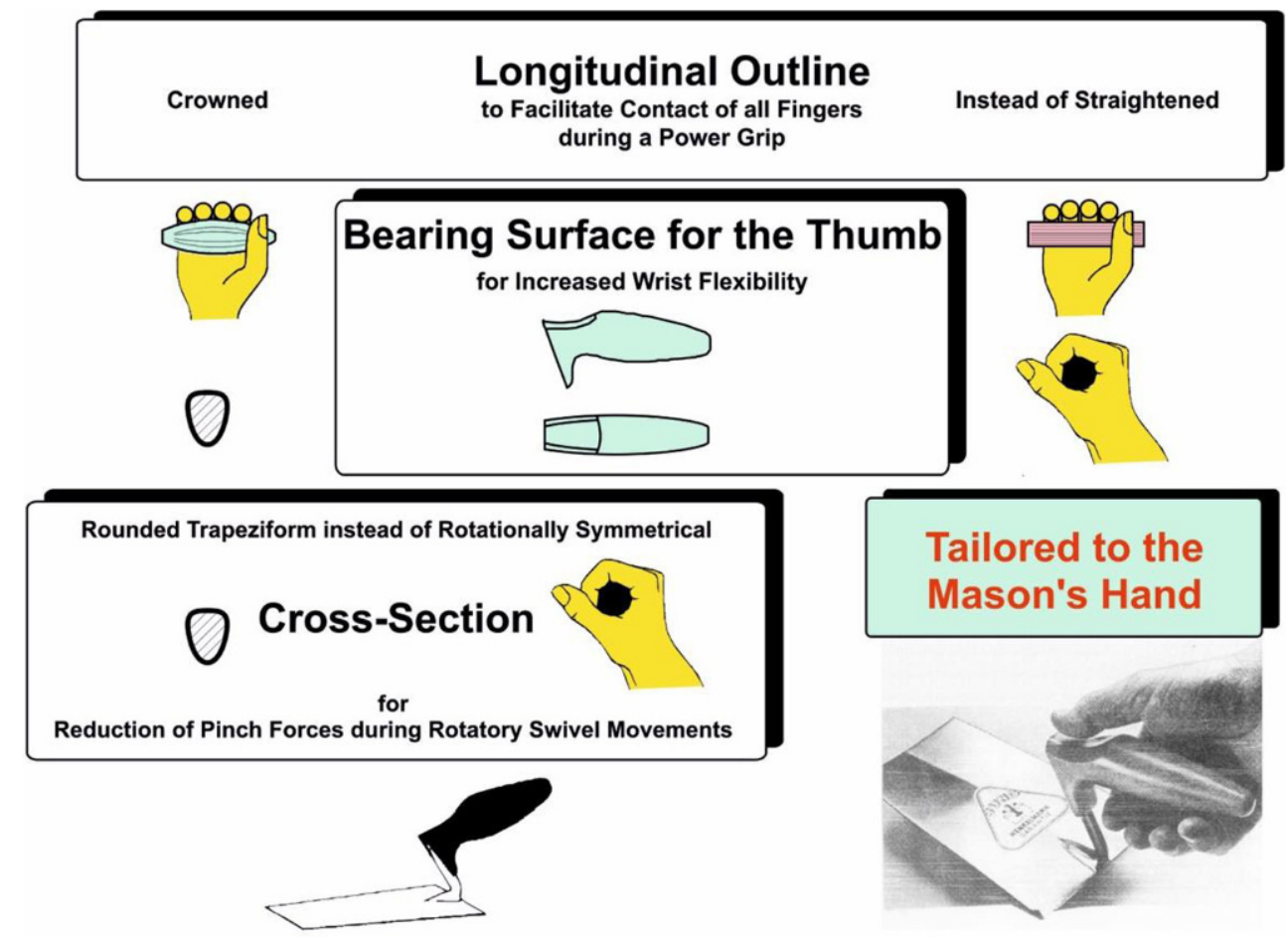


graphy and subjective rating see Bullinger and Solf (1979, 1997) and Strasser et al. (2007c).

\subsection{Ergonomically designed file handles}

For a flat or a square file, the use of a file handle according to a German standard (DIN 395 1968) (cp. upper left part of Fig. 26) is not a compatible solution. The main task consists in producing plane surfaces. Therefore, a special design (cp. upper right part of Fig. 26) can be helpful in supporting the "feeling" of a parallel position of the file blade to the work piece surface. To create this feeling is nearly impossible with a circular cross-section, but much easier with the help of a rounded 4-edge.

As the largest diameter must be located where the biggest hand curvature is found, compatibility to the hand cannot be achieved by file handles according to standard solutions. During filing, a closed kinematic chain created by hands and the tool is normally required for efficient working, during which a naturally preferred working direction exists at about $60^{\circ}$ between frontal plane and movement directions. As most other activities should also be performed in the maximum physiologic reach during a frontal orientation of the worker to the work bench, a vice prepositioning of approximately $30^{\circ}$ (cp. lower right part of Fig. 26) would be helpful, especially in a training workshop. For details and the evaluation of the ergonomic quality of file handles see Kluth et al. (2007).

In the following electromyography may be shown as a powerful means for the optimization of movement-based work design.

Fig. 26 File handle according to German Standard DIN 395 1968 (upper left part) and an ergonomically designed handle (upper right part), and favorable $30^{\circ}$ prepositioning of the vice on a work bench (lower right part)

Abb. 26 Feilengriffe gemäß der Deutschen Norm DIN 3951968 (oben links) und ergonomisch gestaltete Griffe (oben rechts) sowie günstige Voreinstellung des Schraubstocks von $30^{\circ}$ gegenüber der Werkbank (unten rechts)

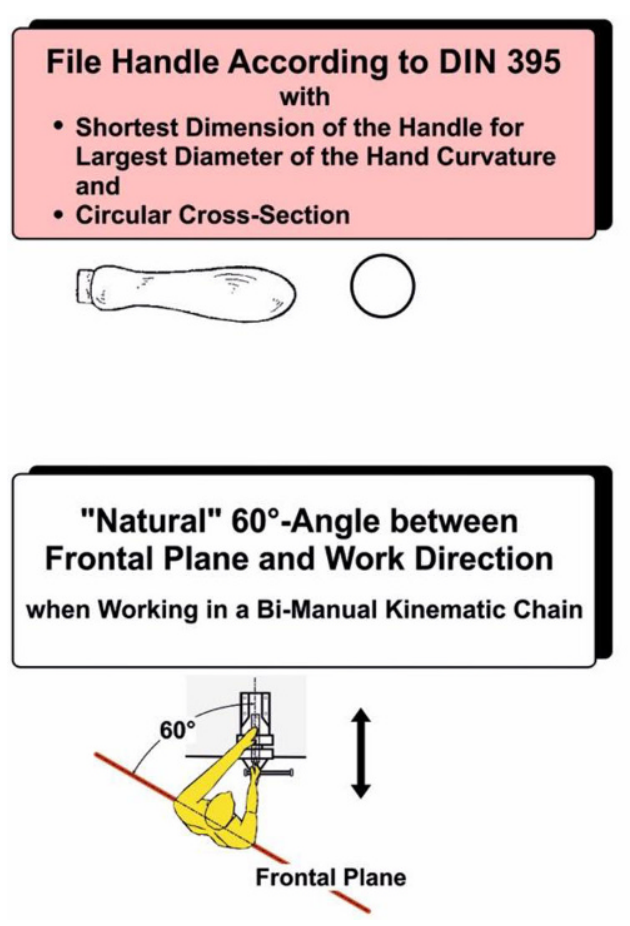

\subsection{Electromyographic methods for optimization of movement-based work design in harmony with physiological laws}

Until now, planning methods like "Systems of Predetermined Motion Time" used for motion-technical work design of assembly activities consider only time allotted to the worker as the most important topic. Therefore, these methods should be completed by a kind of "Systems of Predetermined Strain" in order to support a future-oriented and preventive way of thinking in ergonomics.

If a dominant manual movement direction during repetitive activities is determined by construction-as is usual for cashier workstations or assembly work-that direction should be matched to the naturally favorable directions of the hand-arm system (cp. Fig. 27).

In this context, fundamental research work supported by multi-channel electromyography (details see Strasser et al. 1989) proved that load handling from different starting points $\mathrm{S}$ within the reach to a common destination $\mathrm{Z}$ causes highly varying physiological cost that has to be paid to the same operational output. By means of computerized analyses of the time series of electromyographic activity EA and applying the already reported standardization procedure and splitting-up of EA into static and dynamic components, the handling direction of $150^{\circ}$ turned out to be the most inconvenient for the subjects. The evaluation-compatible circular diagram of the direction-dependent EMGcomponents presents, for this special angle, the maximum values for the static as well as the dynamic components. But for $30^{\circ}$ angles - as well as for movements originating 
Fig. 27 Compatible arrangement of test design, evaluation methods applied, and results (from an experimental ergonomic study)

Abb. 27 Kompatible Anordnung des Versuchsdesigns, der angewandten Auswertemethoden und der Ergebnisse (aus einer experimentellen ergonomischen Studie)
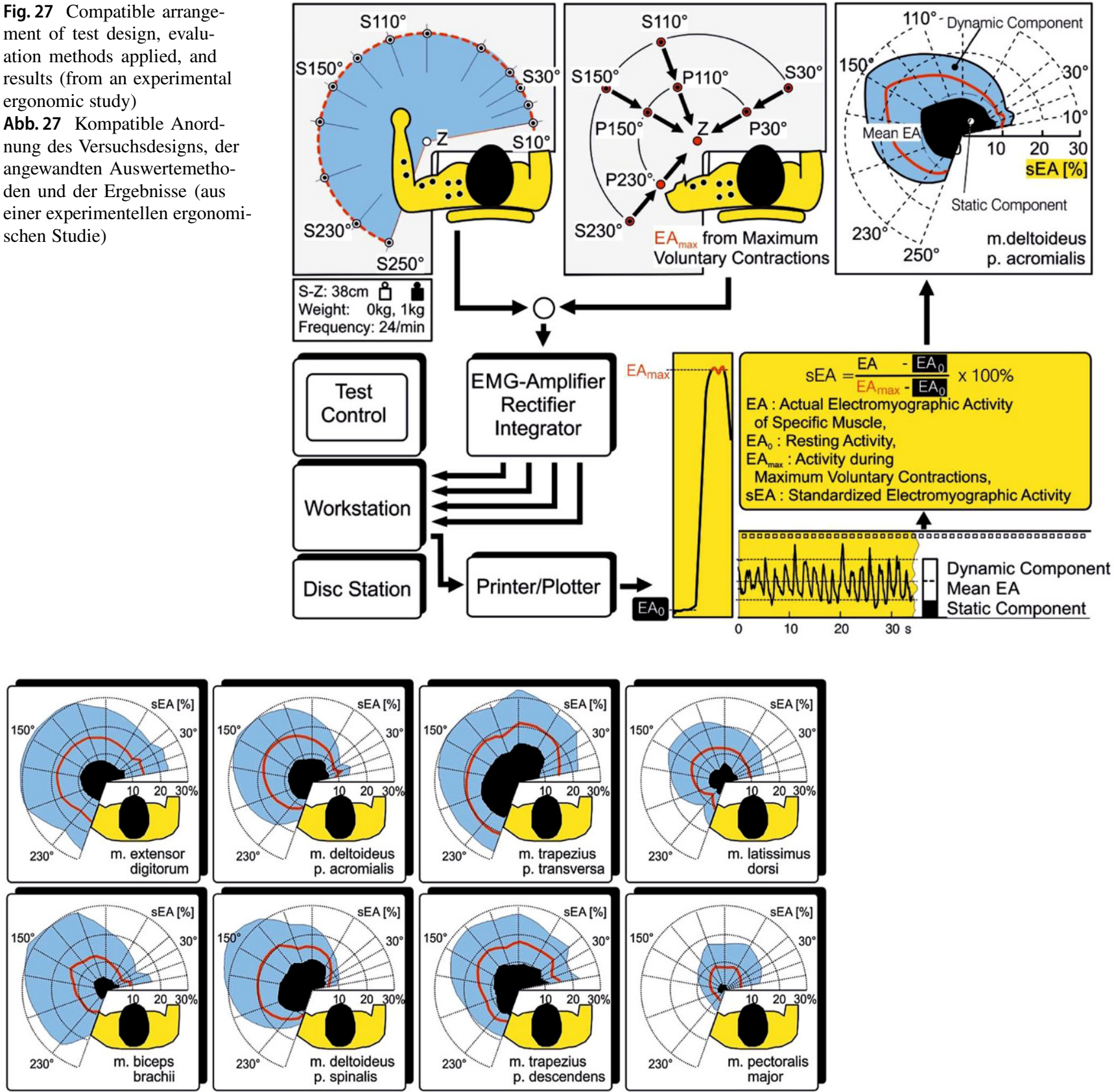

Fig. 28 Static and dynamic components of the Electromyographic Activity sEA (\%) (black respectively blue areas of the circle diagrams, red line indicating mean sEA) of 8 muscle groups from the forearm, the upper arm, the shoulder, and the upper parts of the torso during manual materials handling in different directions between $10^{\circ}$ and $250^{\circ}$. (Means from $11 \mathrm{Ss}$ during manipulation of an external load of $1 \mathrm{~kg}$ over a distance of $38 \mathrm{~cm}$ at a working speed of 24 cycles/min)

Abb. 28 Statische und dynamische Komponenten der Elektromyographischen Aktivität sEA (\%) (schwarze bzw. blaue Bereiche der Kreisdiagramme mit roten, die mittlere sEA indizierenden Linien) von 8 Muskelgruppen des Unter- und Oberarms, der Schulter sowie des oberen Teils des Rumpfes während horizontaler Armbewegungen im Greifraum in verschiedenen Richtungen (zwischen $10^{\circ}$ und $250^{\circ}$ ) auf einen körpernahen Zielpunkt zu. (Mittelwerte von 11 Probanden während des Bewegens einer externen Last von $1 \mathrm{~kg}$ über eine Distanz von jeweils $38 \mathrm{~cm}$ bei einer Arbeitsgeschwindigkeit von 24 Zyklen/min) 
from the backward reach-the muscular strain-as shown in this example-is almost half below that value. In test series-as shown in Fig. 28-the typical direction-dependent strain for several important muscles of the hand-arm system and the upper torso could be registered, so that these results can be used for the planning and design of compatibility between required and performed movement directions in manual work, resulting in the minimization of total strain.

During an applied investigation into different body postures and movement directions of a cashier's left arm, via electromyographic evaluations left-to-right or forward movements (Fig. 29) proved to be the most appropriate for a frontal alignment of the subject to the conveyor belt. This was true for "Lifting" or "Pushing" goods and minimal physiological cost was associated with pushing goods from the left to the right and not vice versa.

\section{Complex applied ergonomics design example: scanner checkouts with goods throughput from left to right}

In the following, the issues of laboratory and complex applied ergonomics field studies may show that the layout of the check-stand in self-service shops amongst others has to be designed to allow hand-arm movements of the cashier in harmony with physiological laws. For details of the analysis and evaluation of former existing workplaces and er- gonomically designed and evaluated check-stands see Kluth (2001).

Multi-channel electromyographic measurements already in the early 90's of the last century (Strasser et. al 1991) proved that movements of the left arm over the same distance from left to right are much more favorable than movements from right to left. Similar is true for the right arm for movements from right to left. Furthermore, during checking simultaneously the right arm of a right-handed person can conveniently be used for occasionally still required keyboard input or the money handling after cashing. Fig. 30 contains photos of the left-to-right scanner checkout.

Fig. 31 represents the detailed layout of the check-stand with marked components such as the conveyor belt, a display, a bi-optic scanner, a keyboard, the receipt printer, a till drawer, a money safe and a seat for the cashier. Fig. 32 visualizes that the bi-optic scanner has not been placed in front of the cashier but compatibly to the left elbow-joint.

This physiologically favorable position of the scanner (aligned to the elbow joint) allows that all items (goods) which arrive at the light barrier of the conveyor belt can be moved over the scanner with a simple sweeping motion of the left forearm from left to right (instead of the traditional (unfavorable) movement from right to left). A scanner placed directly in front of the cashier sometimes demands movements of the whole hand-arm-shoulder system. Due to fundamental anatomy and physiology knowledge, the flexor muscles of the hand-arm system (e.g. the biceps) are much (about twice) stronger than the weaker extensors (e.g. the
Fig. 29 Sitting position frontal to the counter (upper halve) or frontal to the conveyor (lower halve) in conventional checkstands with backward movements of the left hand-armsystem or movements "to the left" (upper and lower left part) and in ergonomically designed check-stands with movements "to the right" (lower right part) Abb. 29 Sitzposition frontal zur Kassenbox (obere Hälfte) oder frontal zum Förderband (untere Hälfte) bei konventionellen Kassenständen mit Bewegungen des linken Hand-Arm-Systems „nach hinten“ bzw. „nach links“ (oben und unten links) und bei ergonomisch neu gestalteten Kassen-Arbeitsplätzen mit Bewegungen (des linken Arms) „nach rechts“ (unten rechts)

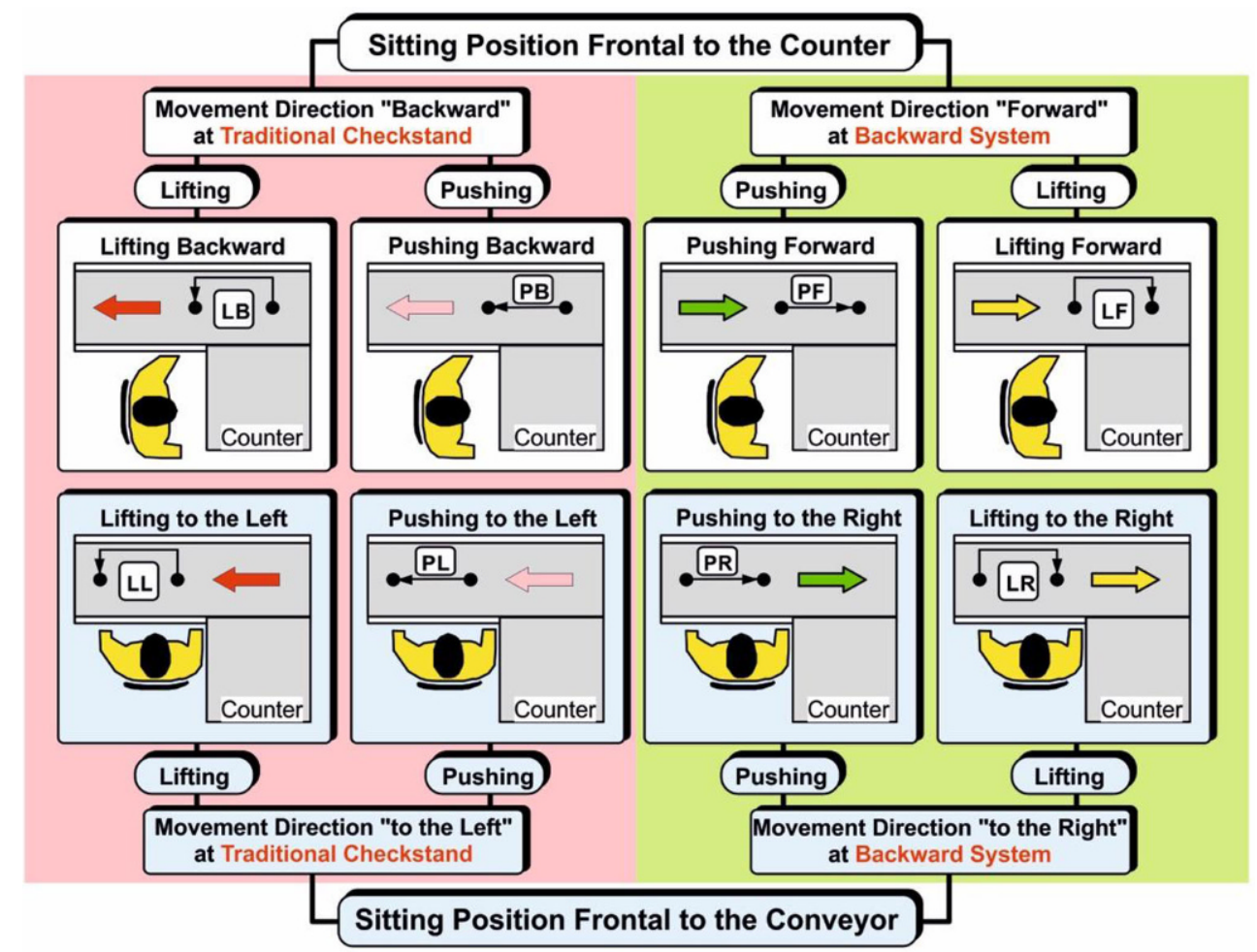


Fig. 30 Photo of the step-bystep developed "left-to-right" scanner checkout

Abb. 30 Foto des ,Step-byStep“ entwickelten Linksabweiser-Kassenstandes
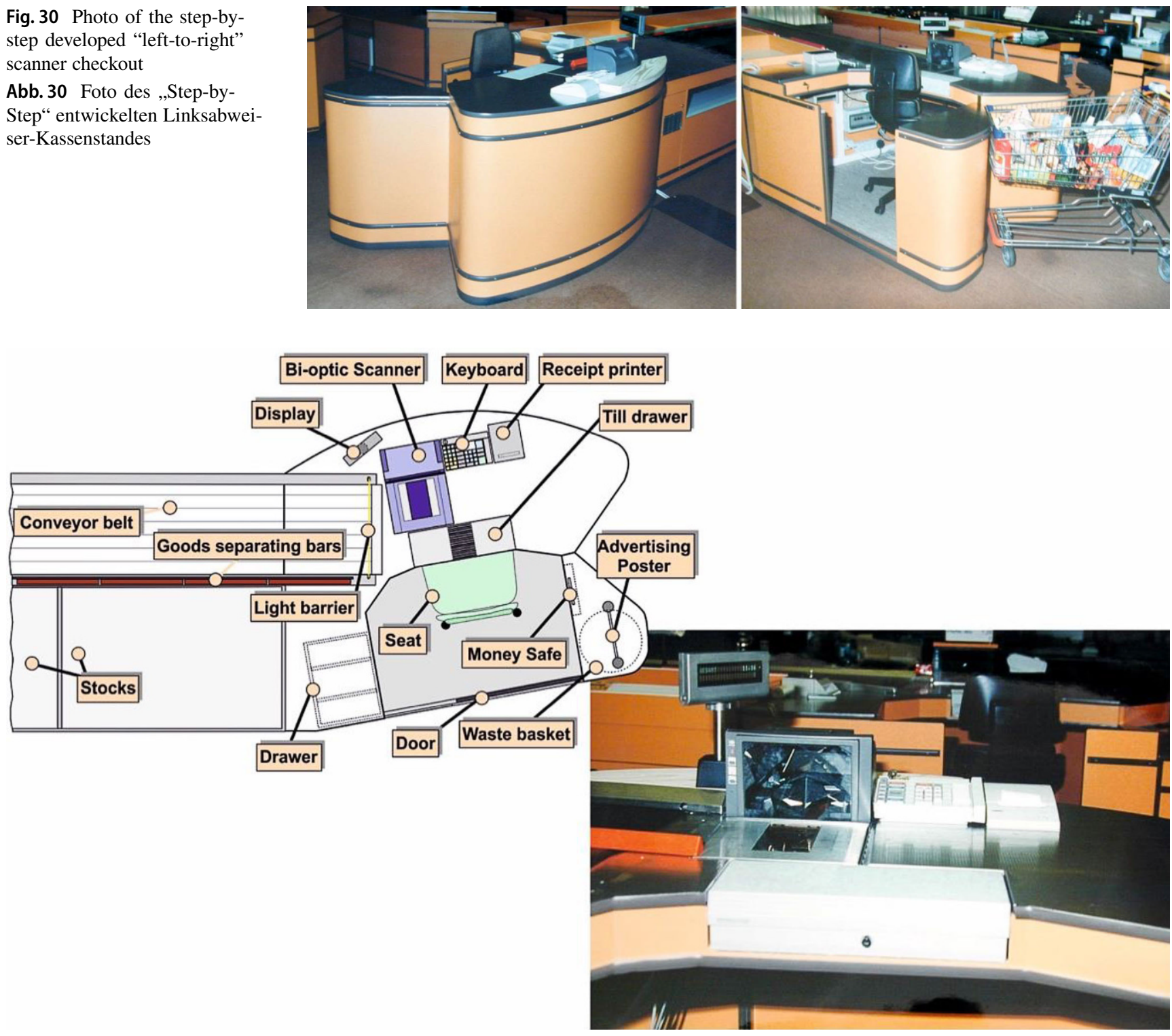

Fig. 31 Schematic layout of the ergonomic scanner checkout with marked components (upper left part) and view of the tools used for checking in true perspective of the staff (lower right part)

Abb. 31 Schematisches Layout des neu entwickelten Scanner-Kassenarbeitsplatzes mit markierten Komponenten (oberer linker Teil) und Blick auf die Arbeitsmittel aus der Perspektive der Kassiererin (unterer rechter Teil)

triceps) involved in material handling. So, already theoretically as proposed by Strasser (1990) it could be expected that a cashier in a left-to-right goods throughput system would experience a lower physical workload. Furthermore, the arrangement of the conveyor belt angled about $15^{\circ}$ to the check-stand and not parallel to the bi-optic scanner, the till drawer and the seat enables pinch gripping of the goods with a reduced dorsal extension of the hand which is limited to just $60^{\circ}$. In addition to the bi-optic scanner detecting the (EAN) price code on the items in the horizontal and vertical plane, the code is not positioned just once but on several sides of the items. This allows a very quick scanning with- out any turning and moving of the goods on the scanner window.

Fig. 33 shows a customer putting goods on the conveyor belt (1), going ahead and pushing the shopping cart (2), putting the goods into the shopping cart (3) and the vis-àvis position of a customer and the cashier during money transaction (4).

Finally, in addition a special workplace (a TandemCheckout) shown in Fig. 34 was developed. This is a combination of a the already described checkout with goods throughput from left to right with the left arm (provided for right handed persons) and a reciprocal arrangement, mainly 

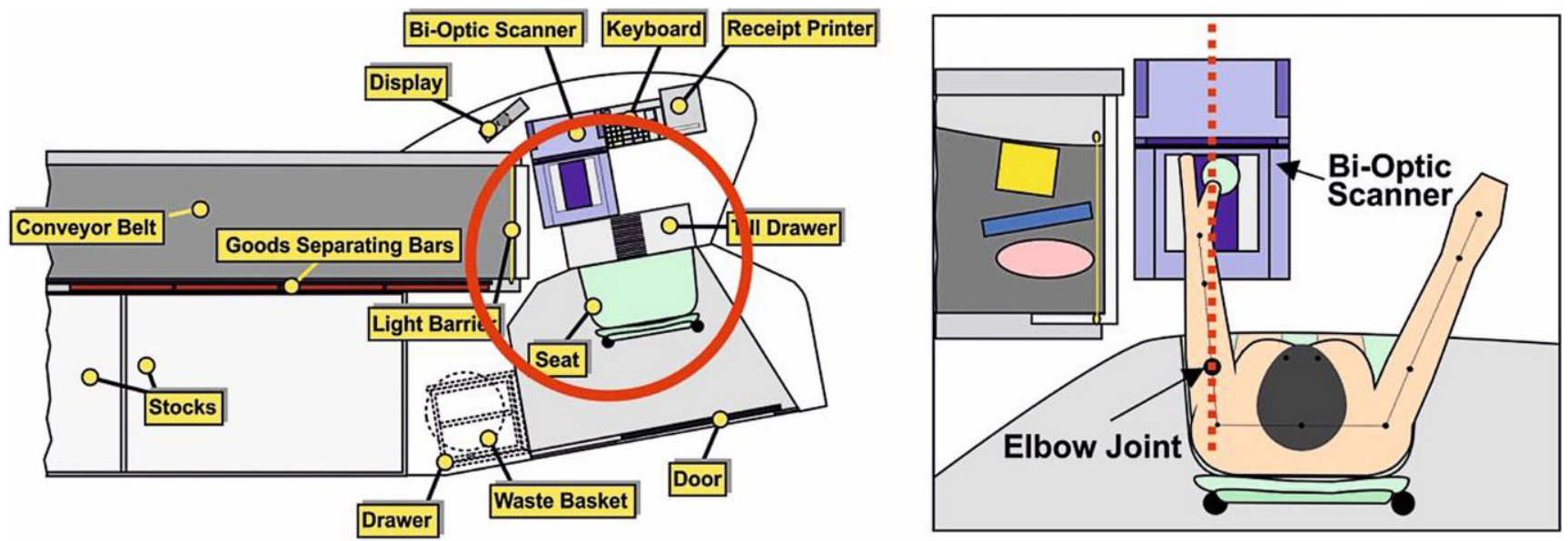

Fig. 32 Checkout (left part) with arrangement of the bi-optic scanner not in front of the torso but compatible to the left elbow joint (right part) of a right-handed cashier

Abb. 32 Draufsicht auf den Kassenarbeitsplatz (linker Teil) mit einer Anordnung des Bi-Optik Scanners nicht direkt vor dem Rumpf, sondern kompatibel zum linken Ellbogen-Gelenk einer rechts-händigen Arbeitsperson (rechter Teil)
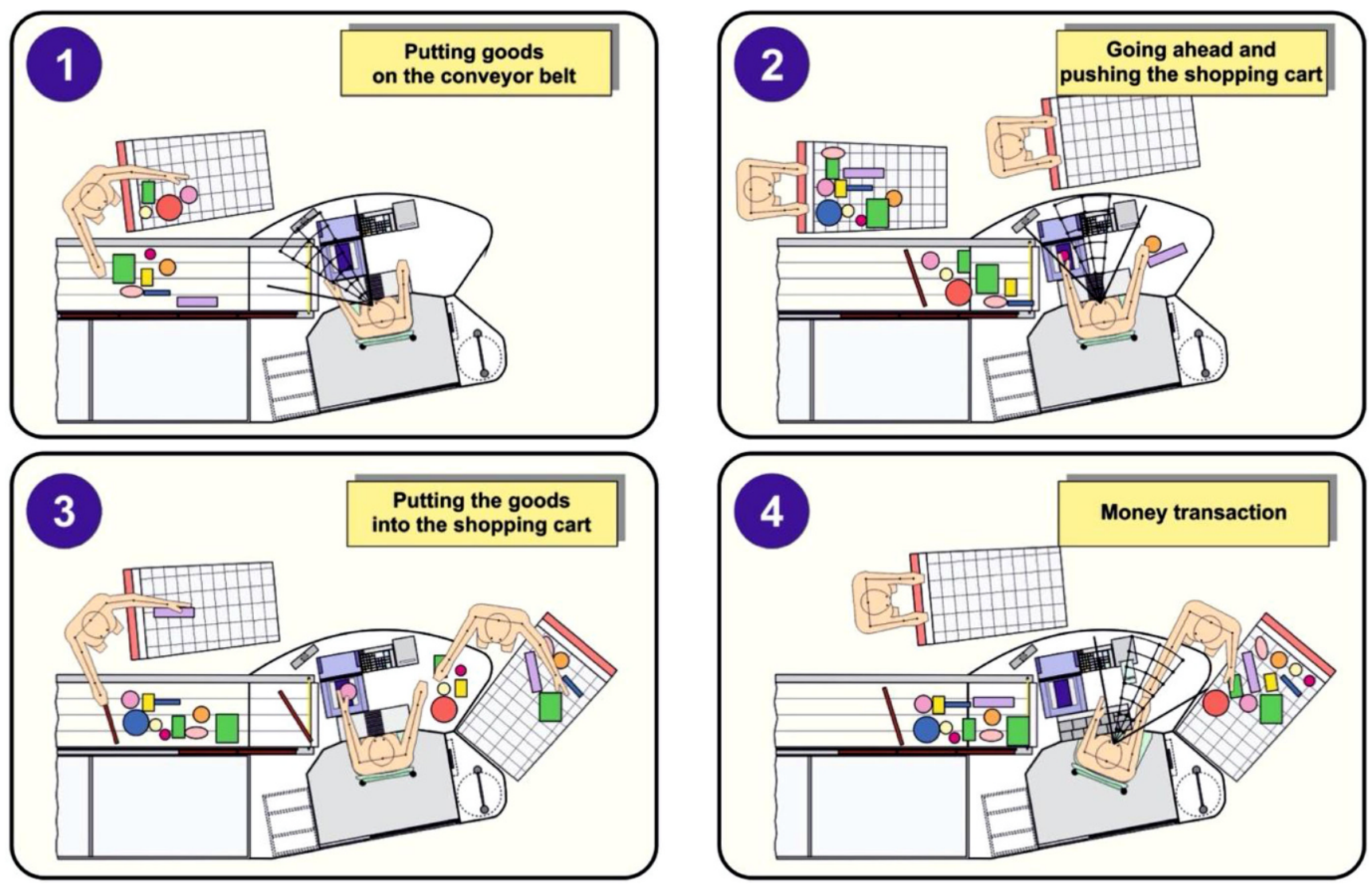

Fig. 33 Schematic outline of a complete working cycle at the checkout with goods throughput from left to right

Abb. 33 Schematische Darstellung eines kompletten Arbeitszyklus bei einem Kassenarbeitsplatz mit Warendurchsatz von links nach rechts 
Fig. 34 Checkout accommodating both $5^{\text {th }}$ and $95^{\text {th }}$ percentile cashiers

Abb. 34 Kassenarbeitsplatz, räumlich passend sowohl für eine 5-Perzentil-Frau als auch für einen 95-Perzentil-Mann

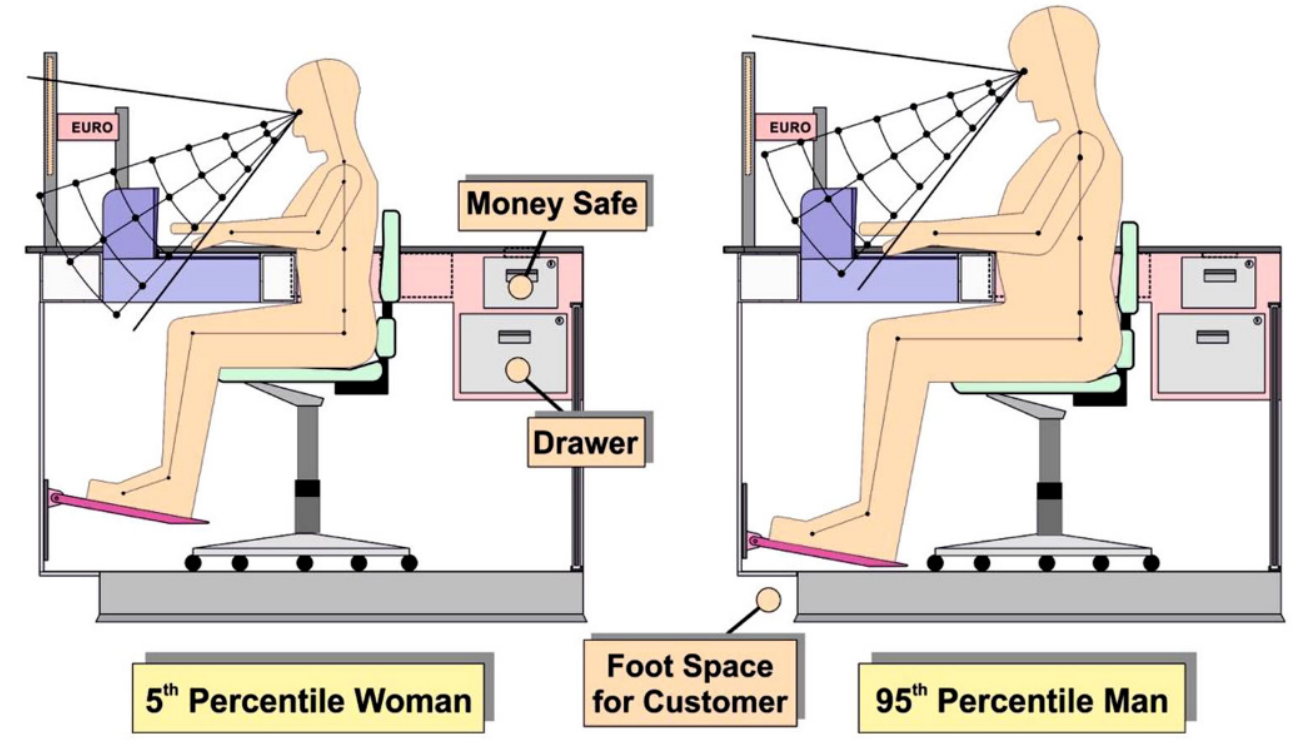

provided for left handed persons (around 15\% of the population) for whom also most convenient working conditions should be provided. This arrangement of a check stand with two conveyor belts due to less necessary space in a shop is favorable both from an economics and ergonomics point of view. It may also be mentioned that herewith job rotation can be practiced if desired by the staff.

It goes without saying that all the developments had been realized in a spatial layout according to Fig. 34 accommodating both typically small (female $5^{\text {th }}$ ) and tall (male $95^{\text {th }}$ ) persons by a simply height-adjustable footrest and a special development of an ergonomically optimized chair.

Together with twin-checkouts (cp. Fig. 35), this method of material-handling meanwhile has entered general application in more than 40.000 checkouts of an internationally acting discounter in several countries all over the world. It is most compatible with regard to muscular strain, at least while seated. Rather than such a realization, the present goods-handling in lots of other discounter shops at traditional forward-operation cashier systems is still an incompatible pushing or lifting mostly by the left hand from front to back or from right to left. A stereotypical insistence on old-fashioned and traditional habits represents the barriers against necessary improvements.

According to classical concepts and principles applying well proven methods of ergonomics research and work design, which are described in detail by Strasser (2009), the new developed working places have been comprehensively evaluated in both ergonomics laboratory and field studies (Kluth, 2002; Kluth and Strasser, 2003a, b, 2005).

Meanwhile several discounters have tried to copy the ergonomically optimized working places, however with more or less success. Unfortunately, they were unable to implement decisive details (e.g. the correct placement of the bi-

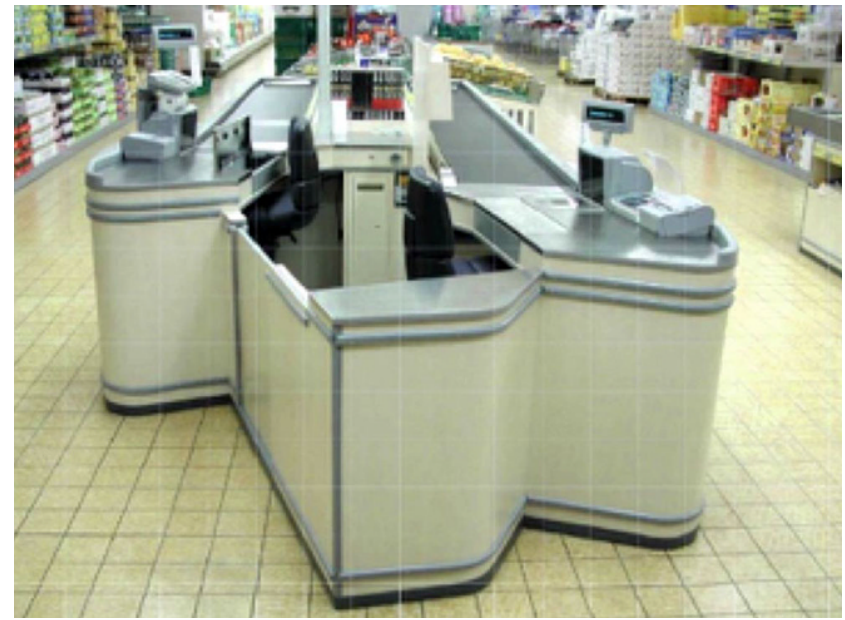

Fig. 35 Tandem-checkout

Abb. 35 Tandem-Checkout

optical scanner). Just in these days a famous discounter in England provides checkouts with scanners placed directly in front of the cashers. The same is true for another internationally acting discounter who, in addition to the unfavorable scanner placement e.g. has angled the conveyor belts in twin-checkouts in the wrong direction herewith substantially increasing the dorsal extension of the hand and retroversion of the arm.

\section{Compatibility between anatomical and functional joints in products as a prerequisite for comfort}

From an occupational medicine point of view, sitting postures, especially in an office environment, are of great im- 
Seat Construction with Synchronized Tilting Angles of Seat Pan and Backrest for Dynamic Sitting
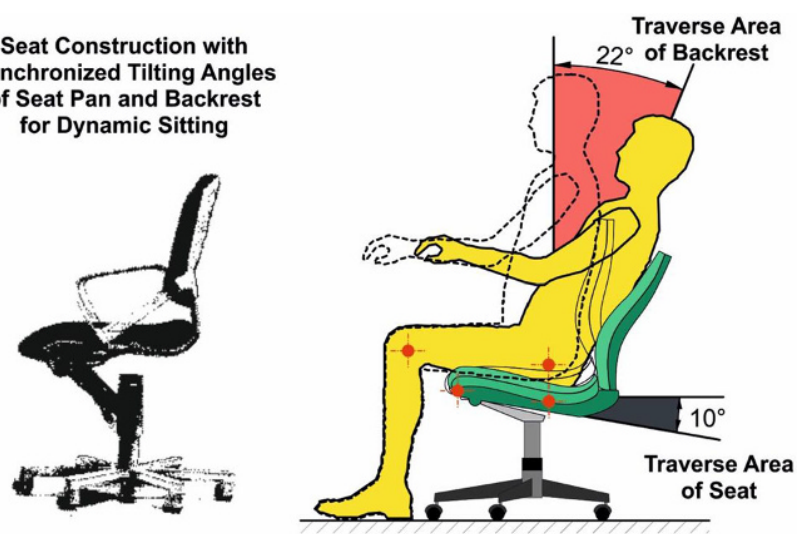

Fig. 36 Functional joints of the seat pan and backrest compatible to the anatomical joints of the knee and hip (chair with synchronous technique, enabling traverse areas of $22^{\circ}$ and $10^{\circ}$ for the backrest and the seat pan, respectively)

Abb. 36 Funktionale Gelenke der Sitzfläche und der Rückenlehne, kompatibel angeordnet zu den anatomischen Gelenken des Knies und der Hüfte (Sitz mit Synchron-Technik, der eine Bewegung der Rückenlehne bzw. der Sitzfläche bis zu $22^{\circ}$ nach hinten bzw. bis zu $10^{\circ}$ nach unten ermöglicht)
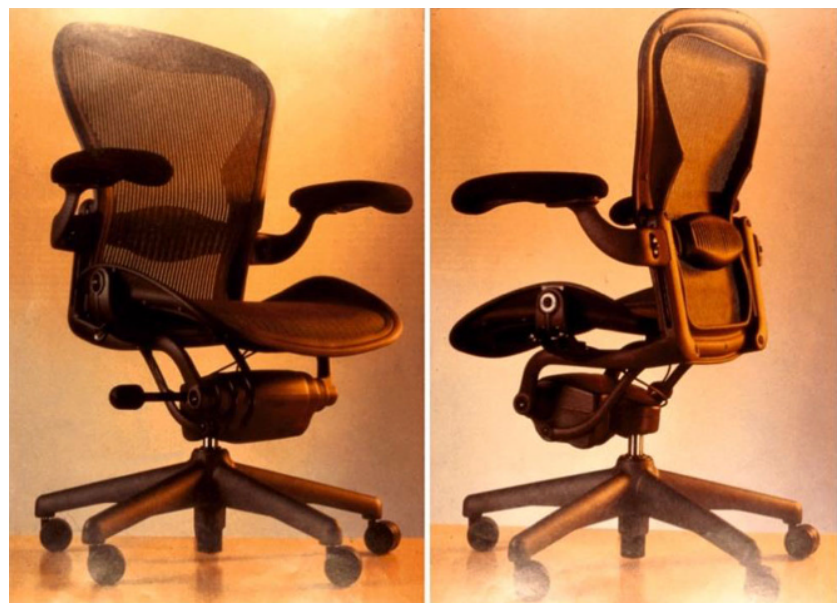

Fig. 37 Herman Miller's Aeron chair, the most perfect of all perfect solutions

Abb. 37 Herman Miller's ,Aeron“, der perfekteste aller perfekten Bürositze portance, and ergonomically-designed office chairs have a high potential with respect to preventive occupational safety. Therefore, with the help of Fig. 36, it shall be pointed out, that in functional fields, compatibility must rank higher than aesthetic and design demands.

A swivel chair designed for dynamic sitting, must support primarily the lumbo-sacral area in all postures. Furthermore, the levering of the lower leg in the backward posture and the "shirt-pull-out effect" as a consequence of relative movements between the backrest and the back which generally occur in seats constructed according standard proportions (DIN EN 1335-1 2000; DIN EN 1335-2 2007), must be prevented. This is only possible if anatomical and functional joints are arranged harmoniously, if the seat pan's center of rotation is not positioned directly under the spine but located in the area of the seat pan's front, near the knee, and if, in addition, the backrest's center of rotation is adapted to the hip joint. The synchronization of the swivel area for the seat and the backrest is, therefore, the result of a compatible orientation of the chair's functional elements to physiological characteristics. Fig. 37 depicts the most appreciated development of an office chair with synchronous technique, fulfilling all functional and ergonomic requirements. It can be ordered in three sizes according to personal body dimensions and the weight of the user.

\section{Compatibility of body dimensions and provided space in confined areas}

For sitting in confined areas, compatibility of body dimensions and allowed space is of high importance, whereby users diverging from the $50^{\text {th }}$ percentile (as mean values) should not be directly excluded. For interior dimensions and space in a car the $95^{\text {th }}$ percentile of users of course, is decisive.

In this respect, the use of three-dimensional standard stencils (Fig. 38) for the design of interior automobile dimensions can be very helpful. Nowadays, many an automobile company is quite willing to use ergonomic slogans every now and again which promise-a bit auspi-
Fig. 38 Sitting posture of a car driver (body stencils according to the German Standard DIN 33 408, part 1)

Abb. 38 Sitzposition eines PKW-Fahrers (KörperumrissSchablonen gemäß der Deutschen Norm DIN 33 408, Teil 1)
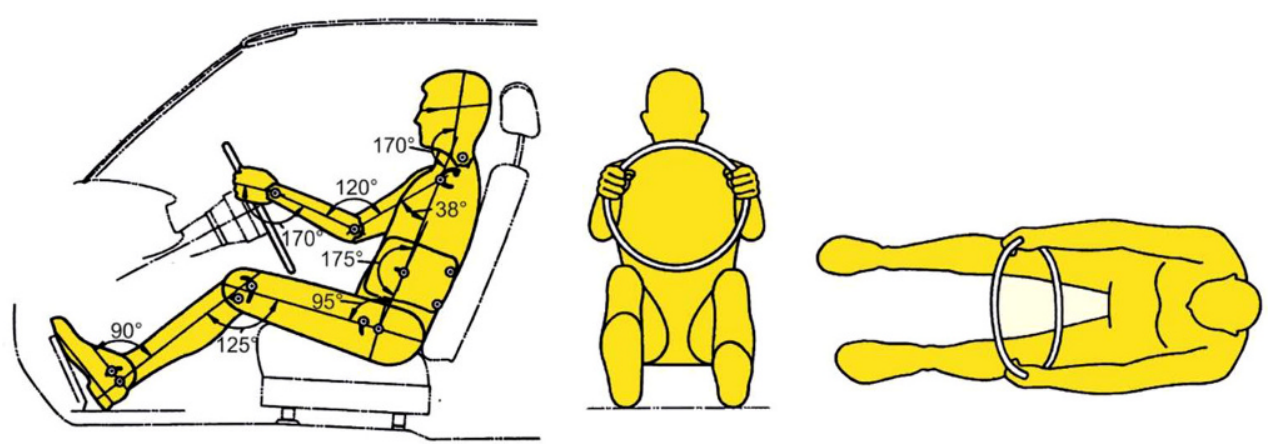


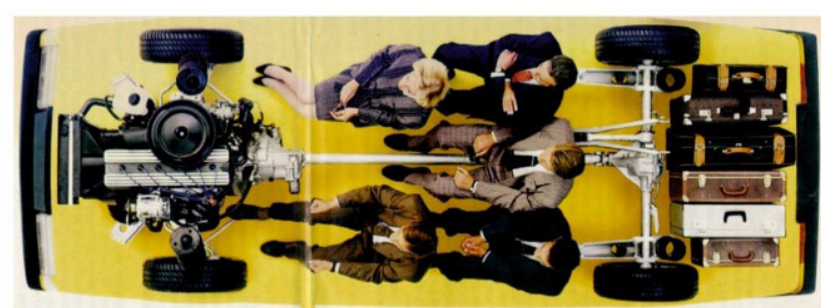

We Build Cars that Transport not just Technology, but Human Beings as well

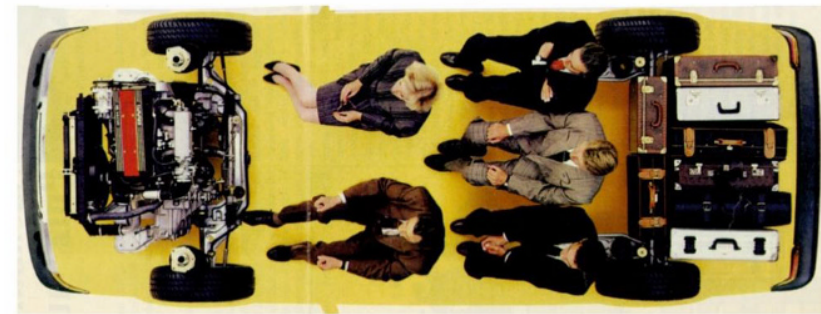

Fig. 39 Cars that comfortably transport human beings (lower part) with respect to space

Abb. 39 Komfortable Autos, die tatsächlich genügend Platz bieten für 5 Personen (unterer Teil)

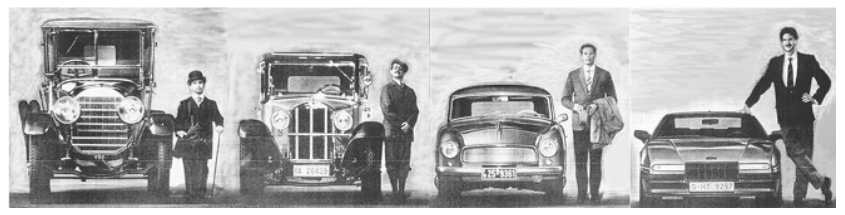

Fig. 40 During the last one hundred years man and car have drifted further and further apart-Acceleration of mankind, reduction of interior dimensions in a car, an incompatible counteractive development

Abb. 40 In den letzten 100 Jahren haben sich Mensch und Auto immer weiter auseinandergelebt. Die Akzeleration der Menschheit und die Reduktion des Raumangebots in einem Automobil, eine wahrlich inkompatible, gegenläufige Entwicklung ciously-according Fig. 39 by which they promise "We build cars that transport not only technology, but human beings as well".

Yet, a sceptic point of view still now is appropriate, since even a well-known and market-leading company in Europe had the information that during the last one 100 years man and car have drifted further and further apart (cp. Fig. 40) and that a counter-development between man and automobile took place, yet it did not chose to make good use of this knowledge. Even if today almost every car is designed with interior dimensions able to accommodate 4 or 5 persons, these interior dimensions still seem to be oriented only towards the mean values of the European population and not at the $95^{\text {th }}$ percentile of Northern or Middle Europe. It must be questioned, whether the acceleration of mankind and distinct regional differences with regard to the stature of persons, which do not fit into the standard wardrobe of national or international guidelines and standards, were taken into account.

It may be interesting what Kaufmann T. Keller-former head of Chrysler and confirmed hat-wearer in a speech a Stanford University once said when propagating Chrysler's products:

"It may have gone out of fashion with you in California. But there are places in this country (USA) with millions of people - both men and women - who sit behind the steering wheel and on the back seat wearing a hat". "We build cars to sit in-not to piss over".

For a typical Bavarian-that is the state where the author is from-but also for a Sumo wrestler of considerable size (see left part of Fig. 41) not only in height but often also of notable girth, lack of compatibility with respect to the
Fig. 41 About the doubtfulness of synthetic standard stencils as compatible reflections of different body types Abb. 41 Zur Fragwürdigkeit von synthetischen Normschablonen bzw. Normalpersonen als kompatiblem Abbild von regional unterschiedlichen Körperbautypen

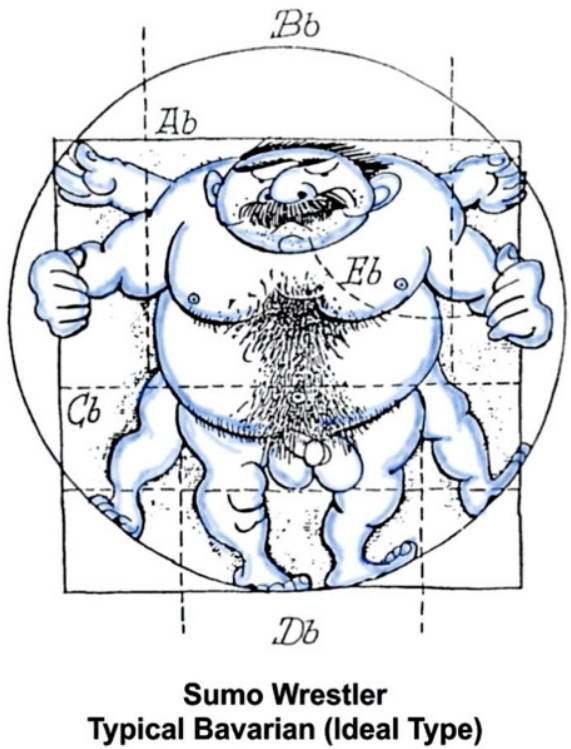

Typical Bavarian (Ideal Type)

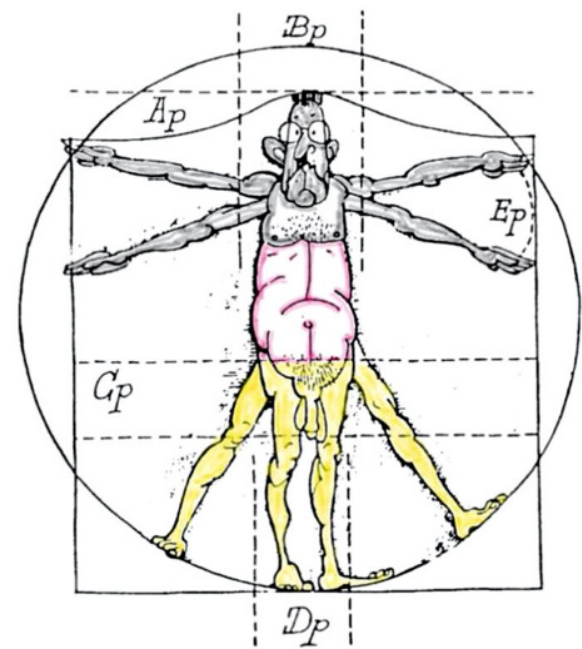

Etherealized Scientist Typical Prussian 
necessary space in many a car will make that car feel like a "Procrustes bed". Perhaps the automobile makers have oriented themselves more to a typical Etherealized Scientist (see right part of Fig. 41) as a potential client for their cars.

After this little and by no means serious digression about German tribes and their compatibility problems with their set of wheels, in the following more technical aspects of compatibility will be regarded.

\section{Harmonizing interior and exterior dimensions of work places (for $95^{\text {th }}$ and $5^{\text {th }}$ percentile users) via $5^{\text {th }}$ percentile of eye and shoulder reference point and appropriate seat height adjustment}

At first an example for interdependencies of criteria and for the joining of interdependent design areas will be given in order to achieve compatibility of the work space to human dimensions (cp. Fig. 42).
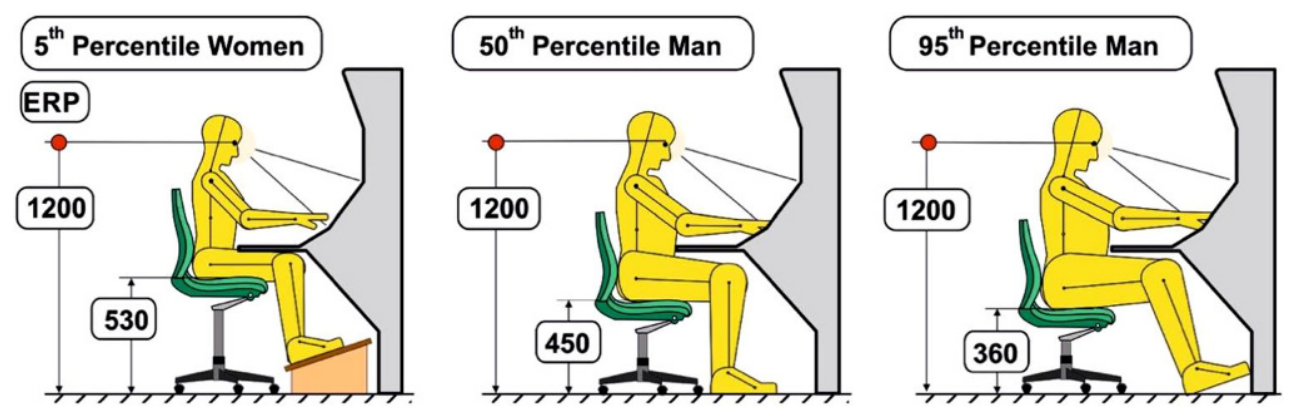

Fig. 42 Console with $5^{\text {th }}$ Percentile Women, $50^{\text {th }}$ Percentile Man and $95^{\text {th }}$ Percentile Man with individual eye reference point, adjusted, each, to constructive Eye Reference Point (ERP $1200 \mathrm{~mm}$ above floor)

Abb. 42 Konsole mit 5-Perzentil-Frau, 50-Perzentil-Mann und 95-Perzentil-Mann mit jeweils individuellem Augen-Bezugs-Punkt, angepasst an den konstruktiven Augen-Bezugs-Punkt (ERP 1200 mm über dem Boden)
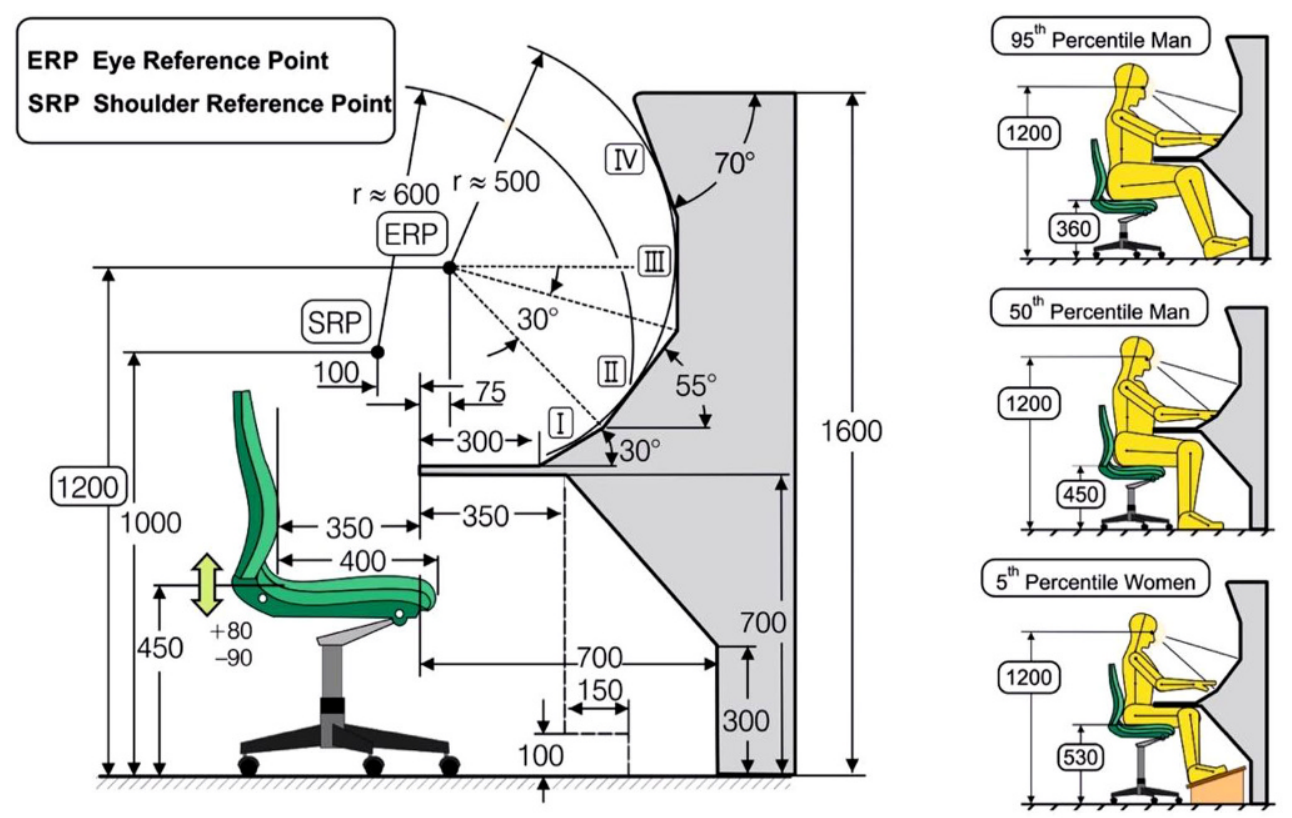

Fig. 43 Constructive eye and shoulder reference points oriented at $50^{\text {th }}$ percentile values for a console with 4 sections in the upper part and leg space compatible to also $95^{\text {th }}$ percentile. The height adjustment range of $450 \mathrm{~mm}+80 \mathrm{~mm}$ and $450 \mathrm{~mm}-90 \mathrm{~mm}$ of the swivel chair enables users from the $5^{\text {th }}$ to $95^{\text {th }}$ percentile to harmonize individual and constructive reference points for an equally convenient visual and manual working height

Abb. 43 Konstruktive Augen- und Schulter-Bezugspunkte nach 50-Perzentil-Werten für eine Konsole mit 4 Oberteilen und einem Beinfreiraum auch für 95-Perzentil-Männer. Die Verstellbarkeit der Sitzhöhe von $450 \mathrm{~mm}+80 \mathrm{~mm}$ und $450 \mathrm{~mm}-80 \mathrm{~mm}$ zwecks Abstimmung der individuellen auf die konstruktiven Bezugspunkte ermöglicht Nutzern zwischen dem 5.- und 95.-Perzentil gleich günstige visuelle bzw. manuelle Arbeitsbedingungen 
One should, for example, not be too generous with the interior dimensions of consoles shown in Figs. 42 and 43 because every centimeter of extra height for leg space has negative consequences on the working conditions in the upper area of a console. Therefore, it is advisable to use $95^{\text {th }}$ percentile dimensions at most for the interior dimensions (see Fig. 43). For the upper part of consoles, reach (according to the $5^{\text {th }}$ percentile of the hand arm system) and visibility of instruments are decisive. The vertical height of the eye and shoulder reference points (ERP and SRP) for the design of the reach requirements and visibility aspects should result in the $50^{\text {th }}$ percentile measurements (of the eye and shoulder height) above a mean seat height. This, however, is valid only on the prerequisite that taller users can also choose a lower seat height than smaller users and vice versa. Therefore, the height adjustability must be oriented on the $5^{\text {th }}$ and $95^{\text {th }}$ percentile. As in the upper region of a console, $5^{\text {th }}$ percentile measurements have to be used for the design of the exterior dimensions. It is therefore obvious that different design objectives must be taken into account in a reasonable compromise to come up with solutions fitting $5^{\text {th }}, 50^{\text {th }}$ and $95^{\text {th }}$ percentile users.

\section{Stimulus/stimulus-compatibility in the sensory interface of a man-machine system or man-computer-interactions for minimization of physiological expenditure}

In the following, stimulus/stimulus-compatibility in the sensory interface of man-machine systems should, at least, be roughly illuminated. This design objective is of high importance, with respect to occupational medicine, especially for VDU workplaces, among others, in order to avoid asthenopic complaints (cp. Fig. 44).

Normally, data or texts of manuscripts are printed in black ink on white paper, and when they are to be typed into a PC or workstation, it should follow without question, that they should be presented on the monitor as shown on the left part of Fig. 44, in the same positive depiction of black letters on a light screen. A VDU screen with positive polarity is compatible to the positive depiction of black letters on white background instead of the inverse presentation of white letters on a black background (see right part of Fig. 44). Compatibility of natural and technical display creates a higher visual acuity for the same numeric contrast, lowers the danger of reflections by mirroring light sources, and decreases the adaptation demand of the eye. Absolutely unfavorable are presentations as shown in Figs. 45 and 46. Ergonomists with at least a basic knowledge about the functioning of the human sense organs, hopefully would never try to present information in red characters on a blue background or vice versa. In work physiology it is well known that there exists a wavelength-dependent refraction of light in the lens. Since electromagnetic wavelengths representing the color blue are focused before the retina, and wavelengths representing the color red are focused behind the retina, corresponding simultaneous presentations induce chromatic aberration, i.e. almost impossible identification of the color information. In the past, very often power presentations as shown in Fig. 46 proved absolutely incompatible to the functioning of the eyes.

The Figs. 47 and 48 represent stimulus/stimulus-compatible information presentations well-known in industry since already long time.

\section{Stimulus/response-compatibility in the arrangement of controls and displays for enhancing information transmission and safety}

Conforming to classical ergonomic terms, compatibility is mostly deducted from experience as well as from proven and traditional expectations of a sensory combination of
Fig. 44 VDU with positive polarity as a stimulus/stimuluscompatible interface in a manmachine system for minimizing adaptation effort during the change from looking at a manuscript to viewing the VDU screen as an eye to technology

Abb. 44 Bildschirm mit positiver Polarität als Reiz-Reizkompatibles Interface in einem Mensch-Maschine-System zur Minimierung des AdaptationsAufwandes beim abwechselnden Blick auf ein Manuskript und den Bildschirm

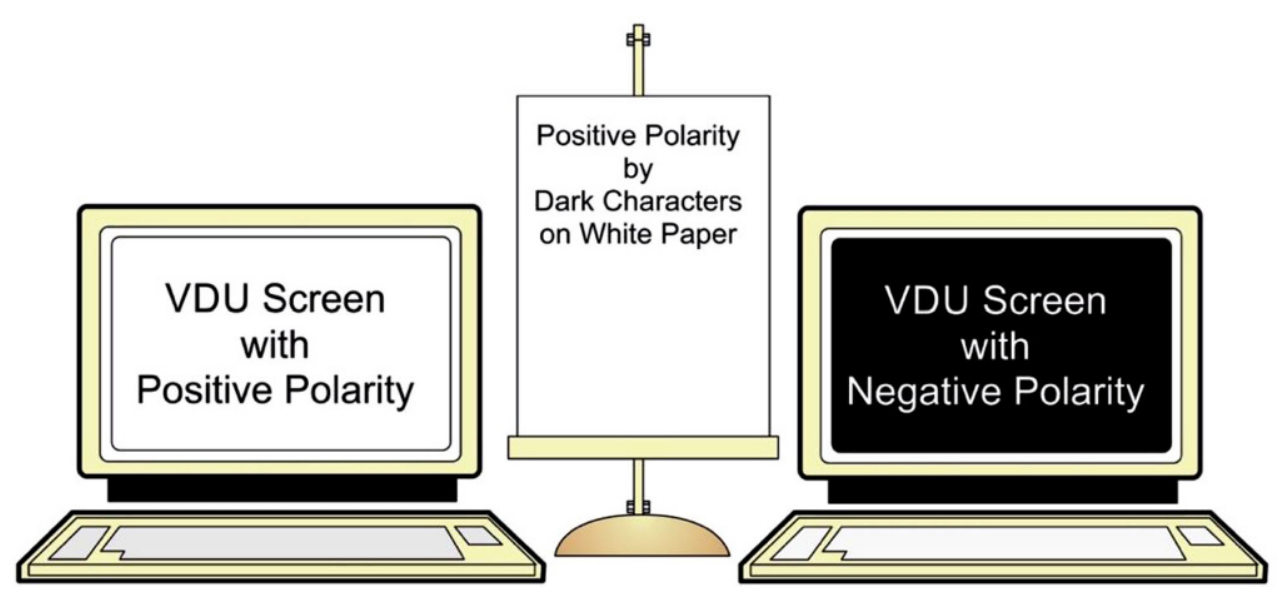




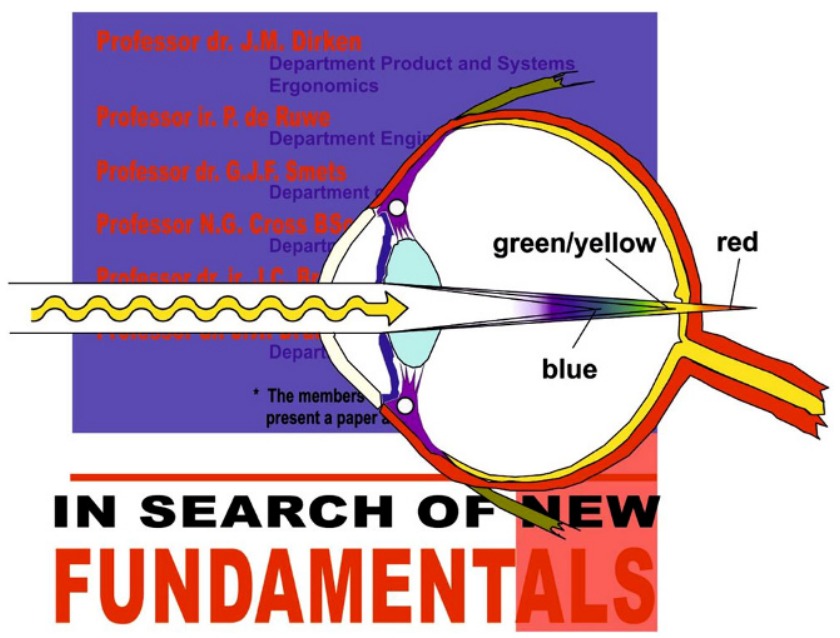

Fig. 45 Unfavorable presentation of red characters on a blue-colored surface inducing "Chromatic Aberration" due to wavelength-dependent refraction of light in the lens

Abb. 45 Ungünstige Darstellung von roten Buchstaben auf einem blauen Untergrund mit „,chromatischer Aberration“ als Folge der wellenlängenabhängigen Brechung des Lichtes in der Linse
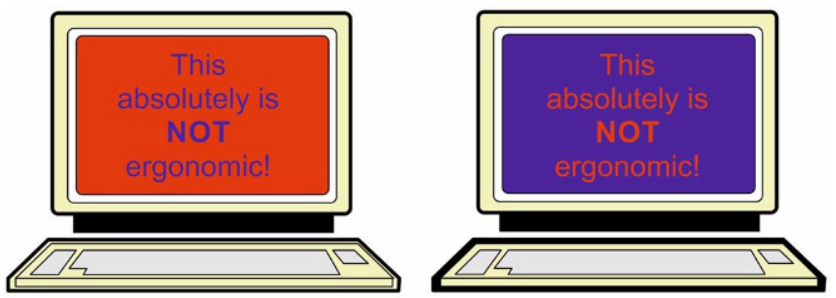

Fig. 46 Colored presentations with "Chromatic Aberration" Abb. 46 Farbdarstellungen mit ,,chromatischer Aberration“

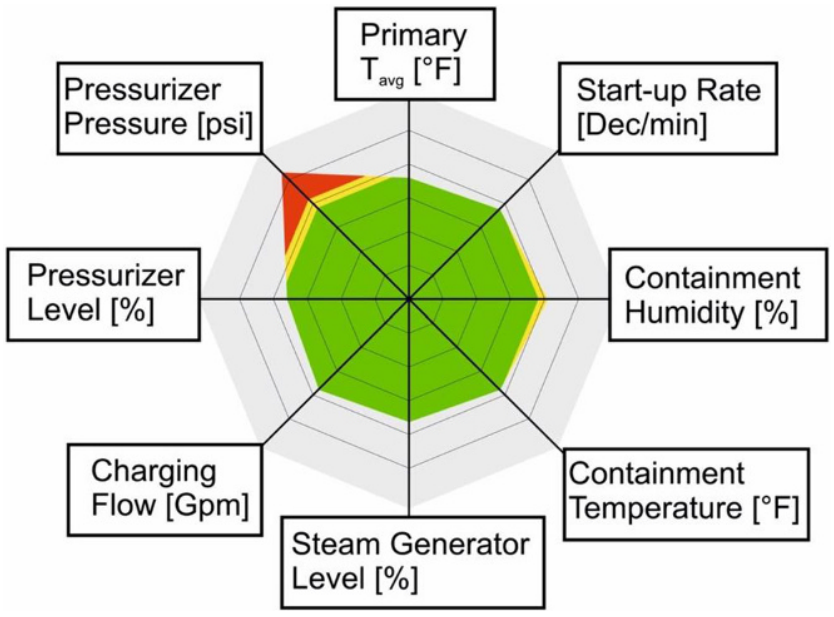

Fig. 47 Plant Safety Status Display for the integrated representation of the nominal value and deviation of several values of variables "at a glance"

Abb. 47 Plant-Safety-Status-Display zur integrierten Darstellung von Sollwerten und der Abweichung mehrerer Werte von Variablen auf einen Blick

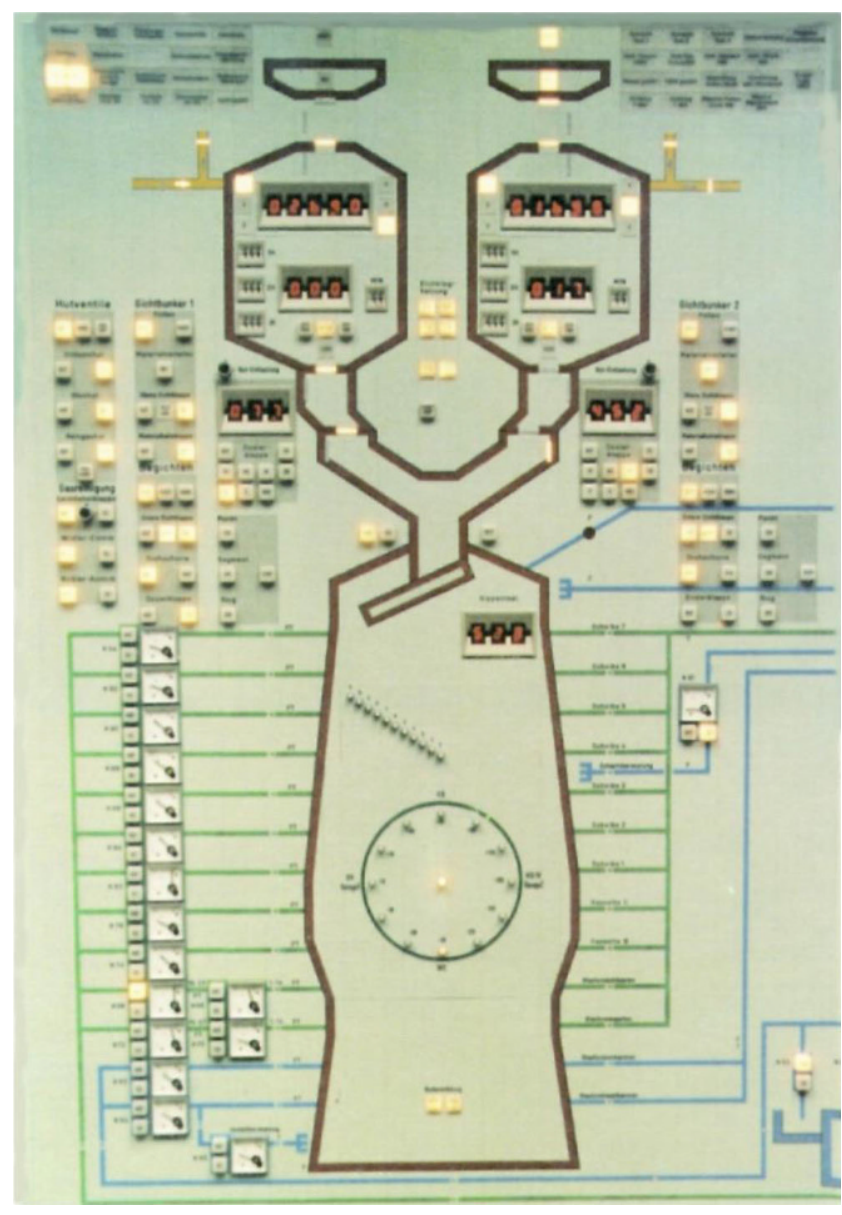

Fig. 48 Stimulus/Stimulus-Compatibility via presentation of process data and information from a blast furnace in virtual reality at the places where they were produced

Abb. 48 Reiz-Reiz-Kompatibilität bei der Übermittlung von prozesstechnischen Daten und Informationen von einem Hochofen auf einem Leuchtschaltbild in einer Messwarte (an virtuellen Stellen, an denen sie entstehen)

causes and effects, so that reaction and effect-i.e., controls and displays - can be linked unambiguously to the corresponding action. Such a satisfactory realization of stimulus/ response-compatibility will be shown with the help of the following Fig. 49 through 53.

Sliding controls with straight, i.e. translatory movements, and horizontal scales or rotatory movements of knobs and round scales (as shown in the upper left part of Fig. 51) are without a doubt the most unambiguous means for a clear presentation, so that these combinations offer an optimum of safe operation, whereas all other combinations represent a gradual loss of compatibility. In theory, all the combinations of controls and scale indicators presented are compatible, but only the two arrangements in the upper left corner of Fig. 51 are optimal, since, in addition to the layout, the type of movements of control means and indicators on the scales are also fully corresponding. Similar is true for the arrangement of knobs and scales in the left and middle part 
Fig. 49 Compatible accomplishment of 2-dimensional control displacements and cursor changes on a monitor (left part) and placement of controls, displays, and symbols for the fuel elements in the control room of a nuclear power plant (right part)

Abb. 49 Kompatible Zuordnung zwei-dimensionaler Stellteilauslenkungen zu Anzeigenänderungen auf einem Bildschirm (links) mit komplexem Anwendungsfall der orts-kompatiblen Anordnung von Stellteilen, Anzeigen und graphischen Symbolen für die Brennstäbe in einer Kernkraftwerks-Warte (rechter Teil)

\section{Compatible Accomplishment of 2-Dimensional Control Displacements and Cursor Changes on a Monitor}

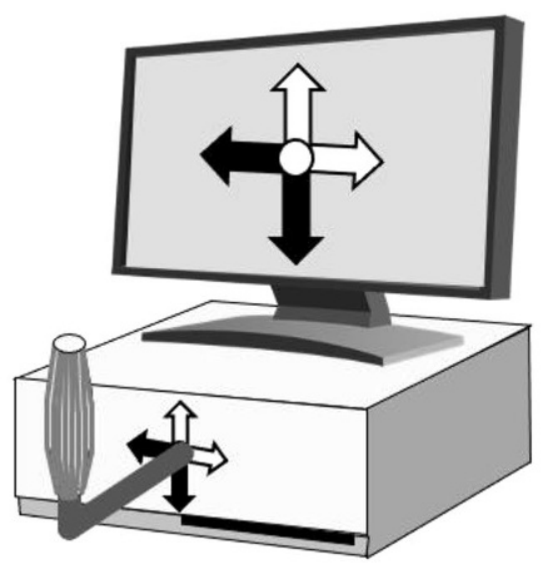

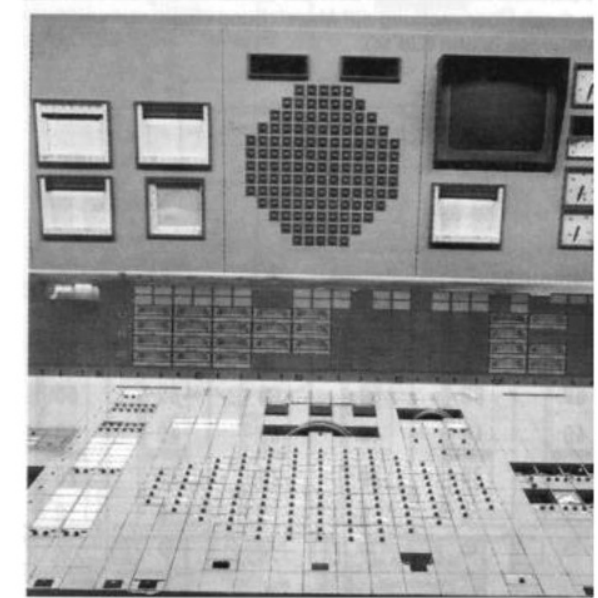

Compatible Placement of Controls, Displays, and Symbols for the Fuel Elements in the Control Room of a Nuclear Power Plant

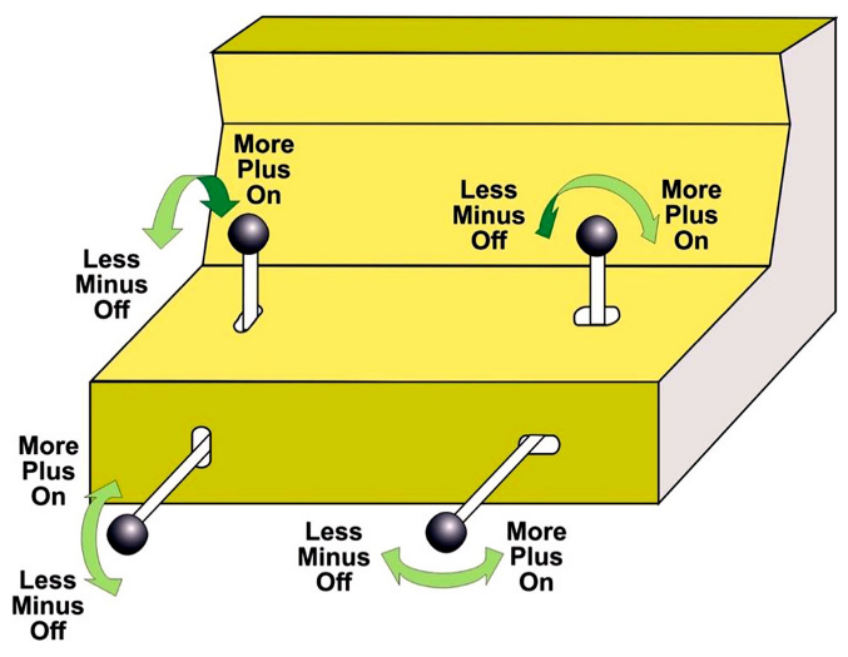

Fig. 50 Movement directions of controls in the 3-dimensional space and expected effects (Stimulus/Response-Compatibility)

Abb. 50 Bewegungsrichtungen von Stellteilen im dreidimensionalen Raum und zu erwartende Effekte bzw. Veränderungen einer Stellgröße im Sinne einer $\mathrm{Zu}$ - oder Abnahme bzw. von „An“ oder „Aus“ einer Funktion (Reiz-Reaktions-Kompatibilität)

of Fig. 52, while the arrangement of a rotatory control element placed in a vertical plane is not especially compatible to the information presented by a cursor on a longitudinal scale as shown in the right part of Fig. 52.

The same is true for the spatial coordination of a sample of controls and displays on a panel or on an instrument board (cp. Fig. 53) where the highest unambiguous solution should be realized. Two scales, arranged one above the other, as shown in arrangement A cannot be directly associated with the appropriate controls, which are positioned side by side. It is only possible with correspondent guide-
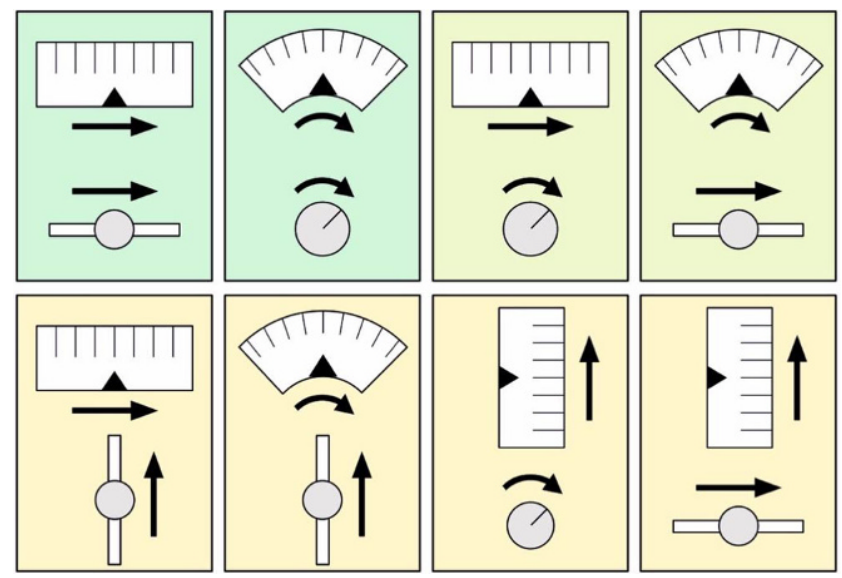

Fig. 51 More or less compatible relations between translatory and rotatory displacements of controls and connected displays with straight and sector scales-Decrease of the highest possible degree of corresponding movements to arrangements where the displacement of the control and changes on the display are rectangularily connected Abb. 51 Mehr oder weniger kompatible Zuordnungen von translatorischen und rotatorischen Auslenkungen eines Stellteiles zu Anzeigen auf einer Langfeld- und Sektor-Skala. Der Grad an Kompatibilität nimmt, ausgehend von sich entsprechenden Bewegungsformen bei den beiden Zuordnungen (oben links) zu den Anordnungen ab, bei denen zwischen Stellteilauslenkung und Veränderung der Anzeige ein Winkel von $90^{\circ}$ besteht

lines. The same is true for arrangement B. Even in arrangement $\mathrm{C}$, the highest possible degree of order is not reached, and the use of additional guidelines would be advisable, whereas, for a misunderstanding of the most compatible arrangement $\mathrm{D}$ to occur, a person would have to be distinctly obstinate to confuse both the instruments and their coordination to the controls. 

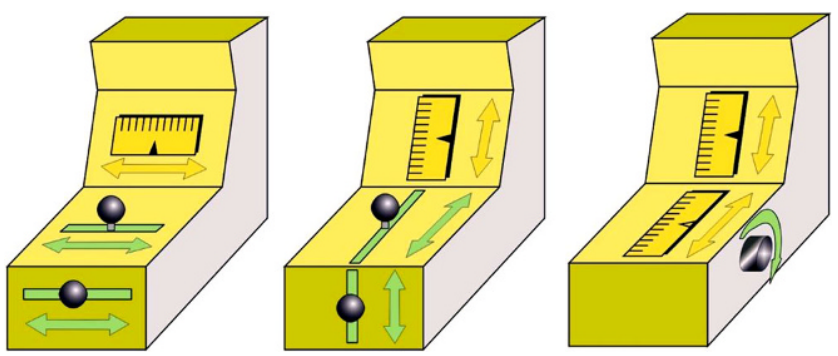

Fig. 52 Controls and displays in various planes arranged compatibly. Highest grade of unambiguity in the left. Less favorable accomplishments in the middle. Knobs and scales in different planes as in the right part lead to uncertainty of the correct interrelation of causes and effects Abb. 52 Kompatibilität bei der Anordnung von Stellteil und Anzeige in verschiedenen Ebenen, mit höchster Eindeutigkeit bei der Anordnung links und bereits gewissen Unsicherheiten in der Zuordnung von Ursache und Wirkung mit Drehknopf und Langfeldskalen in versetzten Ebenen

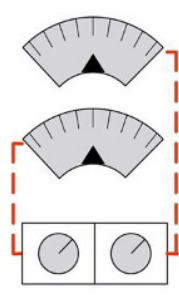

A

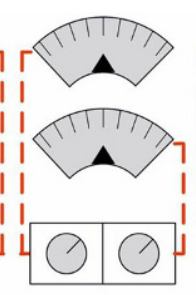

$\mathrm{B}$

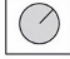

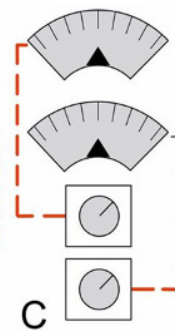
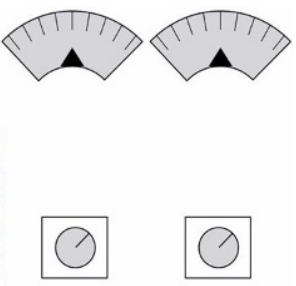

D

Fig. 53 Spatial coordination of several controls and displays with an increasing degree of unambiguity from A to D. In the arrangements A and $\mathrm{B}$, controls would not be compatible to displays without correspondent guidelines

Abb. 53 Räumliche Zuordnung von mehreren Stellteilen zu Anzeigen mit von A nach D steigendem Grad an Eindeutigkeit, wobei die Anordnungen A und B ohne Zuordnungspfade (,,Sensorlinien“) nicht kompatibel wären

\section{Compatibility in the field of software as a means for avoidance of frustration and for reducing psychological stress}

Finally, also some aspects of software compatibility may be addressed, whereby the aim of more and more important software-ergonomics approaches must be to increase stimulus/response-compatibility with regard to working with modern information and communication systems.

Even a very simple word processing program which is designed in terms of human-adapted or user-oriented criteria must allow communication in a natural language. It must enable access to the screen via a "question-and-answer game", and the program must prevent user confusion, which can be caused by dragging him along the often winding paths through the jungle of internal tangles of the program structure. Solely when a system is capable of understanding user questions as key stimuli, if it answers unambiguously with clear decisions, which support the progress of the program, can it be regarded as compatible with re- spect to its software. Otherwise, a feeling of being at the mercy of the computer program, a feeling of helplessness while working with the system, will inevitably be the consequence.

Stimulus/response-compatibility can often be negatively influenced by a too highly realized degree of technical capability, as too many different options and conceivable technical program possibilities have no relevance for the "normal" user and his generally lower demands. In Fig. 54 the causes for low software-compatibility, as is very often found in practice, shall be demonstrated.

It is hardly possible to determine every detail of a client's needs in advance or that what a customer envisages (left upper part of Fig. 54). As a consequence, the user describes his expectations or ideas to the software-specialist very often only in a vague manner (left lower picture in Fig. 54). What was understood by the software specialist and then transmitted to the programmer possibly cannot always be realized because of inevitable coordination failures as a consequence of tayloristic work organization. Consequently, the system installed for the customer (lower right block in Fig. 54) can vary greatly from his original wishes. Instead of a complex variety of diverse options, the customer actually might have wanted a mostly simple solution, like a conventional key to a cylindric lock for opening the door to technology (upper right block in Fig. 54).

\section{Conclusions and prospect}

When trying to sum up the ideas of this paper, it is again necessary to underline - as it has been done already in the past by Strasser (1993) and Strasser (2007) - the extra-ordinary importance of compatibility as a high potential for high performance of a work system and for preventive measures in the field of occupational safety. It must be taken into account that the properties and functional principles of the human organism on the one hand and the possible technical design components of a work system on the other hand must fit. A compatibly designed and ergonomically shaped tool or equipment can help to reduce the prevalence of occupational diseases and repetitive strain injuries. Compatibility always leads to lower physiological cost in a way that the same output results from a lower demand of human resources or even a higher performance will be attained. Even harmony between human aspects and economic objectives can be achieved in working conditions and it must no longer remain a "gray theory". To a corresponding question "Productivity and Ergonomics-Are they Compatible?" a positive answer was given by Resnik (1997), and Hendrik (1998) already in the 90's of the last century had addressed convincingly "The Economics of Ergonomics" by presenting a sample of ergonomic interventions. 
Fig. 54 Visualization of possible causes for deficits in software compatibility

Abb. 54 Visualisierung möglicher Ursachen für den Mangel an Software-Kompatibilität

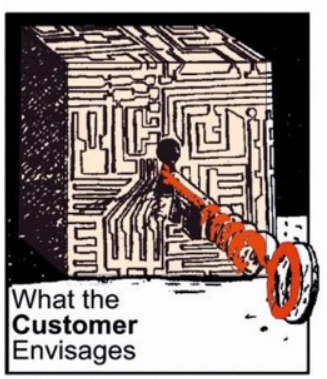

The Troublesome Genesis of a Computer Program

Depiction of Possible Reasons for the Lack of Software Compatibility
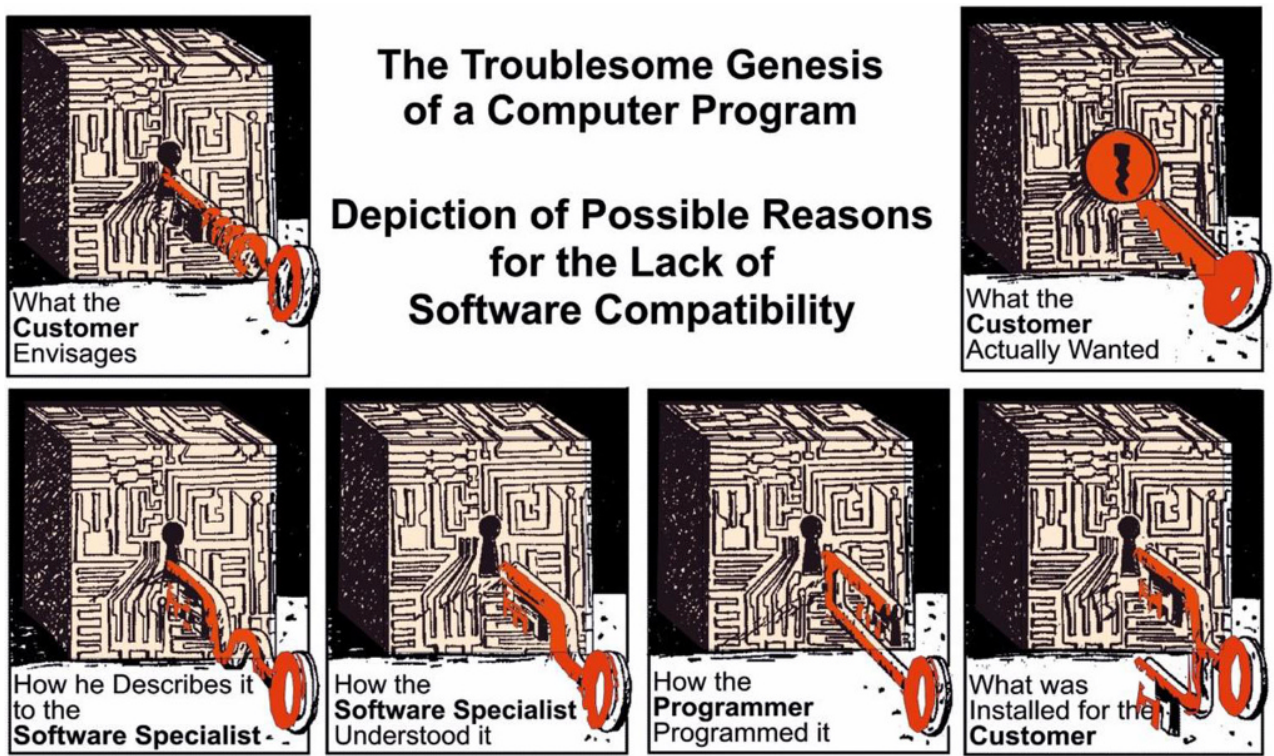

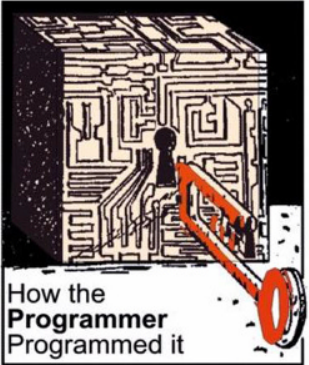

Compatibility also supports the quick perception and transmission of information in a man-machine system, and as a result of lower requirements for decoding during information processing, spare mental capacity may enhance the system's safety. In the field of software, compatibility also helps to avoid psychological frustration. However, ergonomics cannot be successful in this area without comprehensive and funded knowledge of the functioning of the human body. In the future, an increasing sense of responsibility and duty has to lead to co-operations between occupational physicians, industrial engineers, designers and ergonomists in the field of work design, taking into account the often cited but seldom truly applied slogan depicted in Fig. 55.

Funding Open Access funding enabled and organized by Projekt DEAL.

Open Access This article is licensed under a Creative Commons Attribution 4.0 International License, which permits use, sharing, adaptation, distribution and reproduction in any medium or format, as long as you give appropriate credit to the original author(s) and the source, provide a link to the Creative Commons licence, and indicate if changes were made. The images or other third party material in this article are included in the article's Creative Commons licence, unless indicated otherwise in a credit line to the material. If material is not included in the article's Creative Commons licence and your intended use is not permitted by statutory regulation or exceeds the permitted use, you will need to obtain permission directly from the copyright holder. To view a copy of this licence, visit http://creativecommons.org/licenses/by/4. $0 \%$.

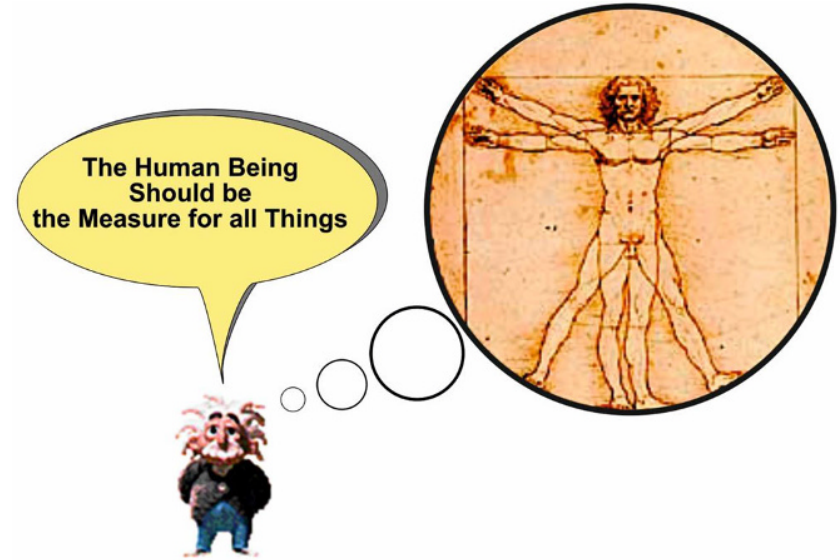

Fig. 55 "The Human Being Should Be the Measure for All Things" Abb. 55 „Der Mensch sollte stets das Maß aller Dinge sein“ 


\section{References}

\section{Cited literature}

Bullinger H-J, Solf JJ (1978) Produkt-Ergonomie hilft Berufskrankheiten vermeiden - Exemplarische Darstellung der Ursachenanalyse und der Problemlösung. REFA Nachr 31(1):17-21

Bullinger H-J, Solf JJ (1979) Fallstudie Maurerkelle. Umsetzung arbeitswissenschaftlicher Erkenntnisse in die Handwerkspraxis. Hum Prod Hum Arbeitspl 5:16-18

Bullinger H-J, Solf JJ (1997) Ergonomische Arbeitsmittelgestaltung I - Systematik. Wirtschaftsverlag NW, Verlag für Neue Wissenschaft, $\mathrm{GmbH}$, Bremerhaven

Hendrik HW (1998) The economics of ergonomics. In: Scott PA, Bridger RS, Charteris J (eds) Global ergonomics-proceedings of the cape town ergonomics conference. Elsevier, Amsterdam, pp 3-10

IEA International Ergonomics Association (2006) Core competencies in ergonomics. In: Karwowski W (ed) International encyclopedia of human factors and ergonomics, 2nd edn. CRC Press, Taylor \& Francis, 19-26

Imada AS (1991) The rationale and tools of participatory ergonomics. In: Noro K, Imada AS (eds) Participatory ergonomics. Taylor \& Francis, London, pp 30-51

Karwowski W (ed) (2006) International encyclopedia of ergonomics and human factors. Part I - part XIII, 2nd edn. Taylor \& Francis, London, New York, pp 1-13606

Keller E, Strasser H (1996) Ergonomic evaluation of an armrest for typing via electromyographic and subjective assessment. In: Mital A, Krueger H, Kumar S, Menozzi M, Fernandez JE (eds) Advances in occupational ergonomics and safety I. IOS Press, Amsterdam, pp 838-845

Keller E, Strasser H (1998) Electromyographic and subjective evaluation of a wrist rest for VDT operators. Occupat Ergonom 1(4):239-257

Keller E, Becker E, Strasser H (1991) Objektivierung des Anlernverhaltens einer Einhand-Akkord-Tastatur für Texteingabe. Z Arb Wiss 44(1): 1-10

Keller E, Fleischer R, Strasser H (2004) Estimated and experienced subjective assessment of the ergonomic quality of a keyboard. Occupat Ergonom 4(2):121-131

Kluth K (2001) Analyse, Beurteilung und ergonomische Gestaltung von Arbeitsplätzen in Selbstbedienungsläden. Habilitationsschrift Universität Siegen. Höppner und Göttert

Kluth K (2002) Development of an ergonomically optimized scanner checkout. In: Potvin J (ed) Advances in occupational ergonomics and safety, vol 6, pp 1-5

Kluth K, Strasser H (2003a) Physiological costs associated with working at a scanner checkout with goods throughput from left to right and at a conventional checkstand with keying in the prices. In: Strasser H, Kluth K, Rausch H, Bubb H (eds) Quality of work and products in enterprises of the future. Ergonomia, Stuttgart, pp 267-270

Kluth K, Strasser H (2003b) Subjective evaluation of a newly developed scanner checkout in comparison with a conventional cash register system via standardized working tests. In: Strasser H, Kluth K, Rausch H, Bubb H (eds) Quality of work and products in enterprises of the future. Ergonomia, Stuttgart, pp 275-278

Kluth K, Strasser H (2005) Physiologische Kosten bei der Arbeit an der Discounter-Kasse - Linksabweiser-Scanner-Kasse versus traditionelle Kasse mit manueller Preiseingabe. Z Arb Wiss 59(3-4):263-272

Kluth K, Chung H-C, Strasser H (2004) Verfahren und Methoden zur Prüfung der ergonomischen Qualität von handgeführten Arbeitsmitteln - Professionelle Schraubendreher im Test. Schriftenreihe Ergo-Med, vol 5. Curt Haefner, Heidelberg
Kluth K, Kellerman HG, Strasser H (2007) Assessment of the ergonomic quality of file handles. In: Strasser H (ed) Assessment of the ergonomic quality of hand-held tools and computer input devices. IOS Press, Amsterdam, Berlin, Oxford, Tokyo, Washington, DC, pp 143-151

N. N. (1998a) Core Competency for Practitioners in Ergonomics. IEA (International Ergonomics Association), Professional Practice \& Education Committee

N. N. (1998b) Working Paper for Development of Practice Criteria and Levels of Certification in Professional Ergonomics. Joint Committee on Ergonomics-Affiliated Occupational Practices (JCEOP), Bellingham, Washington/USA: 227-2811

N. N. (1994) User's Guide - Microsoft Natural Keyboard, Microsoft Corporation, Redmond, USA

Resnik ML (1997) Productivity and ergonomics-are they compatible? In: Das B, Karwowski W (eds) Advances in occupational ergonomics and safety II. Proceedings of the Annual International Occupational Ergonomics and Safety Conference, Washington DC. IOS Press and Ohmsha, Amsterdam, pp 481-484

Strasser H (1990) Evaluation of a supermarket twin-checkout involving forward and backward operations. Appl Ergon 21(1):7-14

Strasser H (1991) Different grips of screwdrivers evaluated by means of measuring maximum torque, subjective rating and by registering electromyographic data during static and dynamic test work. In: Karwowski W, Yates JW (eds) Advances in industrial ergonomics and safety III. Taylor \& Francis, London, New York, Philadelphia, pp 413-420

Strasser H (1993) Ergonomie - Arbeitsplatz, Kap. 2.4.5. Kompatibilität. In: Hettinger T, Wobbe G (eds) Kompendium der Arbeitswissenschaft. Kiehl, Ludwigshafen/Rhein, pp 228-242

Strasser H (1994a) Reducing prevalence of occupational diseases and physiological costs by obeying the rule of compatibility in work design. In: Aghazadeh F (ed) Advances in industrial ergonomics and safety VI. Taylor \& Francis, London, New York, Philadelphia, pp 151-158

Strasser H (1994b) Ergonomic efforts aiming at compatibility in work design for realizing preventive occupational health and safety. In: Mc Fadden S, Innes SL, Hill M (eds) Proceedings of the $12^{\text {th }}$ Congress of the International Ergonomics Association, vol 4. Human Factors Association of Canada, Toronto, $p$ 469. ISBN 0-9698544-3-9

Strasser H (1995a) Ergonomic efforts aiming at compatibility in work design for realizing preventive occupational health and safety. Int J Ind Ergon 16(3):211-235

Strasser H (1995b) Kompatibilität als Ziel der ergonomischen Arbeitsgestaltung von Mensch-Maschine-Systemen. Zentralbl Arbeitsmed Arbeitsschutz Ergonomie 45(1):6-21

Strasser H (1998) Tasks and objectives of ergonomics in academic training and research. In: Scott PA, Bridger RS, Charteris J (eds) Global ergonomics-proceedings of the Cape Town ergonomics conference. Elsevier, Amsterdam, pp 791-794

Strasser H (2000) European Ergonomist-quantity and quality of ergonomics education and experience as well as certification procedures according to CREE and Germany's education system. In: Podgorski D, Karwowski W (eds) Ergonomics and safety for global business quality and productivity. Central Institute for Labor Protection, Warsaw, pp 63-70

Strasser H (2007) Assessment of the ergonomic quality of hand-held tools and computer input devices. IOS Press, Amsterdam, Berlin, Oxford, Tokyo, Washington DC

Strasser H (2009) Principles, methods and examples of ergonomics research and work design. In: Schlick CM (ed) Industrial engineering and ergonomics: visions, concepts, methods and tools. Springer, Berlin, Heidelberg, pp 363-381

Strasser H, Bullinger H-J (2007) A Systematic Approach for the Analysis and Ergonomic Design of Hand-Held Tools and Control Actuators-Visualized by some Real-Life-Examples. In: Strasser H 
(ed) Assessment of the Ergonomic Quality of Hand-Held Tools and Computer Input Devices. IOS Press, Amsterdam, Berlin, Oxford, Tokyo, Washington DC, pp 1-22

Strasser H, Keller E (1997) Ergonomic evaluation of a wrist rest for VDU work via electromyographic methods. In: Salvendy G, Smith MJ, Koubeck RJ (eds) Design of computing systems: cognitive considerations. Advances in human factors/ergonomics, vol 21A. Elsevier, Amsterdam, pp 615-618

Strasser H, Müller K-W (1999) Favourable movements of the handarm system in the horizontal plane assessed by electromyographic investigations and subjective rating. In: Gilad I (ed) Special issue in Memoriam of Erwin Tichauer. Int J Ind Ergon 23:339-347

Strasser H, Zink K (2007) Modular course provision for professional ergonomists with micro- and macro-ergonomic design competency in the system "human being-technology_organization". Theor Issues Ergonomics Sci 8(4):349-363

Strasser H, Fleischer R, Keller E (2004) Muscle strain of the hand-armshoulder system during typing at conventional and ergonomic keyboards. OER 4(2):105-119

Strasser H, Fleischer R, Keller E (2007a) Muscle strain of the handarm-shoulder system during typing at conventional and ergonomic keyboards. In: Strasser H (ed) Assessment of the ergonomic quality of hand-held tools and computer input devices. IOS Press, Amsterdam, Berlin, Oxford, Tokyo, Washington DC, pp 75-88

Strasser H, Gross E, Keller E (1991) Electromyographic evaluation of the physical load of the left hand-arm-shoulder system during simulated work at eight different cash register arrangements. In: Karwowski W, Yates JW (eds) Advances in industrial ergonomics and safety III. Taylor \& Francis, London, New York, Philadelphia, pp 457-463

Strasser H, Keller E, Müller K-W, Ernst J (1989) Local muscular strain dependent on the direction of horizontal arm movements. Ergonomics 32(7):899-910

Strasser H, Wang B, Hoffmann A (2007c) Evaluation of the ergonomic quality of masons' trowels. In: Strasser H (ed) Assessment of the ergonomic quality of hand-held tools and computer input devices. IOS Press, Amsterdam, Berlin, Oxford, Tokyo, Washington DC, pp 127-142

Zipp P, Haider E, Halpern N, Rohmert W (1983) Keyboard design through physiological strain measurements. Appl Ergon $14: 117-122$

\section{Standards, Guidelines, Regulations}

BK 2101 (1963) Erkrankungen der Sehnenscheiden oder des Sehnengleitgewebes sowie der Sehnen- oder Muskelansätze, die zur Unterlassung aller Tätigkeiten gezwungen haben, die für die Entstehung, die Verschlimmerung oder das Wiederauftreten der Krankheit ursächlich waren oder sein können. BArbBl. 24
BK 2103 (2005) Erkrankungen durch Erschütterung bei Arbeit mit Druckluftwerkzeugen oder gleichartig wirkenden Werkzeugen oder Maschinen. BArbB1. 3

BK 2104 (1979) Vibrationsbedingte Durchblutungsstörungen an den Händen, die zur Unterlassung aller Tätigkeiten gezwungen haben, die für die Entstehung, die Verschlimmerung oder das Wiederauftreten der Krankheit ursächlich waren oder sein können. BArbB1. 7/8

DIN EN 1335 (2000) Office Furniture-Office Work Chair-Part 1: Dimensions-Determination of Dimensions, German Institute for Standardization, Beuth Verlag, Berlin, Germany

DIN EN 1335 (2007) Office Furniture-Office Work Chair-Part 2: Safety Requirements, German Institute for Standardization, Beuth Verlag, Berlin, Germany

DIN EN 2137-2 (1999) Text and Office Systems-Keyboards-Part 2: German Keyboard for Data and Text Processing: Key Arrangement and Allocation of Graphic Characters to Keys, German Institute for Standardization, Beuth Verlag, Berlin, Germany

DIN 2137-13 (1995) Text and Office Systems-Alphanumeric Keyboards-Part 13. German Keyboard for Data and Text Processing; Key Arrangement and Allocation for Split and Tilted Keyboards, German Institute for Standardization, Beuth Verlag, Berlin, Germany

DIN 395-12 (1968) File Handles, German Institute for Standardization, Beuth Verlag, Berlin, Germany

DIN 5268-2 (1973) Screwdriver Handles, German Institute for Standardization, Beuth Verlag, Berlin, Germany

DIN 6440-5 (1988) Masons Trowels, German Institute for Standardization, Beuth Verlag, Berlin, Germany

ISO 9241-4 (1998) Ergonomic Requirements for Office Work with Visual Display Terminals (VDTs)—Part 4: Keyboard Requirements, International Organization for Standardization

\section{Further Reading}

Strasser H (2008) Kompatibilität - Leitlinie für ergonomische Arbeitsgestaltung und präventiven Arbeitsschutz. In: Produkt- und Produktions-Ergonomie - Aufgabe für Entwickler und Planer Conference Proceedings, 54. Kongress der Gesellschaft für Arbeitswissenschaft. GfA-Press, Dortmund, pp 17-28

Strasser H, Kluth K, Keller E (2007b) A knowledge-based system for utilizing electromyographic methods for the measurement of physiological costs associated with operating hand-held tools and computer input devices. In: Strasser H (ed) Assessment of the ergonomic quality of hand-held tools and computer input devices. IOS Press, Amsterdam, Berlin, Oxford, Tokyo, Washington DC, pp 41-55

DIN 33408 (2008) Body Templates-Part 1: For Seats of All Kinds, Application Examples German Institute for Standardization, Beuth Verlag, Berlin, Germany 